University of San Diego

Digital USD

2013-05-01

\title{
Work/Life Boundary Management in an Integrative Environment: A Study of Residence Life Professionals Who Live at their Place of Work
}

Pressley Robinson Rankin IV PhD University of San Diego

Follow this and additional works at: https://digital.sandiego.edu/dissertations

Part of the Leadership Studies Commons

\section{Digital USD Citation}

Robinson Rankin IV, Pressley PhD, "Work/Life Boundary Management in an Integrative Environment: A Study of Residence Life Professionals Who Live at their Place of Work" (2013). Dissertations. 849. https://digital.sandiego.edu/dissertations/849 Digital USD. It has been accepted for inclusion in Dissertations by an authorized administrator of Digital USD. For more information, please contact digital@sandiego.edu. 
WORK/LIFE BOUNDARY MANAGEMENT IN AN INTEGRATIVE ENVIRONMENT: A STUDY OF RESIDENCE LIFE PROFESSIONALS WHO LIVE AT THEIR PLACE OF WORK

\author{
by \\ Pressley Robinson Rankin IV \\ A dissertation submitted in partial fulfillment \\ of the requirements for the degree of \\ Doctor of Philosophy \\ May 2013 \\ Dissertation Committee \\ Robert Donmoyer, Ph.D., Chair \\ Fred J. Galloway, Ed.D., Member \\ Zachary Green, Ph.D., Member \\ University of San Diego
}


(C) Copyright by Pressley Rankin IV All Rights Reserved 2013 


\begin{abstract}
How individuals manage work/life boundaries when they live at the place they work, as opposed to working from home, is a gap in both work/life literature and in higher education literature. An obvious example from higher education is the resident life professional that lives in the residential facility that she or he oversees. Living in a residential facility creates challenges to boundary creation. The job requirements; pressures from students and staff; supervisor expectations, both spoken and unspoken; and the physical location of their home within the building creates a highly boundary integrative environment making the establishment of boundaries difficult. The purpose of this study was to understand how resident life professionals' use of space, negotiation of technology, and boundary management style adapt to handle the integrative environment in order to prevent or manage stress and burnout.

This qualitative study used a constructivist grounded theory approach that included in-depth semi-structured interviews with twelve participants who were selected from a national survey of resident life professionals using maximum variation sampling. The sample included both public and private universities and contained participants from six out of the nine ACUHO-I regions.

Interview transcripts were coded using grounded theory methods of open and focused coding. The constant comparison technique and memo writing were used throughout the coding process to develop analytical categories and themes. Analysis of the relationships between the participants' data, the codes, categories, and themes lead to the final production of a process model of boundary management in a highly integrative environment. This model illustrates how boundary stressors like student needs,
\end{abstract}


supervisor expectations and behaviors, seasonal and student events, staff needs, and the physical setup of the professional's personal space, lead to integrative coping strategies of boundary management that are primarily learned from experience by the resident life professional. Understanding the integrative environment and how resident life professionals leam to cope with the constant boundary stressors is significant to both resident life leadership and the professionals themselves. Increasing integrative coping strategies could help to fight burnout and increase retention for an important entry-level job in residence life. 


\section{DEDICATION}

I dedicate this dissertation to the fulfillment of my childhood dreams and to wine, for as they say in Latin: Tantum cum vinum habere potestis scientiam. 


\section{ACKNOWLEDGEMENTS}

As the great African proverb says, it takes a village to raise a child, so too did it take a village for me to produce this document. First I want to acknowledge and thank my committee who guided me through this process. Dr. Fred Galloway who believed in me from the beginning and Dr. Zachary Green who aided me in reflection and deeper understanding. I especially want to thank my committee chair Dr. Robert Donmoyer who guided me, drank with me, and danced with me all the way to the finish of this dissertation.

The creation of this work relied heavily on the support of my dear friend and mentor Dr. Corey W. Johnson. Corey answered question after question and was remarkably patient when reading drafts or applying motivations. Most likely this would not exist without him. Nick Franco, Don Trinh, and Karina Bedolla were my close friends who patiently listened to me go on and on about complaints, ideas, and frustrations. They gave me direct support and wine, for which I am very appreciative.

I am a man of plenty when it comes to close friends. Rob Stimart, Susan Craven, and Shawn Patrick Ryan all provided friendship, love and care that I needed during this process. Many others, who I won't name because they are less likely to read this, also gave me comfort and support during this last very stressful year.

I cannot leave out my family as well. My boyfriend Hari Gonzalez was perhaps the closest to the crazy and deserves a metal for his patience and his 4-star editing skill. Of course my parents P.R. and Elaine Rankin as well as my sister Kathy gave me the love, life skills, and experiences that motivated me to the point I am today, along with much needed financial support- Thank you Mom and Dad. 
Finally I also would not be at this point without my strong spiritual beliefs.

Believing that I was being guided by a higher power has given me strength during my entire educational career. A combination of prayer, spells, and tarot readings guided me along the way. I want to thank the spirits that helped me on this journey; Venus spirit of love, Ganesh, remover of obstacles; and Saraswati, spirit of intellect and creation. I am also sure a muse or four may have visited me along the way. Last but not least, God who guides us all toward a place of peace and love... Thank You. 


\section{TABLE OF CONTENTS}

DEDICATION - vi

ACKNOWLEDGEMENTS -...-vii

LIST OF TABLES - -

LIST OF FIGURES -

CHAPTER ONE: INTRODUCTION - 1

Background of the Problem -- 1

Purpose Statement--_- 5

Research Questions-- 6

CHAPTER TWO- REVIEW OF THE LITERATURE -

Introduction --- 8

The Constructs of Boundaries --. 10

Psychological Construct-1- 10

Developmental Construct --_-

Organizational Construct--

Boundary Theory: Domains and Roles-a-19

Domains - -

Roles --

Work/Family Border Theory--_-30

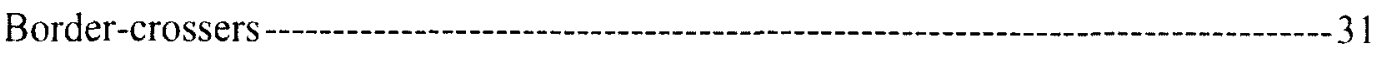

Border-keepers --- 
Work/Family Border Theory Propositions

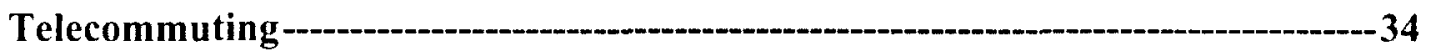

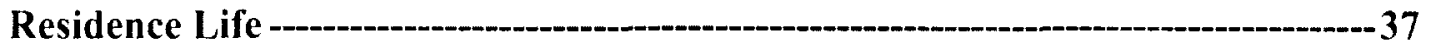

CHAPTER THREE- METHODOLOGY -

Introduction -

Study Design-1-1-

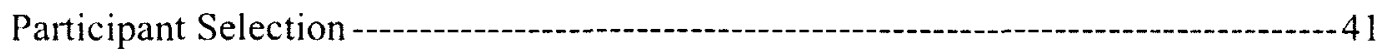

Data Collection Methods - 48

Data Analysis Methods -

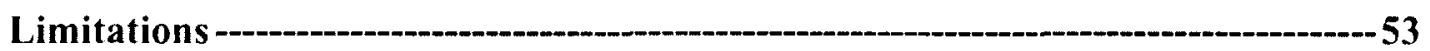

CHAPTER FOUR: FINDINGS-

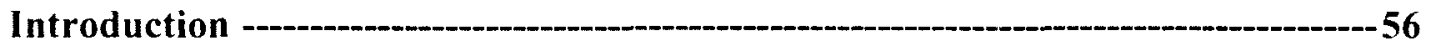

Relevant Definitions - 57

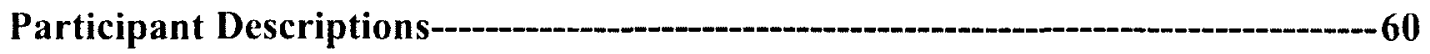

The Integrative Continuum, Themes, and Categories - 61

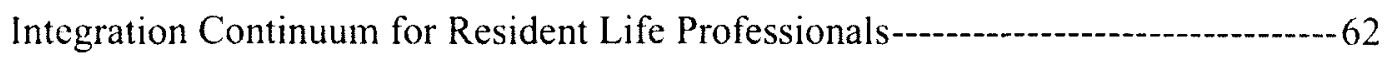

Use of Space -

Boundary Management in an Integrative Environment -

Negotiating Emerging Technologies -

Summary - 101

CHAPTER FIVE: DISCUSSION, IMPLICATIONS, AND RECOMMENDATIONS

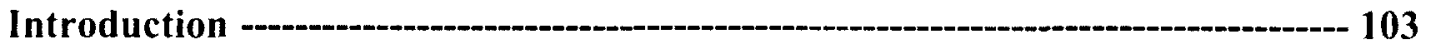


In What Ways Do Residence Life Professionals, Who Live Onsite, Manage Their Work/Life Boundaries?

What Role Does Technology, and, More Specifically, Social Media, Play in

Boundary Management for These Resident Life Professionals?

If Resident Life Professionals are Creating Boundaries Around the Domains of

Work and Life, is it Due to a Desire to Achieve Some Type of Work/Life Balance or is There Another Rationale at Work?

How, if at all, does Boundary Management Contribute to Job Satisfaction for

Resident Life Professionals and How Does Training, or Lack of Training, Impact

Resident Life Professionals' Work/Life Boundary Management? -..............-.-. 116

A Model of the Integrative Environment --. 120

Implications for Leadership and Practice -_- 124

Recommendations for Future Research -

Conclusion -- 130

REFERENCES-.-1- 134

APPENDICES- 144

A. Initial Semi-Structured Interview Guide--- 144

B. Altered Semi-Structured Interview Guide - 147

C. Participant Extended Profiles - 


\section{LIST OF TABLES}

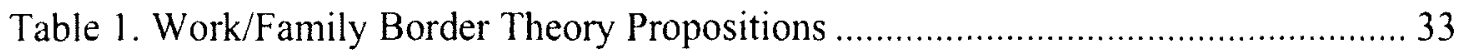

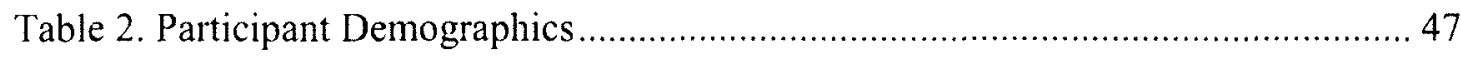

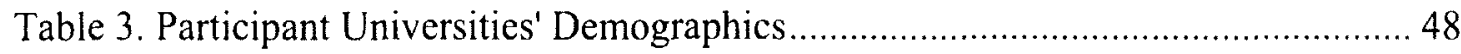

Table 4. Themes, Conceptual Categories, and Focused Codes .................................... 51

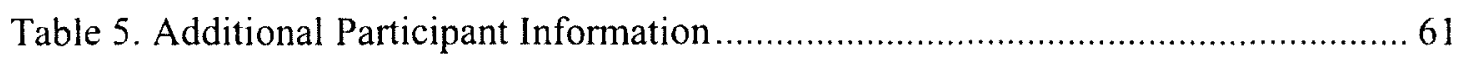

Table 6. The Integration Continuum for Resident Life Professionals ......................... 64

Table 7. Participants' Reported Live-in/on Professional Experience ............................. 65

Table 8. Participants Advice to New Resident Life Professionals .............................. 133 


\section{LIST OF FIGURES}

Figure 1. A Model of the Integrative Environment in Residence Life........123 


\section{CHAPTER ONE}

\section{INTRODUCTION}

\section{Background of the Problem}

The industrial revolution changed the nature of the work landscape from work centered around the home (e.g. handicrafts or domestic production) to paid work engaged in large-scale organizations separate from the home (Clark, 2000; Thompson, 1982; Warhurst, Eikhof, \& Haunschild, 2008a). The separation of the workplace from the home created a struggle between the need for making a living, on the one hand, and the desire to spend time with family and friends, on the other (Ashforth, 2001; Nippert-Eng, 1996a). Since the late 1970 's, a number of researchers have examined how people attempt to balance the need to make a living and the desire to spend time with ones family (Ashforth, 2001; Clark, 2000; Hall \& Richter, 1989; Hochschild, 1997a, 1997b; NippertEng, 1996a, 1996b; Piotrkowski, 1979; Stolba, 2001; Terkel, 1974; Warhurst et al., 2008a).

The changing dynamics of the family unit in most Western countries has recently led researchers to broaden the scope of research from focusing on the balance of work and family, which leaves out large segments of the workforce that currently may be single or without children, to the balance between work and the non-work aspects of life including leisure recreation and personal growth activities (Cohen, 2008; Henninger \& Papouschek, 2008; MacInnes, 2008; Pocock, Skinner, \& Williams, 2008; Ransome, 2008; Warhurst et al., 2008b).

Along with the shift in focus from work/family balance to work/life balance, there has been an increased focus in research around how individuals manage work/life 
boundaries and to varying degrees to balance the various aspects of their lives when they are working from home in what could be considered a post-industrial age (Ashforth, Kreiner, \& Fugate, 2000; Duxbury \& Smart, 2011; Hill, Hawkins, \& Miller, 1996; Hochschild, 1997b, 2008; Myrie \& Daly, 2009; Pilkington, 2007; Shumate \& Fulk, 2004). This newer area in the organizational literature has a primary focus on the management of boundaries and many of these studies build on the work of Nippert-Eng (1996a) and look at the ways people create, manage, and maintain boundaries.

The study of boundaries addresses a concern that Eikhof, Warhurst, and Haunschild (2007) expressed concerning the implicit assumption in work/life balance literature that the domain of work is a negative that needs to be controlled and the domain of home/family is a positive that needs to be protected and expanded. In contrast, Greenhaus \& Powell (2006) found that there are occasions when work and home are allies that work together to enrich individuals' lives. Therefore, by looking specifically at boundary management instead of work/life balance, no assumptions need to be made that one domain or another is more or less important to the participant. This fits with the results of Nippert-Eng's (1996a) study, which found that some individuals prefer to integrate the domains of work and home and create very porous or non-existent boundaries around the two domains. Integration has also been found to play a role in the use of technology to manage work/life boundaries.

Technology such as the home computer, the Internet, and more recently the smartphone is considered partly responsible for the current resurgence in employees working from home (Ashforth, Kreiner, \& Fugate, 2000; Duxbury \& Smart, 2011; Hochschild, 1997b, 2008; Myrie \& Daly, 2009; Pilkington, 2007; Shumate \& Fulk, 
2004). As technology has changed and the nature of work has become less dependent on industrial production, people are now able to work from home more easily and thus the spatial boundaries between work and home established in the industrial revolution are changing (Duxbury \& Smart, 2011; Hill et al., 1996). According to the U.S. Bureau of Labor Statistics, over 20 million people work from home at least part of the time ("Table 7', 2004). Of these workers, $52 \%$ work from home and use their homes as their primary offices.

Studies conducted on people who work from home as their primary office have found that these home-based workers still strive to create boundaries in their lives (Cohen, 2008; Kylin \& Karlsson, 2008; Myrie \& Daly, 2009; Nippert-Eng, 1996; Shumate \& Fulk, 2004). Recent survey results from AOL and Opinion research, however, suggest how difficult it is to do this. The survey found that almost $60 \%$ of a sample of the general population checks their email in bed and $83 \%$ check work email while they are on vacation (Pilkington, 2007). So even with people who do not work from home, there is a breakdown of the traditional boundary that separates home and work. Presumably, this sort of boundary problem is even more problematic for those who work primarily from their homes.

One area of interest in the field of work/life studies that has not been explored in the literature is how individuals manage work/life boundaries when their home is at their work place (a reversal, of sorts, of working at home). Individuals often live at the place they work in settings such as apartment communities, universities, and the military; examples include apartment managers, facility maintenance engineers, university presidents, resident faculty, and some officers and soldiers in the military who live on 
base. The list also includes residence life professionals.

Residence life professionals are an easily accessible population who most commonly live in the residence halls they manage. These professionals are responsible for "creating environments and organizational structures and other interventions that promote student development and education of residents; [they] maintain sufficient order to allow for adequate study, sleep and socializing; and [they] support the academic mission of the institution" (Winston, Anchors \& Associates, 1993, p. xxii). Resident life professionals are often in charge of "supervising, correlating, and integrating the activities of students who live in campus-operated residence halls [and] typically... provide counseling services for students, plan programs, advise student government, and do crisis interventions as situations dictate" (Schuh \& Shipton, 1985, p. 380). The services provided by resident life professionals create a situation in which contact between the domains of work and home overlap more frequently than other populations that live where they work. The intensity created by this overlap, coupled with the availability of the population for study, makes residence life professionals an excellent population with which to explore work/life boundary management.

Certainly those who hold residence life positions exhibit stress and tension associated with living where one works. Studies have consistently shown that resident life professionals have a high rate of burnout and turnover; student affairs supervisors, for example, are reporting difficulty in recruitment for entry-level positions, and there are fewer qualified candidates. (Anderson, Guido-DiBrito, \& Morrell, 2000; Belch \& Mueller, 2003; Belch, Wilson \& Dunkel, 2009; Braham \& Winston, 2006; Collins \& Hirt, 2006; Herr \& Strange, 1985; Renn \& Jessup-Anger, 2008; Wiggers, Forney, \& 
Wallace-Schutzman, 1982). The relationship of boundary management to these problems has not been explored to date.

Belch and Mueller (2003), however, did find that, among the student affairs graduate students in their study sample, quality of life was a major reason they did not intend to pursue a career in residence life. The graduate students "indicated greater intolerance than senior housing professionals of the lifestyle of a live-in staff member that may include late-night disruptions as well as day-to-day challenges of living and working in a single environment" (p. 40). Belch and Muller also noted a gap in research around the quality of life for live-in resident life professionals. This study may begin to address that gap by looking more closely at boundary management in these live-in positions.

\section{Purpose Statement}

How individuals manage work/life boundaries when they live at the place they work, as opposed to working from home, is a gap in both work/life literature and in higher education literature. An obvious example from higher education is the resident life professional that lives in the residential facility that she or he oversees. Living in a residential facility creates challenges to boundary creation. The job requirements; pressures from students and staff; supervisor expectations, both spoken and unspoken; and the physical location of their home within the building creates a highly boundary integrative environment making the establishment of boundaries difficult. The purpose of this study was to understand how resident life professionals' use of space, negotiation of technology, and boundary management style adapt to handle the environment that is created when you live where you work. 
This qualitative study used a constructivist grounded theory approach adapted from Charmaz (2006) that included in-depth semi-structured interviews with twelve participants who were selected from a national survey of resident life professionals using maximum variation sampling. The sample included both public and private universities and contained participants from six out of the nine ACUHO-I regions.

Interview transcripts were coded using grounded theory methods of open, focused, and axial coding. The constant comparative technique and memo writing were used throughout the coding process to develop analytical categories and themes. The three themes found in this study were the use of space, boundary management in an integrative environment, and negotiating emerging technologies.

Analysis of the relationships between the participants' data, the codes, categories, and themes lead to the final production of a process model of boundary management in an integrative environment. This model illustrated how boundary stressors like student needs, supervisor expectations and behaviors, seasonal and student events, staff needs, and the physical setup of the professional's personal space, lead to integrative coping strategies of boundary management that are primarily learned from experience by the resident life professional.

\section{Research Questions}

This study will address the following research questions:

1. In what ways do residence life professionals, who live onsite, manage their work/life boundaries?

2. What role does technology, and more specifically social media, play in boundary management for these resident life professionals? 
3. How, if at all, does boundary management contribute to job satisfaction for resident life professionals and does training or lack of training impact resident life professionals' work/life boundary management?

4. If resident life professionals are creating boundaries around the domains of work and life, is it due to a desire to achieve some type of work/life balancel or is there another rationale at work?

1- Balance here is not meant to imply a $50 / 50$ balance because some other arrangement may feel balanced to the individual. 


\section{CHAPTER TWO}

\section{REVIEW OF THE LITERATURE}

\section{Introduction}

This chapter will describe the fundamental areas of literature relevant to the research I conducted as part of my dissertation research. While classic grounded theory states that a literature review should not be conducted before the research has begun (Glaser \& Strauss, 1967; Glaser, 1978), Charmaz (2006), who has articulated the constructivist version of grounded theory this study's methodology is based upon, argues that some knowledge of the existing literature and major theories in one's area of study should be understood before research is conducted in the field. Therefore Part One of this chapter represents all the literature I reviewed before beginning my research. Part Two of this chapter represents any literature that was added during or after data was collected and analyzed. Charmaz states this thinking succinctly, "in relation to your grounded theory you can use it [the grounded theory that is developed in the study] to direct how you critique earlier studies and theories and to make comparisons with these materials" (p. 164).

Initially I began my research on the subject of boundaries by examining the psychological literature on patient and therapist boundaries and the violation of those boundaries (Pipes, Holstein, \& Aguirre, 2005; Smith \& Fitzpatrick, 1995; Taylor, McMinn, Bufford, \& Chang, 2010). This seemed a good place to start since resident life professionals often have to counsel students as part of their resident development and judicial responsibilities (Belch \& Mueller, 2003; Belch, Wilson, \& Dunkel, 2009; 
Benshoff, 1993; Blimling, 2003; Herr \& Strange, 1985; Kretovics \& Nobles, 2005; Orgera, 2007).

I then moved into a broader look at boundaries in the mentorship literature, which covered less fiduciary types of relationships than the psychological literature most often discussed (Barnett, 2008) and the developmental literature, which looks as the psychological development of the mind (Kegan, 1982; Higgins, Duxbury, \& Lee, 1994; Love, 1995; Love \& Guthrie, 1999). I found this literature applied to my population because resident facility directors are typically considered entry level professionals who, according to studies published on this population, are typically in their mid twenties and in charge of mentoring and developing the undergraduate students under their care (Carpenter \& Stimpson, 2007; Collins \& Hirt, 2006; Renn \& Jessup-Anger, 2008; Winston et al., 1993).

Finally I discovered connections to the organizational constructs of boundaries and how individuals may attempt to balance the domains of work and life through the management of boundaries (Ashforth, 2001; Ashforth, Kreiner, \& Fugate, 2000; Bulger, Matthews, \& Hoffman, 2007; Clark, 2000; Desrochers, Hilton, \& Larwood, 2005; Eikhof et al., 2007; Fangel \& Aalokke, 2008; Gajendran \& Harrison, 2007; Greenhaus \& Beutell, 1985; Hall \& Richter, 1989; Herr \& Strange, 1985; Hochschild, 1997a, 1997b; Leifer \& Delbecq, 1978; Macdonald, 1998; Nippert-Eng, 1996a, 1996b; Terkel, 1974; Warhurst, Eikhof, \& Haunschild, 2008). Through that research I discovered two prominent theories about boundary management: boundary theory (Ashforth, 2001; Ashforth et al. 2000; Nippert-Eng, 1996a, 1996b) and work/family border theory (Clark, 2000). While I do believe that the organizational literature may be most relevant to my research, work/life 
boundary management implicitly includes psychological factors both personal and professional, which cannot be ignored.

Next I will begin a discussion of the theoretical construct of boundaries from a psychological, developmental, and organizational perspective. Following that discussion, I will review the two most recent theories used to discuss boundary management: boundary theory and work-family border theory. Finally, I will discuss some of the more recent relevant studies covering telecommuting (working from home) and offer a brief account of the literature relating to my specific population (residence life professionals).

\section{The Constructs of Boundaries}

\section{Psychological Construct}

The psychological literature on boundaries is typically framed around the therapeutic relationship between the therapist and the client. Smith and Fitzpatrick (1995) state, "the therapeutic frame includes both the structural elements (e.g., time, place, and money) and the content (what actually transpires between therapist and client) of therapy" (p.499). The boundaries between the therapist and the client are based on the therapist's fiduciary responsibilities and are embedded in strict codes of ethics maintained by professional licensing authorities (Pipes et al., 2005). Plaut (2008) defines the management of boundaries in professional relationships as:

Healthy professional relationships require that certain boundaries be maintained, especially if there is a power differential between the parties (e.g., physicianpatient; faculty - student). Boundary violations can be generally divided into three types: sexual harassment (e.g., requests for dating, sexual innuendo, gender discrimination), sexual misconduct or exploitation (i.e., intimacy between professional and either patient or student), and nonsexual dual relationships (e.g., exchanging personal gifts, excessive disclosure, seeing students as patients while in a teaching role). (p. 85) 
Smith and Fitzpatrick (1995) characterize sexual misconduct and harassment as boundary violations but include nonsexual dual relationships in the category of boundary crossing which is less serious and may be necessary therapeutically.

Boundary crossing is characterized as an exchange between the therapist and the client that may or may not benefit that client such as non-sexual touching or gift giving. Among the many different types of boundary crossing the most challenging for the professional is dual relationships (e.g. the client is a friend or colleague of the professional) because they blur the role boundaries and create opportunities for violations to occur (Smith \& Fitzpatrick, 1995).

Since the residence life professionals living onsite in residential facilities are typically entry-level professionals, there might be some identification with the students under their supervision that may lead to friendships and thus dual relationships. A recent survey of resident life professionals indicated that $33 \%$ of the 125 professionals sampled strongly agreed or agreed that they had trouble managing the boundaries around the appropriateness of having a friendship with a student and $11 \%$ agreed or strongly agreed that they have or have had trouble managing the boundaries around the appropriateness of having a sexual relationship with a student, which would constitute a boundary violation (Rankin, 2011).

Barnett (2008) related the psychological concept of boundaries to mentorship and defined them as:

Boundaries are the basic ground rules for the professional relationship. They add a structure to mentorships that provides guidance regarding appropriate actions and interactions for mentors and protégés... the boundaries construct is relevant to all professional relationships that involve a power differential. Thus, boundaries are relevant to the roles of psychotherapist, clinical and research supervisor, faculty advisor, mentor, and all other professional roles... Boundaries 
in professional relationships include dimensions such as touch, location, selfdisclosure, time, gifts, fees, and personal space. Boundaries may be rigidly enforced, crossed, or violated. (pp. 5-6)

The idea that boundaries can be crossed, which is not always a negative, or violated, which is always negative, follows the work of Smith and Fitzpatrick (1995).

While boundary crossings may or may not always be negative they can lead to a slippery slope that may lead the professional into a boundary violation, which is characterized as a crossing of the professional boundary that is harmful for the client or mentee (Barnett, 2008). Most commonly theses boundary violations are of a sexual nature (Barnett, 2008; Smith \& Fitzpatrick, 1995). Looking at boundary violations from a mentorship perspective Barnett states:

Effective mentors will have an emotional investment in their protégés' personal and professional development; a true caring. Yet, at the same time, this closeness and emotional investment must not lead the mentor to boundary violations and inappropriate multiple relationships [the practice of engaging in additional relationships with another individual in addition to the primary professional relationship]. Similarly, protégés may easily come to idealize the mentor, feel special as a result of the commitment and caring evident in the mentor's behavior and the extra time spent together, and be vulnerable to boundary transgressions by the mentor which would violate students' dependency and trust. (pp. 7,10)

It is possible that the close working relationship between resident life professionals and the students they manage as paraprofessionals or the students under their care as the resident facility manager could lead to opportunities for dual relationships and possible boundary violations. It will be interesting to discover if areas around student/professional interaction have different degrees of boundary strength or different types of boundary constructs. Ultimately, since residence life professionals are tasked with counseling, mentoring, and policing the students in their care, multiple relationships and boundary crossing violations may be applicable and are another viable way to examine boundaries. 
Third Spaces. The discussion of psychological issues around boundaries is not complete without a brief examination of the construct of the "third space". This construct was initially developed by the scholar Bahbha (1988) and is defined by him as a discursive space "which represents both the general conditions of language and the specific implication of the utterance in a performative and institutional strategy of which it cannot 'in itself be conscious" (p.20). He goes on to say, "by exploring this hybridity, this 'Third Space', we may elude the politics of polarity and emerge as the others of our selves" (Bhabha, 1988, p. 22).

Bhabha (1988) discusses his construction of a third space in relation to crosscultural knowledge transfer within the framework of postcolonial ideology. Bhabha (1994) argued that the border region between two domains is often a region of overlap or hybridity and can become a third space that contains attributes of each of the two bordering spaces. Moje et al. (2004) further elaborated on bordering spaces relationship to domains and boundaries:

We call this integration of knowledges and Discourses [sic] drawn from different spaces the construction of 'third space' that merges the 'first space' of people's home, community, and peer networks with the 'second space' of the Discourses they encounter in more formalized institutions such as work, school, or church... What is critical to our position is the sense that these spaces can be reconstructed to form a third, different or alternative, space of knowledges and Discourses. ( $p$. 41)

The relevance of third spaces to residence life might apply to new professionals as they navigate the spaces between their professional lives and personal lives. It is possible that they will construct a bounded third space to deal with the differences in discourses between these two domains especially in light of the fact that their construct of the domain of home is located within the construct of the domain of work. 


\section{Developmental Construct}

Developmentally, residence life professionals are typically in there late 20 's and are often new professionals just leaving school to begin their career (Belch \& Mueller, 2003; Herr \& Strange, 1985; Kretovics \& Nobles, 2005; St. Onge, Ellett, \& Nestor, 2008; Winston et al., 1993). Rankin (2011) found the average age for the residence life professionals responding to his pilot survey was 28 ; not surprisingly, the developmental factors these professionals are dealing with are likely both personal and professional.

For the personal development factors I will examine Kegan's developmental stages, specifically the third and fourth stages that most often correspond to this age group (Kegan, 1982, 1994; Lewis, Forsythe, Sweeney, Bartone, \& Bullis, 2005; Love \& Guthrie, 1999). Kegan was chosen based on my examination of the developmental literature for resident life and student affairs professionals and my finding that he is often cited in studies of these individuals. When looking at professional development, I will limit it to the student affairs literature on the professional development of entry-level professionals exemplified in the work of Belch \& Mueller (2003), Renn and Hodges (2007), and Renn and Jessup-Anger (2008).

Kegan (1982) created a system to describe human development using six stages. These stages represent how we see our self in relation to the world through a subject/object relationship. In each stage, we take what is subjective (interior) and make it objective (exterior). This happens through a shift in the subject/object relations (e.g. when a mental construct is a part of a person and they cannot examine it objectively, it is considered subjective to them and conversely when a subjective construct can be examined outside of oneself, then it becomes objective). As someone develops they are 
able to hold many constructs as objects because they develop a high internal locus of control (Kegan, 1982).

Lewis et al. (2005) found, in their study of students at West Point, that many seniors were just entering into Kegan's Stage 3 (interpersonal) and only $19 \%$ had begun to enter Stage 4 (institutional). The results of their study are in contrast to other studies focused on non-military college students which found the transition to from Stage 3 to Stage 4 is well underway during the four years the students are in college (Komives, Longerbeam, Owen, Mainella, \& Osteen, 2006; Renn \& Hodges, 2007; Renn \& JessupAnger, 2008). Assertions from Kegan (1982) also support the transition from Stage 3 to Stage 4 occurring around the end of college sometime in the early 20 's. Therefore, I will discuss Stage 3 and Stage 4 since the population of entry-level resident life professionals is most likely in one of these two stages or transitioning between the two stages.

According to Kegan (1982), Stage 3 is a time when a person's needs and interests (family and society) are the objective and their subjective becomes interpersonal mutuality (peer and personal relationships). Therefore, personal relationships define the sense of self. Stage 4 represents an identification of self, which is based on institutional roles such as career, spouse, church leader, etc. The subjective interior is about ideology, identity, psychic administration, and authorship. During this stage, one tends to accept the rules placed on them by society in respect to the rules of their roles. Kegan describes this stage as being independent and self-defining using the term "self-system identity" (1982, p.227)

Lewis et al. (2005) discuss Kegan's the transition between Stage 3 and Stage 4 looking at the perspective of self-authorship: 
At Kegan's Stage 4, individuals reconstruct and psychologically decenter from their Stage 3 social and interpersonal identifications using individually constructed values and standards. Whereas Stage 3 individuals define themselves in terms of co-constructed interpersonal and social expectations (because they are embedded in simultaneous perspective-taking), Stage 4 individuals construct personal values and standards and then define themselves in terms of how well they are meeting those self-authored standards. The resulting independence from (ability to take a perspective on) social and interpersonal expectations enables Stage 4 individuals to make decisions and commitments in the absence of shared social support and in the face of competing social and organizational expectations. (p. 360)

Self-authorship may be fundamental to this study of residence life professionals since it has become an important student developmental goal for student affairs professionals (Komives et al., 2006; Lewis et al., 2005; Love and Guthrie, 1999).

Love and Guthrie (1999) further add to the definition of self-authorship through the discussion of Kegan's (1994) explanation of the capacity to objectify ones'values and ideals. They say, "this capacity is referred to as self-authorship and incorporates the ideas of self-regulation, identity, autonomy, and individuation, as opposed to relying on others to frame the problems or determine whether things are going acceptably well" (Love \& Guthrie, 1999, p. 72).

Moving from the personal concepts of development to the professional, Renn and Hodges (2007) qualitatively examined a small sample of ten first year student affairs professionals, eight of which were resident life professionals. They found three distinct phases these new professionals go through during their: Pre-Employment and Orientation; Transition; and Settling In. The Pre-Employment and Orientation phase typically lasts only for the first month and is characterized by a desire to fit in and be liked. The Transition phase can last for two to four months and is "marked by concerns about finding a mentor, seeking approval and support from outside, and beginning to 
question fit and competence" (Renn \& Hodges, 2007, pp. 383-384). Finally, the Settling In phase (which since my data collection will be in the spring is the most applicable phase any new professionals I interview) brought increased self confidence and a separation of professional identity from professional competence which might be attributed to an increased subject object shift toward Kegan's (1982) Stage 4 level of development.

Renn and Jessup-Anger (2008) furthered the research of Renn and Hodges (2007) by examining 90 new professionals in the student affairs profession through an openended qualitative survey. They found that:

Participants in our study were working to develop professional identity and navigate cultural adjustments. They were supported in this transition by maintaining a learning orientation and using professional elders. Yet even in these supports, new professionals must transition from a more dependent, student role to an independent, professional peer role where responsibility for job performance is primary and individual development is secondary. In short, new professionals must "grow up" quickly and realize that being in student affairs is no longer just about them. (p. 329)

The research presented by Renn and Hodges (2007) and Renn and Jessup-Anger (2008) is supported by other studies on entry-level student affairs professionals (see Belch, Wilson, \& Dunkel, 2009; Kretovics \& Nobles, 2005; Winston et al., 1993).

\section{Organizational Construct}

As early as the late 1970s, authors were beginning to combine the studies of work and the studies of home in order to look at the relationships-and, more specifically, the boundaries between the two (Katz \& Kahn, 1978; Leifer \& Delbecq, 1978; Piotrkowski, 1979; Pleck, 1977). The ideas concerning boundaries at this point where heavily influenced by organizational theory and can be summed up in Leifer and Delbecq's (1978) definition of boundaries: "the demarcation line or region between one system and 
another, that protects the members of the system from extrasystemic [sic] influences and that regulates the flow of information, material, and people into or out of the system" (p. 41). Early discussions of the work/life boundary also included the concepts of role, domains, and boundary flexibility and permeability; I will now discuss these topics in more detail.

Throughout the 1980's and 1990's organizational scholars added relational aspects from psychology and sociology to the concept of boundaries and continued to examine work/life balance from this perspective (Hall \& Richter, 1989; Higgins, Duxbury, \& Lee, 1994; Hill, Hawkins, \& Miller, 1996; Hirschhorn \& Gilmore, 1992; Schneider, 1987). Schneider best encapsulates the ideas about boundaries, at both the organizational and individual levels, that were developed in this period:

Boundaries define systems and determine the relationships within and between systems. The way in which boundaries are managed affects how organizations function. Establishing and negotiating boundaries create the levels of differentiation and integration necessary for effective functioning... The notion of boundaries is a key concept in the psychology of individuals, families, and groups... Psychological health requires establishing boundaries, while maintaining the necessary relatedness. These boundary issues are revived and become increasingly salient when individuals negotiate their roles in families, groups, and organizations. (pp. 379-381)

Schneider further called for more research around "how boundaries are managed and how that relates to the levels of differentiation and integration necessary for effective functioning within organizations" (p. 379).

Schneider's call was ultimately answered in Nippert-Eng's (1996a) seminal work on how individuals manage the boundaries between the domains of work and home. Nippert-Eng defined the concept of boundaries as "the sociocognitive [sic] borders that envelope categorical contents, [that] must be continually acted out and upon in order to 
exist, whatever form they take over time" (1996b, p. 564). She went on to discuss the nature of the work required to create and maintain these boundaries:

'Boundary work' consists of the strategies, principles and practices that we use to create, maintain and modify cultural categories... boundary work... is the process of creating and maintaining more or less distinct 'territories of the self'. This implies that much of what we see in our boundary work is the classification of certain forms of self, as well as time and space... we portray and reinforce a self through our bodies and our physical, tangible surroundings. As a particular sense of self extends outward, manifesting in visible artifacts and behavior, it can be located in space and time. It becomes associated with a particular environment and its contents, including the people and objects appearing there. So much so, that any of the contents of this particular environment can 'trigger' or evoke the sense of self embedded there... Boundary work takes two forms: boundary placement work and boundary transcendence (or transition) work. Both are essential for placing and maintaining boundaries. Placement work more visibly draws the line between realms [domains] and selves [roles], while transition work helps us accommodate that line, by allowing us to mentally jump back and forth over it. (1996b, pp. 564-569)

Nippert-Eng's definition of boundaries encompasses the mental and the physical aspects of boundary and space creation. Her conceptualization of boundary transition work and environmental triggers create a rich platform from which one can examine the process of boundary management.

\section{Boundary Theory: Domains and Roles}

Nippert-Eng's work in the area of boundary management is part of what is collectively called boundary theory (Ashforth, 2001). Two key components of boundary theory are the concepts of domains and roles.

\section{Domains}

Domains are defined as physical locations to which people subscribe specific categorical boundaries to such as work, home, the gym. Categorical boundaries are socio-cognitive borders that individuals or cultures create and "must be continuously acted out and upon in order to exist" (Nippert-Eng, 1996b, p 564). Other social scientists 
have defined categorical boundaries as "conceptual lines of demarcation that separate domains and domain-relevant behaviors" (Matthews \& Barnes-Farrell, 2010, p. 330). The separation of these domains and the boundaries used to define them are based on individuals actively defining them (Clark, 2000; Kossek, Lautsch, \& Eaton, 2006; Nippert-Eng, 1996a).

Individuals also socially construct the characteristics of the boundaries between the domains, and, depending on the nature of the constructions, some domains may have less ridged boundaries and perhaps even overlap with other domains (Ashforth, Kreiner, \& Fugate, 2000; Nippert-Eng, 1996a, 1996b). Ashforth (2001) further divides domains into three categories; work, home, and third places. Third places consist of physical locations such as church, the health club, or a neighborhood bar (Ashforth et al, 2000).

The three categories of domains appear in social science research to varying degrees. The domains of work and home have been studied for some time within business and organizational contexts in relation to how workers manage the boundaries between the two domains (Ashforth, 2001; Clark, 2000; Nippert-Eng, 1996a) and, more recently, how workers who work from their home manage work/home boundaries within this specific arrangement (Ashforth et al., 2000; Desrochers, Hilton, \& Larwood, 2005; Gajendran \& Harrison, 2007; Hill et al., 1996; Kossek et al., 2006; Shumate \& Fulk, 2004). Third places have not been studied within business or organizational literature but more often are examined in leisure studies literature (Oldenburg, 1989; Stebbins, 1982), albeit without a focus on boundaries. More recently, the concept of third places has also been applied to online games that create worlds within which users regularly interact with others (Steinkuehler \& Williams, 2006; Urban, 2007). 
The common concept in all descriptions of domains is the idea that they are delimited by socially constructed categorical boundaries, which may or may not also have a physical component such as walls, buildings, or online programs. Nippert-Eng defines the act of maintaining categorical boundaries as "boundary work" and she asserts "each time we engage in the process, the actual practice of sorting out, assigning, and defending the inclusion/exclusion or categorical contents into specific mental and physical spaces and times, we show the collective, mental frameworks that guide our lives" (1996, p. 564). While each individual constructs and maintains theses domain boundaries within his or her own cognitive borders, some domains, such as work and home, can be considered to be, to some degree, institutionalized in that most people share a general consensus of what home and work mean (Ashforth et al., 2000).

The extent to which any one individual has control over the management and transition across the boundaries between domains relies upon the nature of the work and the extent to which the domains involved are culturally programmed. It is important to note in any discussion of the domains of work and home that, as Felstead, Jewson and Walters (2005) point out, "there are material conditions, most obviously associated with class, that shape not only individuals' experience of and opportunities at work but also life experience and opportunities, as well as the experience of and opportunities within the relationship between work and life" (p. 11). The lack of discussion of class is one criticism of the work of Nippert-Eng.

Segmentation vs. integration. Ashforth et al. (2000) asserts "the act of creating and maintaining boundaries... complicates the act of crossing from one domain into another" (p. 474). The level of complication is mitigated by the amount of segmentation 
or integration that the individual creates between domains. Nippert-Eng (1996a) in her long-term qualitative study of 72 employees in a northeastern research lab in United States, posited that individuals conceptualize the boundaries between the realms (domains) of work and home as being very distinct and separate (segmentation) to overlapping and porous (integration). She found that extreme segmentors (e.g., those who prefer a complete separation between work and home) often have different clothes, calendars, and key rings for each domain and do not discuss home matters at work or vice versa. Opposite to this, extreme integrators do not see a difference between home and work and often allow aspects one domain to overlap or exist in the other (Nippert-Eng, 1996a). An example of this would be the lab employee who would spend the night on a cot in the lab if he or she worked to late.

Nippert-Eng (1996a, 1996b) ultimately suggests that extreme integrators and extreme segmentors are rare. Instead most people attempt to construct and maintain boundaries that somewhat closer to the middle of the continuum. The boundaries in this middle ground have been managed in many ways and more recently are also being managed with technology. Golden and Giesler (2007) found "that users interpreted their technological practices as expressions of personal agency, using the PDA to control the work-life boundary through both integration and segmentation of work and personal-life" (p. 519). In a mixed methods study of 42 employees who use a personal digital assistant, Golden and Giesler (2007) found that:

Technology introduces an additional dimension into the boundary management dialectic of integration-segmentation. That is, not only do individuals express, at different times, desires for both integration and segmentation of work and personal-life; they also express conflicting attitudes toward the technology itself and toward work (and its relationship to personal-life)... The repertoires present in participants' accounts affirm that, as Clark (2000) suggests, individuals are not 
merely reactive or resistant to organizational pressures to segment or integrate work and personal-life, but are actively managing the work-life boundary through their combined practices and selective appropriation of discursive resources. (pp. 542-545)

Technology then has introduced a different element to the management of boundaries through segmentation or integration. The technological aspects of resident life professionals' boundary management and the desire to segment or integrate the domains of work and home has currently not been researched, however, a trend within the resident life community to integrate social media into their job profile was noted in Rankin's (2011) survey of resident life professionals. Rankin found that $39 \%$ of his respondents reported that the use social media is either required or encouraged in their current position.

Whether through technology or more traditional means of boundary management, Nippert-Eng's (1996a, 1996b) work on domains is important to this study because it establishes and defines domains as social constructs that are managed by the boundaries individuals create. Examining how residence life professionals who live where they work create and define the social constructs of work and home is essential to the understanding of how they manage the boundaries between these constructs. It will also be interesting to see if those who live where they work are more or less likely to integrate or segment the domains as compared to studies on those who work from home.

\section{Roles}

The concept of roles has been studied within the social sciences literature for some time (Ashforth, 2001; Katz \& Kahn, 1978; Marks \& MacDermid, 1996; Pleck, 1977; Shumate \& Fulk, 2004). Katz and Kahn's (1978) classic organizational definition of roles describes behavioral aspects that refer "to the recurring actions of an individual, 
appropriately interrelated with the repetitive activities of others so as to yield a predictable outcome" (p. 189). They further propose that it is roles that link people to each other and to the organization (domain) in which the roles are created.

Bazalgette (2009) further examined roles in relation to the system (which could be a domain) they are in. Using a group relations perspective, he divided role into two components: psychological and sociological. Bazalgette asserts that a 'system' is a construct created within an individual's mind to organize persons, equipment, finances, buildings, and resources. Using the system as a reference, a person expresses his or her psychological role in behaviors they believe are associated with their purpose in the system. While this psychological role is internal, the sociological role is contingent on an individual's perception of the expectations of others within the system: as to how he or she should behave within his or her role in the system (Bazalgette, 2009). While not specifically posited within the organizational literature on domains and roles, both the psychological and sociological role concepts can help to define how individual roles function within the domains (systems) a person interacts in and may be relevant to this dissertation.

Ashforth et al. (2000) expanded Nippert-Eng's (1996a, 1996b) ideas around domain boundaries to the idea of roles and summarized the concept of roles, as it will be used within this dissertation:

Within and across the social domains of work, home, and third places, boundaries tend to be further drawn around roles. Roles tend to be associated with specific individuals who are labeled accordingly (e.g., employee, parent, parishioner). Thus, a role boundary refers to whatever delimits the perimeter- and thereby the scope- of a role. Given the more or less institutionalized nature of work, home, and third place domains, roles tend to be bounded in both space and time-that is, they are more relevant in certain physical locations and at certain times of the day and week. (p. 475) 
This definition of role adds an important aspect to the discussion of boundaries since roles can be enacted within, between, and across the boundaries that are associated with domains. Roles can be domain specific or carried into other domains such as the role of doctor is most often thought of as being associated with a hospital but one could still be a doctor on a plane if called upon to exercise this role.

The need or desire one has to exercise a role outside the role's domain is linked to ones role identification. Role identification occurs when individuals begin to define themselves, at least in part, by a favored role and therefore a part of the a person's self becomes that role (Ashforth et al., 2000). A consequence of role identification, then, is a higher tendency by the individual to attempt to carry that role from one domain to another or to integrate other roles with the identified role, thus changing the nature of all role boundaries. To better understand the impact of role identification, it is important to understand how roles boundaries are constructed and how those boundaries are then traversed.

Flexibility and permeability. The boundaries that define roles have traditionally been discussed using the concepts of flexibility and permeability (Ashforth et al., 2000; Ashforth, 2001; Bulger, Matthews, \& Hoffman, 2007; Clark, 2000; Desrochers et al., 2005; Hall \& Richter, 1989; Kossek et al., 2006; Pleck, 1977). A role that has flexibility is considered to have pliable space and time boundaries and can be enacted in various domains at various times (Ashforth et al., 2000; Ashforth, 2001; Hall \& Richter, 1989). An example of this would be a student working on his or her dissertation at home. The student working at home may be called upon at any time to take up the role of partner or spouse. Thus, inflexible role boundaries are marked by constraints around where and 
when the role can be enacted. A machinist, for example, can only perform her or his role when he or she has the equipment to machine parts.

While flexibility is about where and when a role can be enacted, permeability is considered to be the degree to which an individual can be physically located in a domainspecific role, but psychologically and or behaviorally involved in another (Ashforth et al., 2000; Ashforth, 2001; Pleck, 1977). For example, an administrator who can attend to family matters while at work or bring his or her children to work with them has a permeable work role boundary. However, an employee who, either because of work demands or work rules, cannot take personal phone calls while at work, has a very impermeable work role boundary. Clark (2000) further expands on the psychological component of permeability using the term 'spillover'. Spillover occurs when negative emotions, ideas, or insights from one domain are able to enter into another domain. Roles are typically associated with the domain in which they are created but can be carried over or spilled over into other domains. It is inevitably the flexibility and permeability of a role boundary that makes this transition or spillover easier or harder to accomplish. Thus flexibility and permeability have an important influence on role transitions.

Role transitions. As with domains, role boundaries can also be transitioned. Role transitions happen more frequently since individuals are likely to have several roles within any one domain. Ashforth, Kreiner, and Fugate (2000) refer to the regular movement between roles as micro transitions (e.g. moving from the role of father to the role of spouse). Micro role transitions (or, more simply, role transitions) are influenced by role segmentation and role integration, which are in turn influenced by role flexibility, 
role permeability, and role identity contrast. To understand this process one must first understand role identity, a concept that is a similar to Bazalgette's (2009) concepts of sociological and psychological roles.

Ashforth (2001) defines role identity as "the persona associated with the role, including goals, values, beliefs, norms, interactions styles, and time horizons" (p. 264). He also asserts that role identities are "socially constructed definitions of self-inrole... [which] can vary from strong to weak" (p. 27). Meaning you can believe you are an incredible boss and thus have a strong role identity or you could feel that you are not really qualified to be boss and thus have a weak role identity as boss. The relative strength of ones role identity affects role transitions in that weaker role identities are easier to transition from but may be harder to transition into from a stronger role identity.

Role identity also effects role transitions based on the contrast between roles. Role contrast is seen as "the contrast between the identities [and key features] of the relevant roles" (Ashforth, 2001, p. 264). Low contrast roles (e.g. boss vs. supervisee) are easier to transition between, in contrast to high contrast roles (e.g. employee vs. father). The ease of transition is due to the similarity of the key features of the roles. This is irrespective of the domain. For example, a woman may have trouble transitioning between the role of mother to the role of wife within the domain of home if there is high contrast between the key features of each role.

Role Segmentation vs. role integration. Ashforth et al. (2000) argued "that combining the concepts of role boundary (flexibility and permeability) and role identity (contrast) indicates that a given pair of roles can be arrayed on a continuum, ranging from high segmentation to high integration" (p. 475). Using this idea, they posit that high 
contrast role identities are highly segmented with inflexible and impermeably boundaries, whereas, low contrast role identities are more likely to be highly integrated with flexible and permeable boundaries. Roles that tend to be highly segmented usually "have little similarity between the contexts that inform each role and between the specific goals, values, beliefs, norms, interaction styles, and time horizons that constitutes each role identity, and there tends to be minimal overlap in the physical location" (Ashforth et al., 2000, p. 476).

The benefit of highly segmented roles is the reduction of role blurring (confusing role boundaries) but the cost is an increase in the magnitude of transition between roles (Ashforth et al., 2000; Bulger et al., 2007). Having a large magnitude of transition makes role exit more difficult. Thus, a drill sergeant in the army may have a hard time not ordering her family around when she returns home and becomes a wife and mother. Transitioning role boundaries involves what Ashforth et al. (2000) refer to as role exit. Exiting a role "involves psychologically and perhaps physically disengaging from the role" (p. 478). This can be accomplished as on the domain level through the use of rituals, external cues, or internal cues. Ashforth et al. (2000) provided an example of role exit:

A commuter may begin to psychologically disengage from her home role and prepare for her work role by following her daily routine of showering, dressing in work attire, reading the business section of the newspaper over breakfast, and listening to traffic reports. (p. 478)

Role entry may also be marked with similar rituals or routines.

Role integration in opposition to segmentation increases role blurring but decreases the difficulty of role transition. The lack of difficulty in the transition between roles inherently means "the role exit- movement- role entry sequence may occur rapidly 
with little or no conscious awareness" (Ashforth et al., 2000, p. 480). The lack of conscious awareness can result in role blurring that weakens boundaries between roles and thus allows for more frequent role identity confusion and disruption of a role activity.

Role identity disruption isn't limited to integrators. Ashforth et al. (2000) posit that there is perhaps a greater concern for role identity being interrupted when there is high segmentation between roles given that a boundary violation from another role will cause the segmented roles to compete in ones mind for supremacy in the moment. For example, an undercover narcotics agent would have many issues if her husband showed up during work. However, if both the husband and wife worked as undercover agents for the same police force the likelihood of disruption would be lessened.

Ashforth et al. (2000) suggest that:

Because the cost of segmentation (high contrast) is the benefit of integration (low contrast), and the benefit of segmentation (low role blurring) is the cost of integration (high role blurring), there is an ongoing tension between segmentation and integration that necessitates ongoing boundary and transition work. (p. 482)

This work takes the form of segmentors spending more energy on transitions work and intergraters spending more energy on boundary work. Nippert-Eng (1996a) would also agree that the boundary work associated with maintaining boundaries around domain transitions would also share the same qualities as with roles transitions.

The concepts of roles as presented in boundary theory will be useful in this dissertation in examining the multiple roles residence life professionals play while living where they work. Being able to see how the boundaries around the roles are created and maintained will help to illuminate when the boundaries are possibly violated with negative results for the balance of work and life for these professionals. It will also be 
important to understand roles since the domains of work and life are overlapping for these individuals.

\section{Work/Family Border Theory}

Expanding on previous studies on domains and boundary management, Clark (2000) introduced the idea of 'work/family border theory'. She defined her theory as "a new theory designed to remedy the criticisms and gaps of previous theories on work and family" (p. 750). Central to her theory is the idea that work and home:

Constitute different domains or spheres which influence each other...[and] though many aspects of work and home are difficult to alter, individuals can shape to some degree the nature of work and home domains, and the borders and bridges between them, in order to create a desired balance. (p. 751)

She goes on to say "balance, a consequence of artful border and domain management, is nearly unattainable by definition without identification with roles and activities associated with membership in hoth work and home domains" (p. 761).

Therefore, similar to Nippert-Eng (1996a, 1996b) and Ashforth et al. (2000), Clark also sees that boundary management as being concerned with domains, roles, segmentation, integration, permeability, and flexibility. However, she does conceptualize some differences in the boundaries (borders) between domains, how individuals cross those boundaries (border-crossers), and the people who maintain the boundaries other than the individual (border-keepers). All three of these additional concepts add richness to theories Nippert-Eng (1996a) discussed concerning domains.

\section{Borders}

Clark (2000) defines borders as "lines of demarcation between domains, defining the point at which domain-relevant behavior begins or ends" (p. 756). She suggests that these borders have the properties of permeability and flexibility. While these properties 
work in a similar way to Ashforth's (2001) ideas around role permeability and role flexibility, Clark adds a psychological element in the form of 'spillover'. Spillover occurs when negative emotions, ideas, or insights from one domain are able to enter into another domain (e.g. a man comes home after a bad day at work and yells at his children).

Should a border have a great deal of permeability and flexibility, there will be blending between the domains (Clark, 2000). If a border is blended then it cannot be considered in either domain and thus it creates a borderland. Using the unique concept of borderlands Clark discusses working from home part-time but she does not address working from home fulltime since her work/family border theory is presupposed on the domains of work and home being separate.

\section{Border-crossers}

The boundaries (borders) that create domains are socially constructed and maintained by the individuals that inhabit them (Ashforth, 2001; Clark, 2000; NippertEng, 1996a). Clark (2000) argues, "It is essential to describe the attributes of those individuals who are making frequent transitions between work and family domains" ( $p$. 759). She defines these individuals as border-crossers and asserts that they should be described by the degree to which they are central or peripheral participants in either domain. Central participants can have influence and identification with the domain that they are central to. Therefore, "central participants have influence because of their competence, their affiliation with central members of the domain, and their internalization of the domain's culture and values" (Clark, 2000, p. 759).

The influence Clark (2000) describes gives the individual the power to negotiate and make changes to the domain borders. Whether or not an individual chooses to 
exercise this power to make border changes is tied to their identification with domain responsibilities. If individuals "internalize domain values and...their identity is closely tied with their membership in the domain, their motivation to manage borders and domains increases" (Clark, 2000, pp. 759-760). However, the degree of centrality and individual has in a domain does not give them unlimited power to change domain borders since the setting of these borders is most often an intersubjective activity, socially constructed by many actors within the domain including border-keepers.

\section{Border-keepers}

Clark (2000) defines border-keepers as domain members who have a greater influence over the definition of the domain border. Typically border-keepers in the work environment are bosses, supervisors, other management personnel and/or human resource personnel and, in the domain of home, border-keepers could be spouses. The essential ingredient that defines someone as a border-keeper is some power over the border-crosser. Clark suggests that disagreement about borders between border-crossers and borderkeepers is a primary source of work/family conflict.

\section{Work/Family Border Theory Propositions}

Clark (2000) believes that "border theory can both describe why conflict exists and provide a framework for individuals and organizations to encourage better balance between work and families" (p. 764). Her theory suggests eight propositions, which can be used as tools to help individuals achieve a better balance between work and home. Those propositions are listed in Table 1. 
Table 1

Work/Family Border Theory Propositions

Proposition I a: When domains are similar, weak borders will facilitate work/family balance. b: When domains are different, strong borders will facilitate work/family balance.

Proposition 2: When the border is strong to protect one domain but is weak for the other domain. Individuals will have: a) greater work/family balance when they primarily identify with the strongly bordered domain; and b) lesser work/family balance when they primarily identify with the weakly bordered domain.

Proposition 3: Border-crossers who are central participants in a domain (i.e. who have identification and influence) will have more control over the borders of that domain than those who are peripheral participants.

Proposition 4: Border-crossers who are central participants (i.e. who have identification and influence) in both domains will have greater work/family balance than border-crossers who are not central participants in both domains.

Proposition 5: Border-crossers whose domain members have high other-domain awareness will have higher work/family balance than border-crossers whose domain members have low other-domain awareness.

Proposition 6: Border-crossers whose domain members show high commitment to them will have higher work/family balance than border-crossers whose domain members have shown low commitment to them.

Proposition 7: When work and family domains are very different. Border-crossers will engage in less across-the-border communication than will border-crossers with similar domains.

Proposition 8: Frequent supportive communication between border-keepers and bordercrossers about other-domain activities will moderate the ill effects of situations that would otherwise lead to imbalance.

(Clark, 2000, p. 746)

From the work of Clark (2000) I will utilize the ideas around borders and borderlands to examine the spaces residence life professionals create between the building they work in and the apartment they live in within that building. Bordercrossing activities and processes can be looked at in conjunction with the examination of role and domain boundary transition. The scope of the study can also be broadened by examining border-keepers both on the work side and on the home side to see how they 
added to or detract from the participants' work/life balancing processes. This study may also add to the literature confirming or disproving Clark's (2000) propositions (see Table $1)$.

\section{Telecommuting}

As technology has changed, people are now able to work from home more easily and thus the boundaries between the domains of work and home are once again shifting for the privileged professions that allow telecommuting (Warhurst et al., 2008). Hill et al. (1996) define telecommuting as:

The general term for doing work away from the office via telecommunications equipment... some or all of the job is moved away from the office to another fixed site, usually to the home. A new office is set up at this alternate site with enough telecommunications and other office equipment to get the job done... Most of the equipment fits inside a briefcase and can be easily transported. ( $p$. 293)

According to the U.S. Bureau of Labor Statistics, over 20 million people work from home at least part of the time ("Table 7", 2004). Those statistics also show that $52 \%$ of those workers work from home as their primary office. Studies have suggested that even when people work from home they still strive to create boundaries in their lives (Cohen, 2008; Kylin \& Karlsson, 2008; Myrie \& Daly, 2009; Nippert-Eng, 1996;

Shumate \& Fulk, 2004). Nevertheless, a survey by AOL and Opinion research found that almost $60 \%$ of those polled check their email in bed and $83 \%$ check work email while they are on vacation (Pilkington, 2007). It would seem that managing work/life boundaries are becoming harder with prevalent technology and it is even more difficult when you work from home.

Yet even with these difficulties, studies of people who telecommute have shown that they are still concerned about boundaries around work and home life and about 
managing work/life balance (Ashforth et al., 2000; de Man, de Bruijn, \& Groeneveld, 2008; Desrochers et al., 2005; Gajendran and Harrison, 2007; Kossek et al., 2006; Hill et al, 1996). Gajendran and Harrison (2007) assert that despite two decades of research on telecommuting it is still unknown whether it is good or bad for employees. Kossek et al.'s (2006) study of 245 professional employees who telecommute would seem to agree. The results of their study were mixed with both positive and negative effects in the employees' lives.

Researchers de Man, de Bruijn, and Groeneveld (2008) found, in their study of 1065 Dutch telecommuting employees of a multinational company, that telecommuting increases the permeability of the home boundary even if it is rare and that "telecommuting has a larger impact on boundary permeability for employees who prefer separation than for employees who prefer integration" (p. 107). The struggle to manage boundaries when working at home also has an element of trust involved in it. Kylin and Karlsson (2008) found, in their qualitative study of 14 half-time telecommuters, that the employee's felt the ability to telecommute showed a level of trust from their employer, which the employees wanted to honor. In contrast, the employees felt a certain level of distrust from their neighbors, families, and friends that they were actually working. Thus both the trust and distrust resulted in an increased need to establish and maintain boundaries (Kylin \& Karlsson, 2008).

Using the tenets of both boundary theory and work/family border theory it is clear that in order to telecommute boundaries between the domains work and home must be both flexible and permeable (Ashforth, 2001; Clark, 2000; Nippert-Eng, 1996a, 1996b). This is not true, however, for the role of employee within the domain of home. 
Boundaries can be set between the role of employee and other roles that exist within the home. Shumate \& Fulk (2004) state that telecommuters:

Must juggle their work roles with other roles, including caregiver, friend, significant other, and parent. They must negotiate multiple sets of role expectations without the support of established social norms surrounding homework, and without culturally determined time-space paths to assist with role transitions. (p. 60)

The boundaries telecommuters then establish can range from segmented to integrated and may also differ in their degree of flexibility and permeability (Ashforth et al., 2000; Ashforth, 2001; Clark, 2000). However, how an employee manages boundaries from a boundary theory or work/family border theory perspective when one lives at the place they work has not yet been studied.

Living where you work is different from telecommuting in that the employee is not bringing work home but actually living at their work. An exhaustive survey of the work/life literature did not found any studies that address this issue, however, Macdonald (1996) did examine a similar area. Macdonald found that live in domestic workers create boundaries, such as refusing to perform emotionally charged tasks (e.g., cooking one's native cuisine) and not bringing friends to the home in which they work. He also found in a (1998) study that mothers often desire for the nanny to leave the family space once they are home from work thus signaling an end of the workday and a start of family time.

Macdonald's work does not specifically address the issue when one lives at a work site since the domestic workers are living and working in a home, however, residence life professionals typically work and live in a residential housing facility on campus and represent an interesting population to study the phenomenon of balancing the work/life boundary when you live where you work. 


\section{Residence Life}

Residence life professionals are responsible "for supervising, correlating, and integrating the activities of students who live in campus-operated residence halls [and] typically... provide counseling services for students, plan programs, advise student government, and do crisis interventions as situations dictate" (Schuh and Shipton, 1985, p. 380). Resident life professionals are paid entry level professionals typically embarking on their first full-time position out of school or are sometimes graduate students who receive an assistantship along with a salary and/or a stipend (Frederiksen, 1993; Collins \& Hirt, 2006). The responsibility level for these professionals is higher than that for resident advisors and most often includes the supervision of resident advisors or other student workers. Position titles for these positions include; hall directors, residence directors, front desk managers, hall security managers, residence coordinators, assistant resident directors, and assistant coordinators.

Belch and Mueller assert that "residence life positions, specifically, the resident director, were considered the key entry points for new professionals in student affairs" (2003, p. 29). Frederiksen (1993) concurred and concluded that residence life is "the primary provider of basic student affairs professional work experience" (p. 176). In contrast to the importance of this position as a gateway into student affairs studies have alarmingly shown that resident life professionals have, for some time, exhibited a high rate of burnout and turnover (Anderson, Guido-DiBrito, \& Morrell, 2000; Barham \& Winston, 2006; Belch, Wilson, \& Dunkel, 2009; Collins \& Hirt, 2006; Herr \& Strange,

1985; Renn \& Jessup-Anger, 2008; Wiggers, Forney, \& Wallace-Schutzman, 1982).

Belch and Mueller (2003) found that between 1999 and 2003 the recruitment of 
residence life professionals for entry level jobs, such as resident director, was increasingly becoming harder. Student affairs supervisors indicated that there were fewer qualified candidates; resident directors were vacating positions within a year of employment; and many reported having to open their residence halls with at least one resident director vacancy in the fall. Belch and Mueller (2003) found that among the graduate students in their sample, quality of life was a major reason they did not intend to pursue a career in residence life. They "indicated greater intolerance than senior housing professionals of the lifestyle of a live-in staff member that may include late-night disruptions as well as day-to-day challenges of living and working in a single environment" (2003, p. 40).

Collins and Hirt's (2006) study of 506 student affairs professionals found that residence life professionals were more isolated than other student affairs professionals. They reported:

Residence life staff members were less likely to work with, socialize with, be known by, or feel a sense of collegiality with faculty members than student affairs professionals in other functional areas. This pattern held true for relationships with other student affairs colleagues. Residence life staff members were significantly less likely to work with other student service administrators or to be known by such administrators. In addition, they were more likely to report of high degree of turnover. Residence life staff tended to be insulated within their departments. Compared with their student affairs colleagues, residence life professionals were significantly less likely to work with or be known by academic administrators on campus, including academic deans and the president. In terms of other constituencies, residence life professionals were significantly less likely to be known by clerical staff or to work with local community members than other student affairs staff. On the other hand, they were significantly more likely to work with members of law enforcement agencies. (p. 16)

The insulation and isolation related by these residence life professionals could be a function of their living where they work and the boundaries they are forced to set, however, that has yet to be studied. This study may help to add to the literature around 
this topic and hopefully will address the more general topic of how boundary management is related to this professional isolation.

Because of gaps in the literature around boundary management when you live at your work and the gap in student affairs literature concerning boundary management skills in resident life professionals, it is difficult to say what aspects of boundary theory or work/family border theory may be used by these professionals. It is also not known if these professionals are seeking balance or living with more permeable boundaries. The high rate of burnout within this group may be connected to how they manage their work/life boundaries but that too is not known. This study is designed to begin to address these unknowns. The following section of this proposal will address how I intend to gather data on this interesting population. 


\section{CHAPTER THREE}

\section{METHODOLOGY}

\section{Introduction}

This study utilized a qualitative methodology adapted from Charmaz's (2006) constructivist grounded theory. Constructivist grounded theory studies, like traditional grounded theory studies attempt to construct theory inductively, but they also emphasize how the participants view their situations and take into account the researcher's point of view (i.e., the researcher's constructions of the phenomena he or she has studied) into account as well (Charmaz, 2006). This particular study examined the experiences of resident life professionals who live where they work in order to identify how they experience work life boundary management. The results of this study identified that the live-in environment that resident life professionals inhabit is highly integrative and the professionals create few boundaries. The boundaries they do have are re-enforced through the use of integrative strategies that fight off boundary stressors from the integrative environment. A process model of this was created and is presented in the chapter five.

\section{Study Design}

Drawing heavily from constructivist grounded theory; this study used different forms of coding to build a theoretical process model that emerged from the data derived after analyzing the experiences of the twelve resident life participants (Charmaz, 2006). Data collected and analyzed during this study was understood from an interpretive theoretical perspective, which calls for "the imaginative understanding of the studied phenomenon... [and]... assumes emergent, multiple realities; indeterminacy; facts and 
values as linked; truth as provisional; and social life as processual" (Charmaz, 2006, p. 126). What follows in this chapter is a discussion of how this chosen methodology was adapted and incorporated to this particular study since, as Charmaz suggests, grounded theory methods are "a set of principles and practices, not...prescriptions or packages" (2006, p. 9).

\section{Participant Selection}

The concept of boundaries and, indeed, the notions of work and life are socially constructed distinctions that undoubtedly differ in different societies (Ashforth, 2001; Nippert-Eng, 1996a, 1996b; Warhurst et al., 2008). Currently there are few if any studies examining how these socially constructed boundaries are managed by workers who live where they work as opposed to the much studied area of telecommuting which occurs when one works from the place where one lives.

Residence life professionals represent an easily accessible and data-rich population of workers who live where they work. While a phenomenological study of this population would have revealed a great deal of information on boundary management when one lives at the place they work, I decided that a grounded theory study would go beyond phenomenological description and allow me to construct a theoretical process model that "might help to explain practice or provide a framework for future research" (Creswell, 2007, p, 63).

Participants were recruited in two ways. The first round of participants names were gathered from a survey that was preformed as a pilot before this dissertation was conducted (Rankin, 2011). Participants of that anonymous pilot survey chose to select a link that would take them to a second survey to participate in my final dissertation 
research. Twenty-eight people chose to provide me with their contact information. Since I was conducting maximum variation sampling, I realized that I needed more demographic information from these participants. Thus a second more comprehensive survey was sent to the initial 28 participants. Since only four participants responded to the second survey, the same survey was then was sent to two national list-serves for resident life professionals the Association of College and University Housing Officers International (ACUHO-I) and the National Association of College and University Residence Halls, Inc. (NACURH). The survey collected relevant demographic information specifically to allow me to conduct maximum variation sampling. Over 50 professional's responded to this second longer survey.

Sample Selection Criterion. My first selection criterion for this study was to examine residence life professionals (with an array of titles) and exclude the residence life paraprofessionals since the professionals have more responsibility and, thus, should manifest the phenomenon under study more intensely. The rational for this criterion was based on a distinction drawn in the literature between residence life professionals and residence life paraprofessionals (Barham \& Winston, 2006; Blimling, 2003; Komives, 1991; Winston \& Ender, 1988). Paraprofessionals are typically exemplified by resident advisors who are usually undergraduate students who live in the residence halls with other students and are not paid as staff but instead receive free room and board which sometimes includes a small stipend (Barham \& Winston, 2006; Blimling, 2003; Komives, 1991; Winston \& Ender, 1988). These paraprofessionals are typically assigned to oversee a floor or a wing to a residence hall and, consequently, have a smaller number of students they are responsible for assisting (Upcraft, 1993). 
Resident life professionals are paid entry level professionals typically embarking on their first full-time position out of school or are sometimes graduate students who receive an assistantship along with a salary and/or a stipend (Collins \& Hirt, 2006; Frederickson, 1993). Common position titles for these positions include; hall directors, residence directors, community directors, front desk security managers, hall security managers, residence hall coordinators, assistant resident directors and assistant coordinators. They are responsible for an entire residence hall including the supervision of the resident advisors and front desk staff.

My second selection criterion was that the participants be current resident life professionals living in a residential facility that they are in charge of and/or that they supervise employees located in that building. Within this criterion, no distinction was made based on full-time or part-time status. However, none of the participants participating in the initial sample survey reported being part-time and therefore no parttime participants were interviewed for this study.

My third criterion for participant selection was that the participants must have been in their positions for at least one full semester before they were included. The rational for this is based on the work of Renn and Hodges (2007), which found that the first semester for residence life professionals typically has them dealing with orientation and transition issues, which includes figuring out the system, trying to be liked, and finding a mentor. While the next semester marked the start of the settling in phase, which brings increased self-confidence and a separation of professional identity from professional competence. Thus, I felt participants who have settled in were more likely to be dealing with consistent boundary management issues. Based on this criterion I 
recruited participants ranging from 6 months to 36 years.

Finally factors such as level of education prior to accepting the position, gender, race, ethnicity, region of the country, size of the university, and whether the university was public or private were not criteria for selection, but, were considered for maximum variation sampling.

Selection methods. Participant selection was conducted in several phases.

Phase One. The first phase was an initial sampling drawn from the participant survey. Maximum variation sampling was used to document diverse variations and identify patterns that were common in the sample population (Creswell, 2007). An initial sample of four participants was chosen. They were interviewed and those interviews were transcribed and coded. Maximum variation sampling was chosen because even though differences in the demographic factors discussed above have not been studied in this population, at least in respect to work/life boundary management, other studies of different populations' work/life boundary management issues have found differences in at least two of the factors; gender and class (Ashforth, Kreiner, \& Fugate, 2000; Bulger, Matthews, \& Hoffman, 2007; Desrochers, Hilton, \& Larwood, 2005; Glavin, Schieman, \& Reid, 2011; Higgins, Duxbury, \& Lee, 1994; Macdonald, 1996; Myrie \& Daly, 2009; Stolba, 2001; Warhurst, Eikhof, \& Haunschild, 2008a). Therefore, in order to understand if other factors might influence boundary management in these professionals, all attempts were made to capture a diverse sample population.

Phase Two. In Phase two, the initial codes and categories developed in phase one (for a description of this process see the Data Analysis Methods section that follows) started to yield patterns that will need to be further explored. Additional participants 
were chosen from the participant survey based again on maximum variation sampling. An additional four participants were interviewed in this phase. They were coded using focused coding developed from the initial sample. It was during this phase that I began to see categorical saturation and learned that the population I was studying was very similar despite the different factors targeted in my maximum variation sampling. Saturation occurs when "gathering fresh data no longer sparks new theoretical insights, nor reveals new properties of your core theoretical categories" (Charmaz, 2006, p. 113). Charmaz states that it is possible that saturation might occur at a sample size smaller than 11 individuals, however, she posited that it is not likely. Therefore, I began a third phase of participant selection to verify the early saturation I was seeing in the categories.

Phase Three. In this final phase of participant selection, phase three, theoretical sampling and purposeful intensity sampling were used to select the final four participants. The goal in this phase was to select participants who may elicit data that will help to explicate the categories developed during initial sampling and to aid in conceptual and theoretical development (Charmaz, 2006; Draucker, Martsof, Ross, \& Rusk, 2007). I also wanted to make sure that the categorical saturation I had discovered after phase two was true in relation to my research questions. I chose theoretical sampling because it is "the process whereby the researcher decides what data to collect next and where to find them in order to continue to develop the theory as it emerges" (Holton, 2010, p. 28). Purposeful intensity sample was also conducted because:

By choosing sites, persons, or documents deliberately to gain the maximum amount of data needed to unearth potential categories and their dimensions; systematically, by moving from one person to another on a list to uncover subtle differences; and fortuitously, by gathering data during field observations that were unexpected but are seemingly relevant to category development. (Draucker et al., 2007, p. 1139). 
This final phased allowed me to further define my theoretical model and determine that I had reached data saturation as defined in constructivist grounded theory literature (Charmaz, 2006).

Sample population. The final sample population interviewed in this study consisted of twelve individuals. There were six men and six women (see Table 2). Previous studies of this population generally find that sample populations consist of $58 \%$ $65 \%$ women and 34\%-42\% men (Belch \& Mueller, 2003; Belch, Wilson, \& Dunkel, 2009; Komives, 1991). I made the choice, in phase three of the sampling process, to oversample men as an attempt to discover if there was a difference between the experiences based on gender.

Participants were also asked to provide their ethnicity. Nine participants identified as white or Caucasian. Three participants identified as other various ethnicities. This breaks down to $75 \%$ Caucasian and $25 \%$ other, which matches previous studies that found that resident life and student affairs professionals are typically $67 \%$ to 71\% Caucasian (Belch \& Mueller, 2003; Belch et al., 2009; Komives, 1991). Ages of these participants ranged from 24 to 61 (see Table 2). Finally, half the participants where from public universities and half were from private. They came from six different ACUHO-I Regions and from five different Carnegie size classifications (see Table 3). In addition to the tables provided here, longer participant descriptions are also provided in Appendix $\mathrm{C}$ for those who prefer to supplement these tables with addition description and context. 
Table 2

Participants' Demographics

\begin{tabular}{|c|c|c|c|c|c|}
\hline $\begin{array}{l}\text { Study } \\
\text { Name }\end{array}$ & $\begin{array}{l}\text { Age } \\
\text { Range }\end{array}$ & Gender & Ethnicity & $\begin{array}{l}\text { What is your } \\
\text { current title? }\end{array}$ & $\begin{array}{l}\text { Years in } \\
\text { Current } \\
\text { Position }\end{array}$ \\
\hline Sam & $25-29$ & Female & Caucasian & Residence Director & 3.5 \\
\hline Steve & $30-34$ & Male & Caucasian & Resident Director & 1.5 \\
\hline Trevor & $30-34$ & Male & Southeast Asian & Resident Director & 4 \\
\hline Dean & $35-39$ & Male & Caucasian & $\begin{array}{l}\text { Assistant Director of } \\
\text { Residential Life }\end{array}$ & 2 \\
\hline Harry & $25-29$ & Male & Caucasian & Hall Director & 0.5 \\
\hline Windy & $20-24$ & Female & Caucasian & $\begin{array}{l}\text { Greek Area Hall } \\
\text { Director }\end{array}$ & 0.5 \\
\hline Nick & $25-29$ & Male & Caucasian & Resident Director & 1.5 \\
\hline Harold & $60-64$ & Male & Caucasian & Hall Director & 36 \\
\hline Rue & $25-29$ & Female & Multiracial & Area Director & 0.5 \\
\hline Sally & $30-34$ & Female & Caucasian & Assistant Director & 8.5 \\
\hline Mary & $25-29$ & Female & Southeast Asian & $\begin{array}{l}\text { Residence Hall } \\
\text { Director }\end{array}$ & 3.5 \\
\hline Megan & $30-34$ & Female & Caucasian & Area Director & 3.5 \\
\hline
\end{tabular}


Table 3

Participants Universities ' Demographics

\section{University Type}

Private- Nonprofit

Private- Religious

Public- Nonprofit

\section{Number of Participants}

1

5

6

\section{ACUHO-I Region}

Great Lakes

2

Mid-Atlantic

1

Northeast

2

2

2

Upper Midwest 3

\section{Carnegie Classifications}

S4/R Small Four-Year, Primarily Residential 2

S4/R Small Four-Year, Highly Residential 1

M4/R Medium Four-Year, Primarily Residential 3

L4/R Large Four-Year, Primarily Residential 1

L4/NR: Large Four-Year, Primarily Nonresidential 5

\section{Data Collection Methods}

Each participant was asked to engage in an interview that might last between one and two hours and that would be conducted over the phone at a time of the participant's 
choosing. The interview was recorded using a traditional voice-recording device for later transcription. I also took field notes during the interviews to add more contexts to the interview transcripts (Charmaz, 2006). Participant interviews were conducted using a semi-structured interview guide (see Appendix A) that was at first based on my research questions, but was later altered (see Appendix B) for subsequent interviews in pursuit of theory or to pursue promising leads (Charmaz, 2006). A semi-structured approach lends itself well to this study since it allows the researcher to have a set of questions derived from the research questions, while also allowing flexibility to probe participants on topics that arise during the interviews (Patton, 2002). Charmaz also stated that, an intensive interview created from a guide that is created with a few open ended, broad questions could help create focus and invite detailed discussion of a topic (2006). Additionally participants were asked if they would be open for a follow-up interview at the end of their interview.

For this study, I conducted in-depth interviews between February 2012 and March 2012. None of the interviews lasted more than 120 minutes additional follow-up was required for several participants in order to clarify confusing or obscured information recorded during their interview. All audio recordings were transcribed by a transcription service and then reviewed by me for accuracy.

\section{Data Analysis Methods}

Initial Coding. For this study, data consisted of transcribed interviews, memos, and field notes. Initial coding was line-by-line, which means reviewing each line in the data and possibly applying codes to them because "detailed observations of people, actions, and settings that reveal visibly telling and consequential scenes and actions lend 
themselves to line-by-line coding" (Charmaz, 2006, p. 50). Initial coding allows the researcher to begin the process of theory building and helps "you to refrain from imputing your motives, fears, or unresolved personal issues to your respondents and to your collected data" (p. 54). For example, if a line from a transcript was I feel pressure in the evenings to answer work calls even when I am not on call the initial line-by-line code for this might be pressure to answer work call.

Each interview was coded line-by-line after it was transcribed. Once the first two interviews were coded in this manner the line codes were gathered together and compared to reduce overlap and standardize the code numbers. Subsequent interviews were coded from this list and new codes were added as needed. After the first four interviews subsequent line-by-line coding did not generate new codes.

Focused Codes. Comparison of the line-by-line codes between interviews allowed me to see which codes came up more often in the data. Using this information, a list of focused codes was created from the line-by-line coding. Focused coding "means using the most significant and/or frequent earlier codes to sift through large amounts of data... [and] requires decisions about which initial codes make the most analytic sense to categorize your data incisively and completely" (Charmaz, 2006, p. 57). An example of this would be if there were many discussions of pressure to work, like described above, the focused code might be 'pressure to work' and would encompass many different lineby-line codes that describe this phenomena. The focused codes I created were then compared across interviews to establish analytic distinction and thus "make comparisons at each level of analytic work" (p. 54). While there were many line-by-line codes, my analysis of the data ultimately found 15 focused codes (see Table 4). 
Table 4

Themes, Conceptual Categories, and Focused Codes

\begin{tabular}{|c|c|c|}
\hline Themes & Conceptual Categories & Focused Codes \\
\hline Use of Space & $\begin{array}{l}\text { Use of Personal Space } \\
\text { Use of Physical Separation }\end{array}$ & $\begin{array}{l}\text { Work during personal } \\
\text { Personal time activities } \\
\text { Work activities } \\
\text { Personal during work } \\
\text { Aspects of living in }\end{array}$ \\
\hline \multirow[t]{3}{*}{$\begin{array}{l}\text { Boundary Management } \\
\text { in an Integrative Space }\end{array}$} & Work/Life Boundaries & $\begin{array}{l}\text { Boundary strategies } \\
\text { Work/personal boundaries }\end{array}$ \\
\hline & $\begin{array}{l}\text { Events Force Work Life } \\
\text { Choices }\end{array}$ & $\begin{array}{l}\text { Work expected lack of } \\
\text { boundaries } \\
\text { Work/life balance }\end{array}$ \\
\hline & $\begin{array}{l}\text { Supervisors Behavior } \\
\text { influences Balance } \\
\text { Relationships and } \\
\text { Boundaries }\end{array}$ & $\begin{array}{l}\text { Supervisors boundaries } \\
\text { Boundaries learned from } \\
\text { experience or training } \\
\text { Boundaries around } \\
\text { relationships }\end{array}$ \\
\hline $\begin{array}{l}\text { Negotiating Emerging } \\
\text { Technologies }\end{array}$ & $\begin{array}{l}\text { Use of Personal } \\
\text { Technology } \\
\text { Use of Work Technology }\end{array}$ & $\begin{array}{l}\text { Facebook/Twitter use at work } \\
\text { Facebook boundaries } \\
\text { Use of mobile phones }\end{array}$ \\
\hline
\end{tabular}

Conceptual Categories. The process of comparison within and across interviews I used was called the constant comparative method and it is considered essential in grounded theory methodology (Charmaz, 2006). According to Holton (2010), "the purpose of constant comparison is to see if the data support and continue to support emerging categories [and] the process further builds and substantiates the emerging categories by defining their properties and dimensions" (p. 27). Charmaz (2006) asserts that focused codes are developed and further focused in order to reduce them to few refined conceptual categories, which "explicate ideas, events, or processes in your data- 
and do so in telling words" (p. 91). Conceptual categories were created from collapsing many focused codes through higher levels of abstraction. After this process, I ended up with eight conceptual categories (see Table 4).

During development of the conceptual categories, memos were used to aid in the creation of the final eight conceptual categories. Memos "catch your thoughts, capture the comparisons and connections you make, and crystallize questions and directions for you to pursue" (Charmaz, 2006, p. 73). I wrote memos in the moment as they occurred to me during data collection and analysis they were freely written with little structure. They allowed me to make and record my ideas about how the data relates to focused codes, the focused codes to conceptual categories, and ultimately the conceptual categories to the final three themes (Charmaz, 2006).

Themes. The final three themes were developed from the conceptual categories that were heavily saturated over multiple interviews (see Table 4). After achieving categorical saturation around interview six, I began the process of grouping the conceptual categories into themes. Subsequent analysis during the next two interviews failed to generate any new categories or themes. But, as stated above, I conducted four more interviews to confirm saturation and to add depth and dimension to the themes, which developed after the first eight interviews. I also used memos collected throughout my process to further refine my themes. Since my memos already helped to illustrate where conceptual categories were incomplete or where there were holes in the analysis, the additional theoretical sampling used to recruit the last four participants allowed me to construct full and robust themes (sometimes referred to as theoretical categories) and allowed me to clarify relationships between themes (Charmaz, 2006). 
The Process Model. While the additional four interviews I conducted did not generate new categories or themes, they did allow me to further saturate my existing categories with more data and thus allowed me to refine my themes through the comparisons and emerging analysis of the data rather than from external prescriptions (Charmaz, 2006). My immersion in the data, along with constant comparative methods, allowed me to develop a theory based on how the individual participants managed their work/life boundaries and attempted to arrive and some level of balance. That theory was an interpretation and depended on constructions of experience from the participants' point of view and the researcher's point of view. I do not attempt to stand outside of the social construction of this study (Charmaz, 2006).

Creswell states:

The intent of a grounded theory study is to move beyond description and to generate or discover a theory, an abstract analytical schema of a process... [and] participants in the study would all have experienced the process, and the development of the theory might help explain practice or provide a framework for further research. $(2007$, p. 63$)$

As a result of my analysis, I was able to generate a theory about the boundary management practices of my sample population as they relate to the integrative environment, which is presented at the end of Chapter $\mathrm{V}$ in a process model called $A$ Model of the Integrative Environment of Residence Life. I believe that this theoretical model will provide a framework for further research on this and other populations that live at the place they work.

\section{Limitations}

As with all studies, there are limitations to this study. An attempt to gather participants, with as much diversity as possible, was the idea behind my initial choice to 
conduct maximum variation sampling. However, even within the 50 possible participants recruited for this study there was limited diversity. I would like to have had more racial diversity and a greater diversity of gender identity. I feel this limitation was inherent in the larger population of residence life professionals; however my attempts to discover and sample more diversity did not pan out. I also feel this was a factor in the early saturation of my data. All my participants, regardless of demographic differences, seemed to have a similar experience of boundary management. This similarity might help mitigate the lack of diversity in my sample.

Another limitation of the participant selection process was the nature of recruitment from national organizations. Membership in national residence life organizations may not be a priority for resident life professionals who are having a hard time managing their boundaries, or who have just started in the field. Membership in a national organization may also not be desirable for those who hate their job and are very unsatisfied with residence life. This could be reflected in the fact that only one participant was in the middle of her first year (the bottom of my length of employment time criterion) and that participant was the only one to truly express dis-satisfaction with her live-in position.

Charmaz states that in constructivist, emergent, grounded theory methods, "researchers construct their respective products from the fabric of the interactions, both witnessed and lived" (2006, p. 178). Since I have never worked in residence life, I do not have any first hand experience of being a live-in professional in residence life. Nor was I a paraprofessional at any time during my schooling. Adding to that lack of familiarity is the fact that I only lived in a residential facility for one year when I was an 
undergraduate. However, Charmaz indicates the "successive levels of abstraction through comparative analysis" used in ground theory will help to mitigate this limitation (if it is indeed a limitation) by grounding me in the participant's words and the comparison of their experiences in their roles as residence life professionals (2006, p. 178).

Finally, Belch and Mueller (2003) found in a quantitative study of paraprofessionals that, of the students who reported that they intended to pursue a position in residence life, the "level and nature of student contact" was the highest rated reason for pursing that position (p. 38). As I found in my research, this indicated a preference for an integrative strategy of boundary management, which means there is little distinction between home and work (Nippert-Eng, 1996). The highly integrative style of the population may have needed a study of some other aspect of work/life balance than boundary management. Therefore my focus on boundary management may not have yielded a complete picture of work/life balance for these professionals. 


\section{CHAPTER FOUR}

\section{FINDINGS}

\section{Introduction}

The purpose of this study was to understand how resident life professionals experience work/life boundary management and to identify the specific processes these professionals use to create and manage their work/life boundaries. There were four research questions what guided my inquiry:

1. In what ways do residence life professionals, who live onsite, manage their work/life boundaries?

2. What role does technology, and more specifically social media, play in boundary management for these resident life professionals?

3. How, if at all, does boundary management contribute to job satisfaction for resident life professionals and does training or lack of training impact resident life professionals' work/life boundary management?

4. If resident life professionals are creating boundaries around the domains of work and life, is it due to a desire to achieve some type of work/life balance or is there another rationale at work?

This chapter presents my findings. I will begin with a review of significant definitions that apply to the study's population; these definitions will aid in understanding the findings that will be presented in the remainder of the chapter. I will then present a brief description of my participants and their situations to allow for a better understanding of the contexts from which the data were generated. I will then present data for each theme organized by the conceptual categories included under the theme (see 
Table 4 in Chapter III on page 51). The theoretical model derived from (and "grounded" in) the data presented in this chapter will be presented in the Discussion chapter that follows and that concludes this dissertation.

\section{Relevant Definitions}

The discussion of boundaries within this study was designed specifically to look at the boundaries between the domains of work and home. The study of these boundaries goes by different names within the literature: e.g., work/family, work/home, and work/life boundaries. I am using the term work/life boundaries with the understanding that life specifically means personal life outside work.

Work/life balance is used throughout this study to describe the process of balancing work and life. It is not meant to imply a 50/50 balance. The balance participants achieved varied and was not indicative of their work/life satisfaction. Participant's were specifically asked about their work/life balance and reported balances ranging from $60 \%$ work and $40 \%$ personal life to $75 \%$ work and $25 \%$ personal life with the most common answer being $60 \%$ to $40 \%$ (see Table 5 ).

The participants in my sample went by the following professional titles: Hall Director, Greek Area Hall Director, Area Director, Resident Director, and Resident Hall Director. All of these professionals, however, fit within the definition of resident life professional. That definition was based on a review of the literature and is as follows: residence life professionals are responsible "for supervising, correlating, and integrating the activities of students who live in campus-operated residence halls [and] typically... provide counseling services for students, plan programs, advise student government, and do crisis interventions as situations dictate" (Schuh \& Shipton, 1985, p. 380). Resident 
life professionals are paid entry level professionals typically embarking on their first fulltime position out of the university or are sometimes graduate students who receive an assistantship along with a salary and/or a stipend (Frederiksen, 1993; Collins \& Hirt, 2006). The responsibility level for these professionals is higher than that for resident advisors and most often includes the supervision of resident advisors or other student workers. Belch and Mueller assert that "residence life positions, specifically, the resident director, were considered the key entry points for new professionals in student affairs" (2003, p. 29). Frederiksen (1993) concurred and concluded that residence life is "the primary provider of basic student affairs professional work experience" (p. 176).

The resident life professionals chosen, as participants, were limited to professionals who live within the residential facility they supervise. However, while conducting my research, I discovered that there are two distinctions appropriate for professionals who live in a residential facility; live-in and live-on. According to my participants, live-in professionals are responsible for the building they live in and directly supervise the staff of that building. Live-on resident life professionals do not supervise the building or pre-professional staff (typically resident advisors) directly, but supervise the live-in professional (typically the resident director) of the building they live in as well as other buildings around campus. In my study, I had one live-on professional and his title was Assistant Director of Residential Life (participant Dean). In this case, Dean trains and mentors resident advisors so he has many staff members under his direction living in the same building he lives in.

Essential to the understanding of my sample is the distinction between boundary integrators and boundary segmentors. Ashforth, Kreiner, and Fugate (2000) assert "the 
act of creating and maintaining boundaries...complicates the act of crossing from one domain into another" (p. 474). The level of complication is mitigated by the amount of segmentation or integration that the individual creates between domains. Nippert-Eng (1996a) posited that individuals conceptualize the boundaries between the domains of work and home on a continuum with being very distinct and separate (segmentation) at one end and overlapping and porous (integration) at the other end. She found that extreme segmentors (e.g., those who prefer a complete separation between work and home) often have different clothes, calendars, and key rings for each domain and do not discuss home matters at work or vice versa. Opposite to this, extreme integrators do not see a difference between home and work and often allow aspects of one domain to overlap into or exist within the other (Nippert-Eng, 1996a).

Nippert-Eng ultimately suggests that extreme integrators and extreme segmentors are rare. Instead, most people attempt to construct and maintain boundaries that are somewhat closer to the middle of the continuum (1996a, 1996b). This was not true for my sample of resident life professionals who live where they work, however. Within this study, I did not find anyone who would be considered on the segmentor end of NippertEng's continuum, but all of my participants would be considered integrators having little separation between the domains of work and home. They all answered work emails, phone calls, and text messages when at home. They all dealt with situations when work forced its way into personal time no matter what they had planned, and recognized that living where they work meant that they were always on duty while in the building outside their apartment. 


\section{Participant Descriptions}

There were twelve participants from six different Association of College and University Housing Officers - International (ACUHO-I) membership regions and from five different Carnegie size classifications (see Table 3 in Chapter III). Nine participants identified as white or Caucasian. Three participants identified as other various ethnicities. Table 5 provides additional information not provided in Chapter III. Relationship status, work/life balance self reported percentages, and total length of time the participants reported being in residence life live-in/on positions has been added. This data was added to help add context to the findings presented here. The relationship status information indicates whether or not the partner was living with the participant or living off campus. All of the off campus partners did spend some nights on campus with the participant. In addition to the new data, the university type and ACUHO-I membership region is provided for each participant. This differs from Chapter III as it assigns the region and type to specific participants. I feel this information will provide further context for the findings presented in the next sections. As indicated in Chapter III, additional context and longer participant profiles are provided in Appendix C. These profiles add information about the residence facility layout and population for each participant. 
Table 5

Additional Participant Information

\begin{tabular}{|c|c|c|c|c|c|}
\hline Pseudonym & $\begin{array}{l}\text { Relationship } \\
\text { Status }\end{array}$ & $\begin{array}{l}\text { Work/Life } \\
\text { Balance } \\
\text { Percent }\end{array}$ & $\begin{array}{l}\text { ACUHO-I } \\
\text { Region }\end{array}$ & $\begin{array}{l}\text { University } \\
\text { Type }\end{array}$ & $\begin{array}{l}\text { Reported } \\
\text { Years in } \\
\text { Live-in/ } \\
\text { on } \\
\text { Positions }\end{array}$ \\
\hline Dean & Single & $60 \%$ to $40 \%$ & Southeast & Private & 5 \\
\hline Harold & Single & No Report & Northeast & Public & 36 \\
\hline Harry & $\begin{array}{l}\text { Fiancé- Long } \\
\text { Distance }\end{array}$ & $60 \%$ to $40 \%$ & $\begin{array}{l}\text { Upper- } \\
\text { Midwest }\end{array}$ & Public & 2.5 \\
\hline Mary & $\begin{array}{l}\text { Boyfriend- Off } \\
\text { Campus }\end{array}$ & $70 \%$ to $30 \%$ & Northeast & Public & 3.5 \\
\hline Megan & Married & $75 \%$ to $25 \%$ & Southeast & Private & 3.5 \\
\hline Nick & Married & $70 \%$ to $30 \%$ & $\begin{array}{l}\text { Great } \\
\text { Lakes }\end{array}$ & Private & 1.5 \\
\hline Steve & Married & $60 \%$ to $40 \%$ & Northwest & Public & 1.5 \\
\hline Sam & $\begin{array}{l}\text { Fiancé- Off } \\
\text { Campus }\end{array}$ & $60 \%$ to $40 \%$ & $\begin{array}{l}\text { Great } \\
\text { Lakes }\end{array}$ & Private & 3.5 \\
\hline Sally & Single & $60 \%$ to $40 \%$ & $\begin{array}{l}\text { Mid- } \\
\text { Atlantic }\end{array}$ & Private & 8.5 \\
\hline Rue & $\begin{array}{l}\text { Partner- Off } \\
\text { Campus }\end{array}$ & $60 \%$ to $40 \%$ & $\begin{array}{l}\text { Upper- } \\
\text { Midwest }\end{array}$ & Private & 4 \\
\hline Trevor & Single & $65 \%$ to $35 \%$ & Northwest & Public & 4 \\
\hline Windy & $\begin{array}{l}\text { Live-in } \\
\text { Boyfriend }\end{array}$ & $65 \%$ to $35 \%$ & $\begin{array}{l}\text { Upper- } \\
\text { Midwest }\end{array}$ & Public & 0.5 \\
\hline
\end{tabular}

The Integrative Continuum, Themes, and Categories

This section first presents the integrative continuum, which emerged from the data as a classification system for the participants based on how they created boundaries in 
different dimensions of their lives. Then 1 present the themes drawn from the data analysis. Each theme is divided into the supporting categories that led to its development. The first theme is use of space and is divided into two categories: use of personal space and use of physical separation. The next theme is boundary management in an integrative space and is divided into four sections: work/life boundaries, events force work/life choices, supervisors' behavior influences balance, and relationships and boundaries. Following that, I present the final theme negotiating emerging technology. It is divided into two sections: use of personal technology and use of work technology. Integration Continuum for Resident Life Professionals

My data suggested that the participants where all integrators as defined by Nippert-Eng (1996a) and see little difference between work and personal time. However, integrators can still create boundaries in their lives. The extent to which each participant created boundaries differed in how the participant used personal space, created personal boundaries with staff and students, as well as how they managed the time they spent working and the time they spent doing personal activities. As the categories and themes emerged from the data, I also began to see that certain participants established more boundaries than others. The establishment of these boundaries did not make them any less of an integrator but did show a difference in the intensity of integration.

It became clear that the three dimensions of residence life my participants all experienced as boundary challenges and opportunities were: space boundaries, interpersonal boundaries (with staff and students), and time management boundaries. Within time management, getting off campus was the most common integrative coping strategy the participants used to create a boundary between work and personal time. 
Since most participants reported that the only time they feel off work was when they left campus, the use of the getting off campus coping strategy was highly indicative of an attempt to establish boundaries and work/life balance.

Once I coupled the dimensions in which the participants discussed boundary creation with the difference in intensity of integration, I was able to define on my own continuum of integration from full integrators who have few if any boundaries between work and life to integrative segmentors, who establish more boundaries on how work flows into their personal lives (see Table 6).

Nippert-Eng (1996a, 1996b) and Ashforth (2001) presented integrators and segmentors as if they were on a spectrum with extremes at either end that did not represent the norm in the middle. The creation of a continuum of integration comes from the data and seems to illustrate the differences I observed in my sample population, which is on the extreme integrator end of Nippert-Eng and Ashforth's spectrum.

Participant placement on the continuum is not an implication of their work satisfaction or success. Instead the continuum is derived from my data to help illustrate the extent to which my participants allowed work to flow into life freely and to provide additional organization to the presentation of the findings. The continuum is not a static scale but a dynamic instrument that changes as participants chose to set more boundaries. Full integrators feel like work and personal time flow together, which may or may not be an issue for them. They create fewer boundaries between work and their personal lives. Integrative segmentors, on the other end of the continuum, try to create some boundaries, where possible, within the context of a work environment that is constantly present, something I call the integrative environment. 
A participant may be in different places within each dimension on the continuum.

Therefore, I assigned a number representing the place each aspect of the dimension was

located on the continuum. The assignment of each aspect to a place on the continuum came from the variation in boundary setting I saw within my sample. Each participant was then given a composite score to explain how I came to his or her placement on the continuum (see Table 6).

Table 6

Integration Continuum for Residence Life Professionals

\begin{tabular}{|c|c|c|c|c|}
\hline $\begin{array}{l}\text { 1- Full } \\
\text { Integrator } \\
\end{array}$ & 2 & 3 & 4 & $\begin{array}{r}\text { 5- Integrative } \\
\text { Segmentor }\end{array}$ \\
\hline \multicolumn{5}{|c|}{ Space Boundaries } \\
\hline $\begin{array}{l}\text { Very likely to } \\
\text { allow staff } \\
\text { and/or students } \\
\text { into their } \\
\text { personal space. } \\
\text { (1) }\end{array}$ & $\begin{array}{l}\text { Likely to } \\
\text { allow staff } \\
\text { and/or } \\
\text { students into } \\
\text { their personal } \\
\text { space. (2) }\end{array}$ & $\begin{array}{l}\text { May or May not to } \\
\text { allow staff access } \\
\text { to personal space. } \\
\text { (3) }\end{array}$ & $\begin{array}{l}\text { Not likely to allow } \\
\text { staff access to } \\
\text { personal spaces. } \\
\text { (4) }\end{array}$ & $\begin{array}{l}\text { Does not } \\
\text { typically allow } \\
\text { staff or students } \\
\text { access to personal } \\
\text { spaces. (5) }\end{array}$ \\
\hline \multicolumn{5}{|c|}{ Interpersonal Boundaries (Staff and/or Students) } \\
\hline $\begin{array}{l}\text { Highly } \\
\text { informal } \\
\text { interpersonal } \\
\text { boundaries } \\
\text { established } \\
\text { with staff and } \\
\text { students. (1) }\end{array}$ & $\begin{array}{l}\text { Less formal } \\
\text { interpersonal } \\
\text { boundaries } \\
\text { with staff } \\
\text { and/or } \\
\text { students. (2) }\end{array}$ & $\begin{array}{l}\text { Some formal and } \\
\text { some informal } \\
\text { interpersonal } \\
\text { boundaries with } \\
\text { staff and/or } \\
\text { students. (3) }\end{array}$ & $\begin{array}{l}\text { Stronger more } \\
\text { formalized } \\
\text { interpersonal } \\
\text { boundaries with } \\
\text { staff and students. } \\
\text { (4) }\end{array}$ & $\begin{array}{l}\text { Sets clear and } \\
\text { formal } \\
\text { interpersonal } \\
\text { boundaries with } \\
\text { staff and students. } \\
\text { (5) }\end{array}$ \\
\hline \multicolumn{5}{|c|}{ Time Management Boundaries } \\
\hline $\begin{array}{l}\text { Considers work } \\
\text { and personal as } \\
\text { one. Less } \\
\text { focus on } \\
\text { distinct } \\
\text { personal time/ } \\
\text { getting off } \\
\text { campus. (1) }\end{array}$ & $\begin{array}{l}\text { Prioritizes } \\
\text { work over } \\
\text { personal time. } \\
\text { May get away } \\
\text { when possible. } \\
\text { (2) }\end{array}$ & $\begin{array}{l}\text { Sets minimal } \\
\text { boundaries around } \\
\text { work time. But } \\
\text { seldom schedules } \\
\text { time off campus. } \\
\text { (3) }\end{array}$ & $\begin{array}{l}\text { Sets some } \\
\text { boundaries around } \\
\text { work time, with } \\
\text { exceptions. } \\
\text { Actively schedules } \\
\text { time away from } \\
\text { campus. (4) }\end{array}$ & $\begin{array}{l}\text { Sets strict time } \\
\text { boundaries } \\
\text { around work, } \\
\text { allowing few } \\
\text { exemptions. Gets } \\
\text { off campus often. } \\
\text { (5) }\end{array}$ \\
\hline Harold (5) & & 00 & & \\
\hline Steve (5) & Nick (6) & $\begin{array}{l}\text { Megan }(9) \\
\text { Trevor }(10)\end{array}$ & Rue (12) & $\begin{array}{l}\text { Sam (15) } \\
\text { Sally (15) }\end{array}$ \\
\hline
\end{tabular}


Further analysis after the continuum was developed also found that the participants who rated as full integrators tended to have been in their position less time than those in the middle and at the integrative segmentor end of the continuum (see Table 7). The outlier of this trend was Harold who has worked in a live-in position for 36 years and is a full integrator.

Table 7

Participants' Reported Live-In/On Professional Experience Related to Their Position on the Integrative Continutum

\begin{tabular}{|lccc|}
\hline Pseudonym & $\begin{array}{c}\text { Reported Years } \\
\text { in Live-in/on } \\
\text { Positions }\end{array}$ & $\begin{array}{c}\text { Position on the } \\
\text { Integrative } \\
\text { Continuum }\end{array}$ & $\begin{array}{c}\text { Weighting on the } \\
\text { Integrative } \\
\text { Continuum }\end{array}$ \\
\hline Dean & 5 & 4 & 12 \\
Harold & 36 & 1 & 5 \\
Harry & 2.5 & 5 & 14 \\
Mary & 3.5 & 3 & 10 \\
Megan & 3.5 & 3 & 9 \\
Nick & 1.5 & 2 & 6 \\
Steve & 1.5 & 1 & 5 \\
Sam & 3.5 & 5 & 15 \\
Sally & 8.5 & 5 & 15 \\
Rue & 4 & 4 & 12 \\
Trevor & 4 & 3 & 10 \\
Windy & 0.5 & 2 & 7 \\
\hline
\end{tabular}

\section{Use of Space}

The theme Use of Space covers the conceptual categories Use of Personal Space and Use of Physical Separation. How the participants used their work/personal space in their attempts to manage boundaries varied within my sample population. While a strict application of Nippert-Eng's boundary management categories would place all the participants into the category of integrators, within my sample there was a spectrum of participants that ranged from those who allowed students and staff access to their personal space (full integrators) to those who kept their personal spaces strictly off limits 
to anyone work related (integrative segmentors). However, in the domain of work, all my participants reported attending to personal aspects of their life while working. This could be as simple as taking personal calls or as complex as having their young child in their office at work. Another commonality in my sample was that when my participants wanted to really get away from work, their personal space on campus was not enough, and to varying degrees, the participants needed to physically leave campus in order to feel a true separation from work.

Use of Personal Space. All of my participants lived in the building they supervised either in a live-in capacity, or, in one instance, in a live-on role. The apartments provided to them by the university are connected to the building hallways and are often in close proximity to the students. While some may also have a private entrance, most did not. Doing work at home was ubiquitous among my participants, especially since a part of their role as a live-in or live-on professional was to be "on-call," which meant that for a certain time each semester the professional had to answer the phone 24 hours a day and handle any issue that might arise. The extent to which my participants used their home for work varied in my sample and seemed to be divided between those who allowed staff or students into their apartment, and those that did not allow access to their apartment.

Boundary setting strategies determined when students or staff could access the apartment including the late night "knock on the door," which was a common experience among my participants. Three of my participants exemplified the idea of integrative segmentors. Sam had the strictest boundaries actively attempting to limit home space interruptions: 
If someone [staff or student] comes to my door and they're, like, "Hey, can I talk to you?" I'll ask "Is this an emergency; do we need to talk now?" Most often, it's not.... I'm really upfront with them about my involvements outside of work. The people that I have in my life, they all know who my fiance is and they are very good about respecting that space for me. I will tell them, "You can knock on my door, and if l ask you if we can talk about this later and the answer is yes, you probably shouldn't knock on my door, just send me an e-mail and I'll get back to you."

Harry likes to set limits as well, saying, "People will come to my apartment and knock on my door; sometimes my RAs will. I try to discourage them from doing that because (a) they know when I'm in my office, and (b) I have a BlackBerry that they can call me on." Mary, who is more in the middle of the integrative continuum, chooses to ignore student calls when she is off, but she added, "If it's my RAs or it's any of my bosses, I will answer the phone call."

Beyond simply answering the door or taking a phone call at home, there were those who actually allowed students and/or staff into their apartment. I have characterized these individuals as full integrators. Nick, Steve, Trevor, Megan, and Windy exemplified the full integrator end of the spectrum, albeit to varying degrees. Nick discussed his wife's role with the students: "She had been very supportive of wanting to invite students over, especially my [student] staff. She has shown the desire to get to know them as people. Like they recognize her, they certainly say hi to her."

Steve, another full integrator who is also married, has a more personal goal in mind with his students and staff:

I have been able to use where I work as an opportunity to have students come over and, because we're so close to the R.A.s, it's nice that my apartment can be sort of a place where the students who live on campus, who miss their home, can come sit on my couch and have a...you know, we can cook food. So I like that I can give students access to that sort of a home kind of feeling. That's a benefit to living on campus and, in a lot of ways, it is very convenient to live where I work. 
Trevor, who is on the full integrator side of the curriculum but closer to the middle of the continuum than the other full integrator types discussed thus far, also expressed a similar interest in helping his students feel at home. As the following comments indicate, however, he limits this goal to student staff only:

My apartment is a sanctuary for my RAs. If they need a place to just kind of unwind or hide, they do come out here especially if they are getting sleep, I do tell them "if you need a place to hide away and study and do not want to be disturbed by residents, by anybody else, you can come and use my apartment. I'm not going to entertain you. I'm not going to chat with you. I'm going to go about my things." I have a little nook in my apartment that's for RAs. They can come, sit there and study, and do whatever they need to. Living where you work gives me the opportunity to be that kind of a support for my RA staff.

Windy and Megan had the most controls in the group of participants who are on the full integrator side of the continuum. Both, on occasion, have meetings with resident advisors in their apartment, but this practice is not the norm for them. Windy has weekly one-on-one meetings in her apartment, while Megan invites staff over for dinner in order to build relationships with them.

Living where you work invariably promotes some sort of integrative environment in residence life. When work literally comes knocking on your door, you cannot avoid work and home overlapping. Still, some participants did manage to create boundaries to allow for private time. Even Harold, who could be viewed as the textbook-perfect example of a full integrator in the participant pool, talked about his alone time as being important. He said:

I always try to take some time in the day where I am in this apartment, and I am by myself, and there ain't nobody bothering me, and they're doing their thing out there, and all those concerns are out there. And either I'm on the Internet or I' $m$ usually on Facebook... or I'm watching TV or playing video games, just doing things that I like to do and just having that alone time. 
Harry, someone who unabashedly occupied the integrative segmentor end of the spectrum, even though he admitted to taking work calls and answering emails in his apartment, also felt he maintained a strong boundary between the personal and the professional. At one point, for example, he stated:

When I come in my apartment, there is no work. The only work that gets done here is me playing video games... This is where I come and de-stress, recharge, and be me. I leave my work in that office and I actually think it's one of the things I'm really good at, is knowing when things can wait until the next day.

Harold and Harry represent two ends of the continuum. Harold needed only to set aside small amounts of time for personal things. Harry, on the other hand, felt he needed to maintain boundaries around his entire personal space to preserve his personal time. Both, however, acknowledged a need for personal time and at least some boundaries that allowed them to have it.

Most participants reported a similar need for on-campus personal time and similar strategies for getting it. A few of them, however, felt that their apartment was not the best space to escape to. Windy exemplified this minority view best:

I think kind of this feeling I can't really fully relax because I'll never know if I have to run out or anything. So I can't really just walk into my apartment and let myself go, I guess, because I'm always anticipating someone knocking on the door or something. It's just not like my apartment it's still like me working.

Windy was not alone in feeling frustration with the integrative work environment. However, it seemed that most of the frustration felt by the majority of participants focused on the journey from the office to the front door, which led them to only truly feel off work when they left campus.

Resident life professionals are well known among their students and staff. They are recognized whenever they are outside their apartments. Staff and students see them 
not only as someone in authority but also as someone who may have the answers they need to a question. This means that a resident life professional is always on duty when they are transitioning from their home to their office, to the parking lot, or to the dining hall. Nick sums this up best, "Even as I come and go at night or on a weekend, [I] still... [must have] basically a game face on as I walk in and out of the residence hall. It's just a really interesting experience."

This lack of personal time when moving about the building or campus, can lead to work happening during personal time. Sally said:

You can't ignore them [students or staff] if they say hi to you or, like, multiple times I'm stopped at night and asked questions about things whether they'd be housing or not. [For instance] the past two nights I got stopped as I was trying to go somewhere and I got stopped by residents, that aren't even my residents, but maybe have lived in my building [at some point] or just know me from around campus, and you just try to answer their questions.

The idea of being "on" whenever you are outside your apartment, as Nick and Sally described, isn't limited to questions. It is part of the responsibility of the resident life professional to address problems they see while they are happening as well. Nick explains, "I've gone out just to leave and found students smoking marijuana in the back. And so now, it's 6 at night, I was on my way to a doctor's appointment, or something personal, and now I have to take time to address this because I can't just ignore it." Other participants reported finding students climbing the building, being noisy, or drinking alcohol and had to address that despite being off. Sally summed up this constant state of being on best when she stated:

There's always students walking around campus. Someone is always going to stop you and try to talk to you so you... in a way, you're never not working, you're never, maybe, not on duty, you kind of always have to be student centered and student developmental and be able to handle problems... So you're just, you're kind of never off. 
This state of "never being off" is one of the hallmarks of the integrative environment. My participants used different strategies to handle the integrative environment found in residence life, which I call integrative coping strategies. These integrative coping strategies may or may not include the setting of boundaries. Instead the strategies, presented from the data, allowed the participants to cope with the allsurrounding integrative environment. One of these integrative strategies that was inspired by this state of "never being off" involved having to leave campus in order to truly feel off work. This strategy was used by all participants and is discussed in the next section about the category: Use of Physical Separation.

Use of Physical Separation. Having to leave campus to feel "off work" was reported by all participants. Leaving campus was the most used integrative coping strategy I discovered in the data, but the degree to which the participant needed this "off campus" time varied.

Harold was the participant who had been in the job for the longest, over 31 years, but needed the least time away. As a full integrator who loves his job, he mostly rents a car and leaves campus for errands:

Today, I have the car rented for 24 hours so I got it this afternoon. I had to go to the dentist's office to pay a bill and then I did a little bit of shopping and that's pretty much it. About once every couple of weeks, maybe, maybe I will go to a movie or something but not too often.

Similar to Harold, Harry doesn't take long trips off campus, but, unlike Harold, he feels his trips are important for not losing himself. He says:

I'll just go off campus to just sit in Barnes \& Noble for three hours, and buy more books than I probably should.... But yeah, just try to get away, and, like I said, you just have to find those things that keep you from losing yourself because it's really easy to lose yourself. 
Harry's strategy for "not losing himself" is an example of how even Integrative Segmentors attempt to maintain boundaries in the integrative environment that surrounds them.

Megan, a participant who comes down closer to the middle of the continuum, cannot always get off campus by car, so she tries to go places on or near campus where she can avoid students, which she calls "laying low." She describes laying low as:

Not walking around my building, just kind of going straight in and straight out. I would say choosing not to eat on campus. I have a meal plan that's part of my compensation. So maybe we choose not to eat on campus for the weekend. We may actually go off campus and visit my husband's family or do something in the surrounding area, but just sort of avoiding students, I guess.

As noted, Megan would occupy a space more toward the middle of the continuum and therefore, struggles more with setting boundaries around personal time than those at the Integrative Segmentor end of the continuum do. Her strategy often is to use avoidance of students and the staff she supervises to keep from being overwhelmed. The need to avoid students and staff comes up in all participants' interviews, and how they managed to avoid students all had one thing in common: a need for planning, forethought, or sometimes trickery.

Nick's story exemplifies the struggles participants who are on the Full Integrator end of the continuum often have in creating boundaries. He told me:

Yeah, it's not always easy. I mean, part of my salary comes with a gym membership, but that means that I have to work out next to the students that I just sat in a conduct hearing with. So, it's tough, but I want to go work out. So do I pay the extra $\$ 50$ a month to go work out off campus or do I take what's given to me as part of my salary and go work out here where l'm next to them? ... For me, I'm OK with that. A lot of times, I can just wear a stocking hat or something and they won't recognize me, almost like a fake moustache or something. 
The choice to make it work with students demonstrates how individuals on the full integrator end of the spectrum will most commonly make decisions that blend work and personal activities. To fight this blending, Nick will schedule his personal time to make sure he gets some time in:

I have some stuff structured into my schedule where I go and work out at a specific time, at least commit to that myself. I also get off of campus for a bowling league on Tuesday nights and I play in a basketball league on Wednesday night, so I try and create that into my schedule for the most part and then sometimes weekends even.... if it has been especially stressful and I don't want to have work creep in, I'll actually leave campus.... So, yeah, it varies a lot.

Nick's planning and scheduling demonstrate that even someone at the Full Integrator end of the continuum attempts to establish boundaries around his time to allow for personal time. Yet, Nick also demonstrates how permeable the boundaries created by full integrators can be. When discussing frustrations, he said,

Tonight is Tuesday, and, as I just said, howling is my nonnegotiable. But guess what, I'm not going to bowling tonight because it is room selection day on campus and, on Friday, three business days ago, we found out that, hey, you all have to staff the central office to be there to help students.

Nick's story illustrates how even when participants attempted to construct firm boundaries, work can win out.

Steve, who is also on Nick's end of the continuum, needs to leave campus more often to cope with the more consuming nature of his integration of the work and personal dimensions of his life. He told me:

I get off campus a couple to three times a week or whatever... I need to be far away so that I couldn't just turn around and be quickly back on campus in 15 minutes. And that really helps me go, yeah, I'm done, this school could be blowing up and on fire and I wouldn't know about it and that really feels like a vacation to me. 
Steve's little vacations are necessary because his personal space on campus is not enough of a respite.

Rue told me much the same thing that Nick did and, in the process, demonstrated that, even when you are closer to the Integrative Segmentor end of the continuum, you still need to get away:

It's hard when I have a day off, I either feel like I need to hold myself up in my apartment or leave campus altogether. The idea of vacation time or a day off has been really difficult for me because I do live where I work and so I almost have to like physically remove myself from work in order to feel like I have a day off.

Sally, also an integrative segmentor, tries to leave campus at least one weekend a month. She stays with friends off campus; "I do have friends off campus and there are times when, you know, time we spent off campus or weekends might be a way off campus with those people or travelling to different cities or doing different things." Trevor, Dean, Mary and Windy also reported different experiences getting off campus when they could, however, each of them had a more causal outlook using this integrative coping strategy in a more random way.

The theme use of space encompasses how participants used personal spaces and physical separation to adapt to living in the integrative environment created by living where they work. Creating a space to get away from work was an act of boundary setting and also an integrative coping strategy the participants used to cope with the integrative environment they lived in mainly by escaping it. Within their personal space, participants created boundaries and, to different degrees, were successful in separating work and personal on occasion, but the nature of the integrative environment meant that, ultimately, work would win out over personal. 
It might seem then that this theme should include a category for Use of Work Space since many participants also had offices in their buildings. During the course of data collection and analysis, I did look at the places where the home domain overlapped the work domain. I collected data on the overlap from both sides. Work happened at home and personal life happened at work. Yet, in terms of the use of space for boundary management, how participants used the workspace did not emerge during analysis as a significant category for the Use of Physical Separation theme. It did, however, show up in the next theme: Boundary Management in an Integrative Environment.

\section{Boundary Management in an Integrative Environment}

The nature of work in resident life creates an environment where people are not only living in the building they manage. Their work also involves people who actually bring work to their front door. As shown in the last theme, students and staff not only knock on the participants doors, they also call on the phone, email, and get involved in shenanigans in the hallways and behind the building that, if observed by the participants, have to be addressed. Therefore, the place to do work is everywhere, and this means that the people I studied inevitably work in an integrative environment. How participants manage their personal boundaries in this environment will be presented in the context of the following categories: (a) Work/Life Boundaries, (b) Events Force Work/Life Choices, (c) Supervisors' Behavior Influences Balance, (d) Relationships and Boundaries.

Work/Life Boundaries. The discussion of boundaries within this category will look specifically at times when participants discussed a boundary they created between work and personal life or when they described a situation that demonstrated a boundary or lack of a boundary between work and personal life. The following two aspects 
presented in the data were a key to understanding the nature of work/life boundaries in this study: boundaries set with staff and/or students and boundaries around work time. This section will examine each of those aspects from the perspective of the integration continuum from full integrators to integrative segmentors.

Full integrators are characterized as having few or no boundaries between work and personal life. Therefore, when it comes to staff and students, a full integrator may establish less formal boundaries with the staff and students, specifically in terms of the times when the participant is working and when they are off duty. Under the theme Use of Space, data have already been presented showing how full integrators will allow staff and sometimes students into their personal space. Typically this is done for work-related reasons, which may include building relationships with their staff members.

Mary demonstrates best the need for creating relationships with staff as a reason for having fewer boundaries. She says:

So by the time our RAs, like, get to the point where they are RAs, they're almost ready to graduate, but they're really not that mature. Most of them are only, like, 19, 20 years old. And they're getting all this responsibility. So, for me, it's looking at not really making them feel like they're alone and out there, so the relationship I built with my staff is that I will be here to help you out no matter what it is. However, it has to be legitimate. You can't call me up midnight for [a] purchase order, however, call me at midnight [when there is crisis with student] and, then if I can go.... I will come out and help.

It's a very supportive relationship. Most of them kind of refer to me as a mom figure in the building because I do look out for them whether it's, "Are you OK? Did you go to class or miss an exam?" whatever is going on. So, it's very, very blurry relationship... There are some RAs that I have a personal relationship with where I'll disclose things about my life... [the RAs] I've know the longest and I know they know the separation between personal life and business life and they know how to handle when I give them information that there are some things that they're not allowed to go and repeat. There are some that I will disclose to and there are some that I will never tell anything to. 
The boundaries Mary sets are dependent on the understanding by the staff of what is important to contact her about, when she is off duty. In terms of Mary's sharing of personal information, the boundary entails knowing that people will know how to handle any personal information shared. These boundaries are very informal and not clearly defined, much like the boundaries that were the stock-in-trade of those like Nick, Steve, and Megan whose willingness to invite students into their home was discussed earlier. Indeed, those who get grouped at the full integrator end of the continuum inevitably establish, at best, quite porous boundaries in a wide variety of areas.

As participants demonstrate more segmentation between work and personal life, more rules are applied to the staff. Trevor established clear boundaries regarding the time he allows staff to spend in his apartment, which was discussed above under the category use of personal space. But he also sets definitive boundaries around certain types of personal information. He said:

I think my RAs have always been very good about respecting my boundaries. I'm very transparent... [with] my RAs about sexual everything. [But] when I tell them, "This is a boundary you don't cross," they're, like, "All right, that's a boundary we don't cross," and then they move on. Actually, it hasn't been that much of a problem.

Rue, who is a 4 on the continuum, also uses the word transparent when discussing her boundaries with staff. While it seems she is merely saying she is available, she is articulating a strategy that keeps the staff from coming to her room and knocking on the door:

I'm pretty transparent with my staff, and so I'll let them know, "Hey, if you need anything, you can text me, and I'll let you know if I can help you, and if not, I'll connect you to somebody else." And so my staff has been really, really good about figuring out what they need me for and what they can rely on each other for, and so I haven't really been bothered a whole lot after I leave the office. 
The establishment of these slightly firmer boundaries through transparent discussions with the staff is characteristic of those in the middle of the continuum. Thus rules are not simply made, but negotiation of boundaries occurs through discussion.

Those on the integrative segmentor end try to set boundaries more formally at the beginning of the school year. Harry exemplifies this best when he discussed how his staff had to adjust to his more formal boundaries:

I always try to be professional and if I strike up connections with RAs, that's great. If I don't, that's fine, too. But I know that I have to kind of... there is a line there and, for me, there is just that line, you know, I always try to make sure I don't go off it because I don't want other people to perceive I'm playing favorites, and I don't want rumors which, of course, is one thing we know especially when you're living at a fishbowl on a college campus, rumors go around, rumors run faster than cheetahs. Yeah, but that was definitely the biggest adjustment for them and for me, truthfully at first, just kind of setting those boundaries. But 1 think now that we've had a semester had four or five weeks now together, I think they've gotten me and I've gotten them and I think it's starting to work itself out.

Sam and Sally also both fall on the Integrative Segmentor end of the spectrum, in part because they both set clear and distinct boundaries with the staff and students. Sam says, "I want to hear about things that they care about. [But] I don't want to just have them see me as like this person they can vent to about anything. I don't want to be their gossip buddy." Sam's statement reflects Harry's idea that while a connection with the staff as a supervisor is good, a personal connection is less important or should be discouraged, thinking that epitomizes those at this end of the continuum.

It is important to remember that the people I interviewed and placed on a continuum are, in fact, people, not ideal types. Consequently, not everyone on the continuum will exemplify every aspect of the continuum category in which they were placed, and they certainly did not exhibit things in in the same way as others who occupy 
the same continuum space. Harold, for example, does not have many boundaries between work and personal time; to him they flow together. Nevertheless, he does set boundaries around his relationships with students and staff. With students, he tries to make them feel at home but he does not make them his friend or allow them in his home regularly. He said, "I have a good rapport with my students and I feel very comfortable with them. Again, I try to make them feel like the living room, the lounges, are their living room, this is their home." With staff, he will have closer relationships, but will not consider them friends until they have left the school.

While Harold may lean toward the integrative segmentor end of the continuum when it comes to his boundaries with his staff, but his ideas about work show how he strongly integrates work and life and is therefore a full integrator. He feels that work and personal life flow together, saying the following in response to a question about work/life balance:

Well, I think it's there. It's not defined. It's not like you punch out at 4:30. I mean it's there when I'm going up to get my morning coffee and I take 20 pictures on the way... So, it's all intertwined to me... I usually spend a fair amount of time in the office and, like I said, it's a very small community so I try to engage people as they walk out the door, "How are you doing? Have a good day. It's supposed to rain. Be careful." Whatever... I have a little window in front my desk that almost everybody passes by to go out to class. And so, l'll spend a fair amount of time with that.

Harold also takes very little personal time. His feelings about personal time are summed up in this statement: "Do I use my vacation? The time, yes, because otherwise you give it away to the state. What do I do with that? I just use it. I don't go anywhere. I'm here. I walk around and take more pictures." Thus, Harold lives on campus, works on campus, and vacations on campus and represents full integration of work and life. 
Steve, Nick, and Windy are also on the full integration side of the continuum.

The difference is the varying degree they set boundaries. Steve, for example, characterized work and life as flowing together in a similar way as Harold did. He says the following about keeping work at bay during personal time: "It's sort of like fighting a rising tide and I can win that by doing some things, but the tide is always rising... and if I wanted to, I could find more work to do." Yet, over time, he has learned to be more intentional about setting boundaries. This intentionality illustrates the importance of experience in the establishment of a boundary setting policy. Talking about the planning his wife and he now do, he said:

Last year, I don't know that we were intentional enough to break up that routine of this work and life and all that sort of all mixed up and so this year, we've been much more intentional about, yeah, the weekend is here, what are we going to do that will make the weekend different than the week? And so, we just plan to, you know, Saturday, we're going to a town down the road and go out for dinner, just to make it significantly different and we planned it because we know that we're doing it so that it breaks up the routine of living and working at the same place... Like I can't... it's very hard to separate out the work and the life, they flow back and forth very easily, and so if I really want to make something change and I really want to be different about that, I need to make some really significant plans and change things significantly. It doesn't happen naturally.

Steve makes an effort to set boundaries by planning events in his personal time. As someone on the full integrator end of the continuum, Steve allows work and personal to intertwine but he does so with a newfound consideration of the consequences.

At the integrative segmentor end of the continuum, participants made more of an effort to plan personal time and set clear boundaries around work and personal life. Sam exemplifies this end of the continuum the best. Talking about how she creates boundaries with her staff, she said:

I would say be really upfront about your boundaries. Well, obviously number one, you need to know what your boundaries are. If your sitting on the train 
talking to your friend and you see a resident of yours, if a boundary that you have is not really engaging them in conversation, you need to say to your staff like, you know, if I'm out with my friends, that's really my time. I'll kind of give you a wave but I would appreciate if you don't sit down and try to have a 20 -minute conversation with me. I know it seems kind of rude but I think that they just respect it when you're really upfront with them and you tell them here is really how I want to operate and the reason I do that is personally for your benefit and you explain to them like if I were at my job all the time, I would just get worn out and I want to make sure I'm coming to work every day prepared to be at my best to help you be your best... So, I am just really clear with them about OK, if you call me and I don't answer, and you leave a message and it's emergency, I'll call you back. So, I think just through trial and error, I've identified those systematic ways of communicating with them. That has helped a lot just being really upfront.

Sam's upfront clear style of boundary setting with staff was mirrored by Sally, Harry, and to a lessor degree, Rue. The differences here between the ends of the continuum relate to how clear and formal participants are when defining their boundaries. This does not mean they still were not interrupted and still did not have knocks on the door; however, they were able to handle those situations based on a formal plan or rule they had previously communicated to the staff and students. The simple fact is that no matter what boundaries are created, staff and students can still impact the resident life professional's personal time. This leads to the next category: events force work/life choices.

Events Force Work/Life Choices. One of the hallmarks of an integrative environment is the idea that work is around you all the time. Work even comes to your front door and knocks. My participants described many situations that required them to work even when they were officially off duty. This section will look at some of those situations that contributed to my understanding of the integrative environment resulting from living where you work in residence life. 
It is important to note that in residence life it is common for resident life professionals to have certain times, outside of what would normally be seen as traditional 9 to 5 business hours, when they are "on duty," meaning that they accept calls from staff not only in their building but in all the buildings on campus. They are the go-to person when a crisis or problem occurs. Typically, this was reported in my study to be either a couple of weekends a semester or one week a semester depending on the university. The events I discuss happen when the participant is not on duty.

My participants reported events that would cause them to work when they were off duty, such as suicide attempts, bedbugs, lockouts, alcohol/drug use, vandalism, fights, fire alarms, and other emergency events. Harry, an integrative segmentor, talks about how this creates a $24 / 7$ feeling of always working:

I think the hardest thing is as much as you can say you want to go home and make this place your home, you really don't go home and it's really difficult to separate that because we really do have, in some ways, a 24/7 job. You can't really prepare for a lot of the things that happen at night like those times when the fire alarm goes off at 2:00am or at 8:00pm at night when someone burns popcorn or at 11:00pm at night on a Friday when you get a call from an RA who says, oh, I have an alcohol bust, can you come up to the fourth floor or that time on a Saturday night where I had a student in the building across the street turn on a shower, go to sleep, and forget to turn the shower off and the whole room was flooded.

Sam also talks about her challenges transitioning between the front door and her apartment:

There had been times that I've like, just come across things myself but I will deal with like Saturday for example, I had a student who was like scaling our building and he thought he was Spiderman. It was like 2:00 in the morning and I was letting my fiancé into the building and I had to deal with that for like two hours.

Intrusive events happen, and many times the resident life professional has no choice but to deal with them. 
Other times there may be some choice involved, but for Steve, a full integrator,

everything boils down to a question of ethics. He says:

I don't feel any expectation like that from supervisors, but, you know, if a student in my building is having a mental health crisis, it would be professionally unethical to say to them, "You know what, I just put in my day off so good luck with that." Like that, that would not work and so it's really... it's a subtle unspoken expectation. And so I feel that, I feel like at work or when I'm here, I could be working, and so we've done this, just, we've done things that say, like, go away from campus, that's like, yeah, I'm sorry that that's happening but I am in Portland right now, I cannot be helpful at all for this. And so that really is like a structural way to manage some of that tension or feeling like I could, at any moment, be doing some work while I'm here.

Steve points out, that while whether or not to get engaged in a work-like situation may look like a choice, some things are unethical and thus not really a choice. Yet especially for the people on the full integrator end of the spectrum, there are times when, though they could choose not to work, they still feel that there is an expectation to work.

There were also events that forced work that participants accepted as part of their job, even though it caused them to work extra hours. Examples cited by interviewees include move in and move out times, student presentations, and resident advisor selection/training, just to name a few. It was common among all participants to talk about times of the year when they had to work long hours with little or no time off. Nick's discussion of his work months encapsulates what many participants said:

Yeah, we work, especially in the months of August, September, and February we work a lot of weekends. In August, I don't think...I don't believe I've gotten more than like one day off in August in the last two years. September is obviously pretty heavy. February was incredibly heavy because the students come back from winter break and so you really want to focus on that first six weeks for your transfer students and your international students that have come in at the semester and as well as getting people off to a strong start so it's heavy on programming. Then we start RA selection and so we had a weekend of our group process where we bring in candidates for interviews. Today is the $28^{\text {th }}$ so I think I had three weekend days off this month and that's probably not as typical. I would 
say for the most part, if you're not on duty and there's nothing else scheduled, then you're good- but a lot of stuff does seem to fall on the weekends.

While these events are planned and expected when you take a job in residence life, they still create an environment in which work can be expected to occur at any time (and, frequently, all the time). All participants reported understanding these expectations prior to taking their position, but they expressed different levels of satisfaction with the reality of working so much.

Never feeling off work is, in essence, the nature of working in an integrative environment. Work is all around you. Even when you try to set boundaries, those attempts can be thwarted by the work, itself, and by living where you work. I want to end this section with a descriptive quote from Sally expressing her frustration with the integrative environment:

I think, as much as you try to be private, it isn't. There's always students walking around campus, someone is always going to stop you and try to talk to you so you... in a way, you're never not working, you're never, maybe not on duty, you kind of always have to be student centered and student developmental... So you're just... you're kind of never off.

The next section will discuss how supervisors also put pressure on the participants' boundaries due to their own lack of boundaries.

Supervisors' Behavior Influences Balance. One of my research questions sought to understand how training or mentorship affected the work/life balance and boundary management of the participants. Initially I asked participants about training. What I soon discovered was most participants had little training in boundary management or work/life balance. Instead they reported that what they learned about boundaries and work/life balance came from their supervisors, either from mirroring the supervisor's behaviors or from the supervisor's mentorship. I adapted the interview guide to 
specifically examine the supervisor's role in the boundary management and work/life balance of the participants. This section will reflect the results of all participants' conversations about their supervisors' effects on their boundary management.

Only one participant reported that their supervisor had good work/life boundaries. Dean stated that his supervisor supported him in establishing and maintaining his boundaries and that she also had strong boundaries. He described the support he received as follows:

I have a great supervisor who is really focused on professional development, focused on the need to be happy, and the success of the department and how that all balances together. She definitely acknowledges that $I$ need to have a strong work-life balance [and]... when she leaves in the evening; she's gone for the evening.

Other participants reported that their supervisors talked about the importance of having strong boundaries. The difference here was that Dean's supervisor actually modeled boundary management, something that was not reported by other participants.

What supervisors most often modeled in terms of boundary management was constant work. Where they worked might differ. Some supervisors worked on campus constantly, while other supervisors who would leave work on time but send emails at all hours of the night. Rue's account of her supervisor's concern about taking time off but still sending late night texts is a good example of what I saw from most participants:

My supervisor is single and has a very active social life. She wants us to do that as well, and so she's constantly encouraging us to get out of town and take time for ourselves and "don't feel bad about taking a day off if you need to or go work half a day, take care of you first because I want you to be successful in your job as well and you're not going to be that way if you're not taking time off for you." However, with that being said, my supervisor's supervisor gets in the office, like, $7 \mathrm{o}$ 'clock in the morning and doesn't leave until 4:30, and both of them will oftentimes send emails late at night because they have smartphones. And so, for me, it's hard because those are really early in the morning, and I won't get in the 
office until 8:00, 8:30, and I feel like l'm behind because it [the message] was sent at 7:00. And so what I internally interpret that as is, like, "Oh, you're not on your game." But I know that that's not what their intentions are, like it's never an emergency and if they need me, they're going to call me. And so it has more to do with my internalizing of what I'm seeing happening than it does with what they physically say, when they actively encourage and support.

Sally, Steve, Trevor, and Nick all discussed similar frustration with late night emails from their supervisors making them feel that they should also be working at that time. Trevor likes to create stronger boundaries and actually confronted a previous supervisor. "It was a conversation with my previous supervisor and I said, 'Look here, just because you send an email at $1 \mathrm{am}$, it doesn't mean I'm going to respond. Let's get that expectation clear."' Trevor stressed establishing boundaries with his supervisor, but he was the only one that reported doing that.

Ultimately, the majority of my participants related stories about how their supervisors tried to encourage them to have boundaries and not to copy their behavior. Sally described this phenomenon best:

So, he [supervisor] just gets... he is really...completely overworked. He does not have a good balance, he will tell us that. We can see it, yeah, we could see it in how he is, personality, stress, you know, spelling things wrong in e-mails, responding to e-mails twice, just those types of things. You can just tell, he has way too much and he doesn't take time for himself and he verbalizes that to us. I think he knows that he is unbalanced and he said that and I think part of the reason that he is unbalanced is he doesn't want to see us be unbalanced so he takes some of work and he puts that on him. So, you know, I don't think he expects that, that we're unbalanced as well but I think sometimes, maybe he functions in a way and he thinks that we do but if we don't function in that way, he's trying but he doesn't expects us to, if that makes sense.

Sally not only describes the imbalance between what is said and what is done from the supervisors but she also shows a typical concern for her boss that was common in almost all the participants. 
The concern Sally expressed above seemed to lead to an increased pressure to violate boundaries around work/life separation with most participants. Nick explains:

My supervisor, I appreciate her, she is one of the hardest working people in our department as an assistant director, but she will tell you herself that we should not follow her lead on how to find balance because she will work nonstop. She'll work on the weekends, she'll send e-mails at night, and it's tough because I want to go home at 5:00, I know that I should, and in the past I have, but if I go home at 5:00 or if I don't work at all on the weekends, I won't get the job done and I don't want to face those consequences.

The concern that not working would reflect badly on themselves, or that their boss would be disappointed in them was common amongst participants. This concern for their supervisors reflected the fact that virtually all participants appeared to genuinely like their supervisors, worried about being respected by the supervisor, and that their supervisors worked too hard. Only Harold reported unhappiness with his supervisors, which centered on their lack of support for him maintaining balance in his work.

Participants' stories about how their supervisors influenced their balance showed the importance of the relationship between the supervisor and the participant in the establishment of work boundaries. The next category, relationships and boundaries, explores the role personal relationships had in the process of boundary management and the establishment of work/life boundaries.

Relationships and Boundaries. This is the final category under the theme boundary management in an integrative environment. Consistent with what was written about the previous categories is the idea, here, that the integrative environment in residence life has work constantly trying to encroach onto personal time. Clark (2000) defines border-keepers as domain members who have a greater influence over the definition of the domain border. The essential ingredient that defines someone as a 
border-keeper is some power over the border-crosser. Clark posits that border-keepers in the home domain, like spouses and partners, can assist in the definition and maintenance of boundaries.

Participants' relationships with spouses, boy/girlfriends, fiancés, and, even, pets influenced how they established boundaries around their homes. However, these traditional border-keepers did not help define boundaries actively; instead, their presence reminded the participants about needing boundaries.

Eight of the twelve participants were currently in some type of relationship. One participant, Harold, a full integrator, had been in a relationship - he had a wife-but the relationship ended due to his job. He described a situation that happened between him and his wife immediately after his wedding. The story was typical of the "knock-on-thedoor" type of situation that was reported by all participants who have or who have had partners live with them:

Quite literally we came back from the wedding ceremony, I'm in a tuxedo, she's in a wedding dress, kind of interesting, and we literally walked in the door, I go into the bathroom and there's a knock at the door, and my wife in her wedding dress answers the door, and this young lady who was a resident named Jane said she lost a quarter in the soda machine. My wife, says, "Listen, Michael is in the bathroom. He'll be out in a few minutes and he'll take care of it." But she wouldn't have it. She wanted her quarter, and she wanted it right there. So, that was pretty interesting.

Harold's wife helped him to establish better boundaries between his work and personal time, but, ultimately, after 13 years, she divorced him, something that he described as well justified. In the end, work won over his wife and, after she left, he went back to a relatively boundary-less existence at work.

Having a live-in relationship did make my participants more aware of their boundaries but did not necessarily help them establish boundaries. It seemed that, in all 
cases, the relationships that work were with people who understood and accepted the integrative environment. Sally, an integrative segmentor who lost a relationship because of her job, summed it up like this:

I think if you're with someone that understands student affairs, it's a lot easier because they get it, they get you, they understand you're on call, you might not have to leave, something pops up, you have to deal with it. If you're with someone that's not in student affairs, I think it can be challenging.

Rue, who is also on the integrative segmentor end of the continuum and who works at a religious university, talked about her girlfriend:

Oh, man, she is really, really great. I don't think I would be able to make it at work if she didn't respect how much I care about my job and how much I care about the relationship I have with my staff members. I make a point to introduce her to them so they know. It's not in the net, like advertised necessarily, like I don't go and lay a flag around and say, "Hey, look at me. Not only am I the person that works here but I'm also in relationship. Oh, and guess what, I'm gay." It's not something I shout from the rooftop, but 1 also don't hide from it either, and so she gets to know my staff members. She talks and usually, because she's with me when I'm walking around the building, like, [or] if we're coming back to my apartment or going out to be somewhere. I usually get pulled into a conversation, and it frustrates her so much, but she deals with it.

Thus, while having an accepting partner is a must, Rue also reports that she is looking for other work because her university is Catholic and only allows married, straight couples to live together in house. Therefore, in this case, the relationship she is in influences her work decisions; showing how those at the integrative segmentor end of the continuum can separate from work in certain situations.

Megan, who exemplifies the middle of the integrative continuum, is also considering leaving her job due to the fact that her family is growing. In her discussion about her family's growth, she also shows how, even with a spouse who doesn't interact with students the way Nick's and Steve's spouses do, she still does not feel compelled to 
establish stronger boundaries as a result of his behavior. As a matter of fact, she becomes annoyed if he establishes boundaries:

We're definitely feeling the space constraint at this point because I mean we live in a nicer apartment than I've had in any of the other places I've lived. But you know, we're at the point where we're thinking about more children, you know my child needs a yard to play in he can't leave our apartment or house and directly get to the grass, you know so that aspect is tough. My husband, well he's lived in with me since we got married, so he's pretty used to living in and living on campus and he has over the years chosen to, I don't want to say avoid students, but you know we make it a habit where he does not have access to the master key to let them in the rooms or access to forms that I would normally have. So generally speaking, he just pretends like he doesn't have any answers and in fact chooses not to answer the door a lot of times, which is annoying to me.

Megan responded to the needs of her partner by setting up boundaries around

forms and keys, in essence respecting his boundaries while remaining annoyed that he did not assist her in allowing work during personal times. Allowing her husband to set boundaries while not really setting firm boundaries for herself is typically of the middle of the continuum.

Megan did, however, have stronger feelings about boundaries with pets, which was reflected in other participants' stories. She discussed how her pet was a factor in her leaving a previous job:

I don't know if you've encountered this in your study, either, but pets are a big deal as far as like rules without pets and what you can and can't have being a livein or live-on professional and being treated as an adult, in fact, I left a position, and a cat was a part of the reason for me leaving.

Megan currently has many boundaries around her current pet dog's interactions with students such as not allowing her dog access to students' apartments, not permitting the dog to roam the building, and not allowing students to walk/watch her dog. Sally, another dog owner in the study, had very similar boundaries. Trevor, while not wanting a pet himself, did note that it was a serious consideration for others at his university. 
As Clark (2000) suggests, pets and spouses did influence participants to think about boundaries but did not help to keep work out of the home, and, in effect, did not function specifically as border-keepers in this study. Instead, it seems that relationships are more of a reminder that there is someone else involved in the work/life balance equation for the participants. This consideration of the needs of spouses, partners, children, and pets, therefore, impacted boundaries by reminding the participants in relationships that personal time was needed for these relationships. Steve described this phenomenon as follows:

I feel like this year is more successful for me and so much as that, you know, my wife and I aren't like at odds of like, we never see each other and whenever you're here, you're always distracted like that. So, I can't say that in an instant that has changed but this year, we started this year, it's like, we've got to do it differently than last year. And so, doing it differently, as I said, you know, we talk about what this week looks like, it's going to be busy or sort of planning and preparing for when times will be more... when I will be more at work and then less at work.

Steve learned over time to be more conscious of planning time because of his relationship. Of course, it wasn't only live-in relationships that allowed for this sort of learning.

Sam, an integrative segmentor, for example, discussed how a visit from her

family allowed her to learn more about setting boundaries around work:

My mom came to visit me once in grad school and it was my first year of grad school and I had a work meeting that in my head, I was like "I have to go to this" and I told her like I can't go to breakfast with you because I have this meeting. And when I told my supervisor after the fact, she was like, "are you ridiculous? Why didn't you just tell me? You totally could have gone and spend some time with your family who you only get to see a couple of times a year." So, I learned then that it's OK to ask like hey, can I take a day off or do you mind if we reschedule because I really want to spend some time with my family and when they came, they had the best time, they felt like this is my apartment. 
Sam learned this lesson early in her career and it allowed her to have stronger work/life boundaries, eventually making her an Integrative Segmentor, though family also had another function. About half of the participants reported that visiting family was one way they got off campus to have more personal time. Nick, who is on the full integrator end of the continuum, talked about how he and his wife get away:

So, it varies, there have been times where if it has been especially stressful and I don't want to have work creep in, I'll actually leave campus. My family lives about two and a half hours from here so we have travelled home a couple of times just to get away from campus and visit with friends.

Mary, who is more in the middle of the continuum, also reported how important it was that her family was within driving distance so she could get away and visit them. In the end, it was relationships that helped some participants remember to get away from work and to make some time for life.

Dean and Trevor did not discuss having relationships while living-in or living-on. Each presented a different picture of living where you work while single. Dean is a four on the Integration Continuum and reported feeling that the coordination of large groups of friends and dating were both difficult in his position. Nevertheless he was happy, overall. Trevor, who was in the middle of the continuum, reported having established stronger boundaries around his work and personal time, even though he allows his resident advisors to spend time in his apartment to escape from their work. He did not feel comfortable pursing a relationship at this time in his career. However, he did report that a female friend visiting him was the inspiration for his conversation about personal boundaries with his resident advisors. 
Ultimately, it seems a musing from Rue, who like Dean is a 4 on the continuum, best captures how relationships function impact boundaries in an integrative environment:

I think that if I were single [my work/life balance]... would probably [be] more about like 80-20. But because I'm in a relationship, it forces me to like, "Oh, yeah, I love you. I want to spend time with you. What's going on in your life." But if I was single, like, I can't even imagine what it would be like to date.

Therefore, while relationships may not act as border-keepers for participants, they did help to re-enforce the need to have boundaries between work and life, at least to a modest degree. Relationships also had another function: they were the primary reason participants reported doing personal life activities during work time. Work related personal life activities where often electronically mitigated and therefore will be discussed more under the next theme, negotiating emerging technologies.

\section{Negotiating Emerging Technologies}

The theme Negotiating Emerging Technologies generally shows how the participants dealt with technology that has emerged within the last fifteen years. Study participants were specifically asked about Facebook, Twitter, and other social media, though they also talked about cell phone use, email, text messaging, and video chat. Facebook and Twitter were specifically asked about because my pilot survey of over 200 resident life professionals showed that $41 \%$ of my respondents were required or encouraged to use Facebook or Twitter at work (Rankin, 2011). This section will examine the two categories: Use of Personal Technology and Use of Work Technology. These categories showed much overlap, as would be expected for integrators who overlap work and personal boundaries in the non-technological aspects of their lives. Thus, in this section I will discuss both categories together, looking first at Facebook, then moving 
to Twitter, and finally ending with a brief look at the other technologies the participants reported using the most. Throughout this discussion I will be looking at boundaries the participants have with these technologies. It should be noted that only one participant, Sally, who works at a smaller private university was not required to use social media for work and did not use any technology other than her cell phone for work. She also did not have a private Facebook or Twitter account and therefore she will not be included in these findings.

Facebook. Facebook is a social network site that allows users to create a profile and interact with people they have approved as "friends." Various privacy settings allow users to create groups of people that can then be allowed or denied permission to see certain content. In effect, Facebook privacy settings allow users to create and maintain boundaries around what content on their profile is shared and with whom it is shared. As noted above, all of the participants except Sally used Facebook personally. Seven of my twelve participants reported having to manage a work Facebook account, as well.

Of the 11 participants who use Facebook, all except Rue and Harold allowed current staff, and sometimes students, as friends, which is another example of how integrative the participants were. Only Rue, who was on the integrative segmentor end of the continuum, maintained two personal Facebook accounts: one for friends and family and the other for professional uses. Harold, who is a full integrator, made it a policy to not friend current students or staff until they have moved on.

Of the nine participants who allowed students and/or staff as friends on their personal Facebook (which I will call "the Nine"), there was some variation in how they established boundaries between work and personal friends on Facebook. The most 
common boundary that the nine reported establishing was similar to the boundary that Steve reported establishing. He claimed, "I don't friend request any student, but I also don't say no to any student that friend requests me." I call this the Awareness of Power Rule. The idea that friending a student or staff member may be unethical or inappropriate comes from the same ethical ideas about friending or dating a staff member or student. You must be aware you are in a position of power over that person. Thus, when participants use the awareness of power rule as a boundary in the friending process on Facebook they are attempting to set this ethical boundary. Trevor, who is a three on the integrative continuum and who also uses the awareness of power rule, wants to make sure he makes his students aware of the accountability that goes along with friendship:

Whenever one my residents or students invites me to be a friend, I never invite any of my students to be my friend. But whenever they do, I have a pre-written statement that I send back with them before I accept any student that essentially tells them, "If you add me to your friends list then I can see your pictures and if there is some kind of picture that tells me to report a violation, I have to treat that seriously and report a violation. If you're ok with that, sure, go ahead, l'll accept your friendship, but if not, I won't take any offense if you decide to rescind the friend offer." ... If they go through with that, then they'll see in my private profile [i.e., his personal pictures and posts]. If they don't, then, that's great too.

Trevor had the most comprehensive policy of all the participants, but he brought up another boundary marker that arises after friending a student: how much can that student see?

Once a student or staff member is friended by a participant, Facebook essentially considers that person as equal to anyone else who is a friend (e.g. high school friends, peers, college friends, personal friends, family, and even grandma). Only the Facebook user can limit what particular "friends" see by putting that friend into a group and limiting what they can access. Seven of the nine had no limits on what their students or 
staff could see or access. Sam, who is an integrative segmentor, described her thinking on having everyone see everything:

No, I don't and I don't see that as a problem. I know I've talked to many people who do see a problem with that but I really don't. At some point, a lot of these young people are going to in some ways be my peers. If I was like 45, 50 and I was still friending some new freshman coming in and that was my only Facebook profile, I might be a little more concerned with like the messages l'd send to my family and things like that but I feel as though in the next five years, if I were to see any of them on the street and we were to have a conversation, I would be totally comfortable with them knowing what I'm up to on Facebook. Like I feel good about who I am outside of work and I feel like I'm cool about things in a healthy way or I'm not ashamed to put anything up there and I surround myself with people who I'm proud that they know about and in a way, I guess it's my way of showing them who I am personally. They can see pictures of my nephew, they can see some of my friends. And I've put up a few of the privacy things so if someone were to tag me in a photo, I can always see that before it's put up there. So I can use a little bit of discretion with what's there and what's not.

Sam reflects a typical thinking among the participants who don't set limits, which revolves around keeping their personal Facebook page clean and appropriate. In effect, most of the participants in the study set boundaries around what they post and not who they friend.

Sometimes it is not enough to decide only to post clean and appropriate material.

If a Facebook was previously not open to students, but, because of a new job, that situation might change, those who work with students - and allow students to friend them-may have to clean house. Mary, who is also in the middle of the integration continuum, describes this cleaning process best, saying:

But I also don't have anything that's very, very personal on my Facebook page. It's like pictures of me and my family, but I cleaned down my page after second year here and pretty much took out everything that had anything to do with my social life back in college, any of the vacation pictures of going to New Orleans or going across the border and having fun with my friends. Like all those pictures are gone. So nobody really could see any of that part of my life. 
Having to keep personal Facebook "clean" was common among those who did not set limits. Nick, who is more of a full integrator, expressed remorse with his friending decisions of the past and indicated that he had begun to set up limits.

Nick was the only member of the nine to specifically limit what staff or students could see. Nick talked about how, after moving from a school that encouraged friending students, he removed students from his page, but still had peers and staff as friends:

I'm starting to wonder, hey, if I switch schools tomorrow, would I do the same? And I think it would depend on the school but if I could certainly go back, I wouldn't have even expanded past like my RD group on Facebook. I wish I would have just kept it at that level. Most of the stuff I talk about, like I don't drink, I don't live a real crazy or exciting lifestyle, so I don't really have anything that I don't mind other people seeing. So, on that end it's OK but I have realized that there are things about what some of the assistant directors post on Facebook that I'm like, "I don't want to know that, I don't need to see this post." So, some of that balance is occurring right now, I'm reflecting about that.

Nick puts all of the school related friends in a group, which has limited access to his more personal posts and pictures. Dean also limits his Facebook but he does so by only allowing students he directly mentors to friend him.

Facebook at work. Rue, Megan, Nick, Dean, and Steve all reported having a Facebook account used for work. These accounts were used to represent the residential facility they managed, their department, or specific staff and student groups within the residential facility. These groups are used to communicate with the students and staff, as Rue explains:

On campus we're really like hyper-connected and like my staff members view a lot of or are connecting with each other through Facebook, and so a lot of times if I need to reach my staff all at once, I'll post something in our... we have a group or whatever on Facebook, and l'll post something there, even if it's like a funny video, like we're pretty casual and then my one-on-ones like staff like to show a different YouTube videos to me every time I use it, and so we do things that aren't typical work things, but I still count them as work things because it's development to what I'm doing. 
Boundaries come into play with work Facebook accounts in several ways. The first is that if the professional also joins a group with their personal Facebook account, they have opened themselves up to the possibility of students friending them personally. Megan, who is in the middle of the continuum, commented on this situation:

Facebook groups and things are one of the ways that our student groups and organizations are advertised. And so, you know, we made a Facebook group for our whole council, and I think I ended up friending those people for whatever reason. So I have some student friends on there, I haven't had the time or energy to go in and create particular settings so that $l$ can friend more students without them seeing pictures from me in college or all the people that are my friends and all of that stuff.

Megan, in short, found here that her involvement with the student groups led to her becoming friends with students when that was not her original goal.

Another work issue that came up for the nine study participants, who have students as friends on their Facebook, is what happens when you see a student who is your friend-either on your personal page or on the official work page-doing something that is illegal or against the rules. None of the participants reported that their university had an official policy on what to do in this situation. Boundary-wise, only Trevor, as already illustrated above, warned the students that he would have to report what he saw if it was on a student's page who was his friend. Mary most succinctly described how the rest of the nine handled this issue. She said:

If it appears on my wall or is something that catches my eye, then I will address it. However, if it's something where they have done it, they posted it, I never saw it, I'm not going to go and stop on pages to see what's going on.

Mary echoed the sentiment that, even though it is part of their jobs to enforce school policy, the fact that Facebook is perceived as a "friend zone" or "a personal space" creates a boundary that most participants would not actively cross. 
Participants also used Facebook to build relationships with students by looking at the students' interests and the events they participant in. They would also use Facebook to put names to faces, especially before a judicial meeting or resident advisor selection. Rue encapsulates what many participants mentioned when discussing work-related uses of Facebook:

Sometimes I've used it to, like, put a face to a name if I can or if I feel like I need $\mathfrak{t}$ know who this person is, have I seen them before, do I know them, am I supposed to know them? I try not to [look them up] just because it puts me in a really precarious situation if I see things that I shouldn't be seeing. Because I do feel compelled to act then..., like, I pull it up and say, "Hey, in your profile picture, it showed the picture of you appearing to be passed out on the floor with a bunch of alcohol bottles under you. Let's talk about the message that this sends." Like, they're not in trouble for doing that but they might be in my office because they were documented for underage drinking, and their RA might have said, "Hey, FYI their Facebook has a lot of activity that documents their drinking." We don't have a book that we can use on social media as a means to necessarily punish someone, but I might use it as a supplemental to have a further discussion.

Navigating emergent technology at work and in personal lives is challenging, especially for people who naturally integrate work and personal life. Nevertheless, not all emergent technologies presented these challenges. Twitter, while used by fewer participants, seemed to present less boundary management issues.

Twitter. Twitter is a social media service that allows users to post messages limited to only 140 characters. Twitter users can follow other people or groups that have a Twitter account. In return, your messages can be searched by anyone online, and those people can choose to follow you as long as you remain public. You can exercise more control over your account by making it private but that is not the norm with this service. Harry, Rue, Nick, and Megan reported using Twitter and all four of them reported mainly using it for work. Megan said, "I just recently got a Twitter account that had to do with a regional conference for housing officers, and they were kind of pushing Twitter. So I 
really am kind of following work people and stuff work-related there." While Harry, Megan and Nick use Twitter to follow groups, Rue uses it to communicate to people from work about work-related material. None of them use it personally and no other participant talked about using Twitter.

Other Technology. All participants reported using their cell phone as a primary means of contact with work. As previously stated, participants reported using the cell phone to check email and respond to text messages that were work-related when they were at home or outside the office. Typically the cell phone was also used by participants for being "on call," which, as described earlier in this chapter, was the time when they were required to be available 24 hours a day to answer emergencies for all housing communities on campus. While it normally was clearly communicated that the phone must be on during 24 hour availability periods, when the participants were not on duty the expectations were sometimes less clear, as Nick explains:

I have other ideas of ways that I'm thinking about, like, for instance, one of the things I just said last night was I think I'm going to start leaving my work cell phone at work since it's just down at my office and I don't know what the level of expectation would be for me to have that phone. It [the expectation] has never really been clearly articulated, but if I have my phone then I'm always reachable. And, so, is that necessary? Like, I don't know, I'm trying to figure [out] some of that stuff.

Nick's thoughts here articulate what several participants described as a lack of clear communication from above as to what the expectations were around boundary setting. This was true for technology as well as for other work/life boundaries.

Participants who where on the integrative segmentor end of the continuum did attempt to create some boundaries around the cell phone including leaving it at work when not on duty or establishing a preferred communication order with the staff; as Harry 
did when he told his resident advisors he expected text messages for common questions and calls only when it was very important. Nick reported that he was thinking about leaving his phone at work in order to set more boundaries but at this time was not ready to commit to that. Nick's story illustrates the learning curve that reflects his more integrative personality and short length of time on the job, only one and a half years.

\section{Summary}

Throughout this chapter I have presented findings related to how participants created and maintained boundaries around work and life as well as how they attempted to construct some form of balance that was comfortable for them. In doing so, I presented the Integrative Continuum for Resident Life Professionals and discussed how the environment resident life professionals live in (i.e., the integrative environment) forces work upon them at all times. While the data reported here suggest that most resident life professionals operate with relatively few boundaries, the data also did indicate that, within the highly integrative environment found in residence life, different integrative coping strategies could be used to manage work/life balance (e.g. "laying low," leaving campus to feel off work, enforcing boundaries against late night interruptions, setting clear boundaries with staff and students, turning off work cell phone when off duty, scheduling personal time, and keeping home space private).

Since the participants reported little or no training in work/life boundary management or how to create some semblance of balance in their lives, integrative coping strategies were learned through experience. Analysis of the data showed the longer the participant stayed in a live-in/on position the more integrative coping strategies they would have at their disposal and also that they were more likely to be labeled 
integrative segmentors. In other words, the data for this study, at least, suggest that there is a relationship between the amount of integrative coping strategies and the level to which a participant creates boundaries within the integrative environment even though the integrative strategies do not necessarily create boundaries.

In the next chapter, I discuss the model I created from the data. The model attempts to illustrate the process my participants used to adapt to the integrative environment. 


\section{CHAPTER FIVE}

\section{DISCUSSION, IMPLICATIONS, AND RECOMMENDATIONS \\ Introduction}

The purpose of this constructivist grounded theory study was to understand the process through which resident life professionals manage work/life boundaries when they live at the same place they work. My study was guided by five research questions. They were: I. In what ways do residence life professionals, who live onsite, manage their work/life boundaries? 2. What role does technology, and more specifically social media, play in boundary management for these resident life professionals? 3. How, if at all, does boundary management contribute to job satisfaction for resident life professionals and does training or lack of training impact resident life professionals' work/life boundary management? 4. If resident life professionals are creating boundaries around the domains of work and life is it due to a desire to achieve some type of work/life balance or is there another rationale at work?

Answers to these questions where found in semi-structured, in-depth interviews with twelve participants who were selected from a national survey of resident life professionals using maximum variation sampling. The sample included participants from both public and private universities and contained participants from six out of the nine Association of College and University Housing Officers - International membership regions.

Interview transcripts were coded using grounded theory methods of open, focused, and axial coding. Constant comparison and memo writing techniques were used throughout the analytic process to develop analytical categories and themes. The three 
themes that surfaced during this inquiry were the use of space, boundary management in an integrative space, and negotiating emerging technologies.

Relevant definitions to review in this chapter are integration, integrative environment, integrative coping strategies, and the integrative continuum. Integration describes a process in which a person creates few boundaries between the domains of work and home (Ashforth, 2001; Nippert-Eng, 1996a). Therefore an integrator will do work related activities at home and personal life activities when at work. All of the participants in this study would be defined as integrators. In order to further differentiate the resident life participants I studied, I used the data to create a continuum of integrators to reflect the varying degrees of boundary setting I found in the data. The Integrative Continuum of Residence Life represents both full integrators, who set very few boundaries and let work and personal life flow together, and integrative segmentors, who set some boundaries to separate work and life (see Table 6 in Chapter IV).

The participants' description of the work environment showed that work literally surrounds them at all times. The students and staff they supervise live in the same building and at any time could bring work to their front door. The pervasive and all encompassing nature of work in residence life as described by the participants is what I define as the integrative environment.

The term integrative coping strategies refer to the different strategies used by the participants to handle the integrative environment found in residence life. These integrative coping strategies may or may not include the setting of boundaries. Instead the strategies, found in the data, allowed the participants to cope with the all-surrounding integrative environment. From participants' reports about their work satisfaction, I found 
that the more integrative coping strategies they practiced, the less frustration they felt and the longer they could endure in the integrative environment.

This chapter presents a general discussion of my findings organized around my research questions followed by the model of the integrative environment that was generated from the study's findings. Finally, I conclude with implications for leadership and practice together with recommendations for future research.

\section{Discussion}

In this section I discuss how my data answer my research questions and I will attempt to address the specific bodies of literature that relate most directly to my results.

\section{In What Ways Do Residence Life Professionals, Who Live Onsite, Manage Their}

\section{Work/Life Boundaries?}

According to the seminal work of Nippert-Eng:

Boundary work takes two forms: boundary placement work and boundary transcendence (or transition) work. Both are essential for placing and maintaining boundaries. Placement work more visibly draws the line between realms [domains] and selves [roles], while transition work helps us accommodate that line, by allowing us to mentally jump back and forth over it. (1996b, pp. 564569)

Resident life professionals in this study focused very little on the placement of boundaries, most likely because they understood they have to move quickly between being off- and on-duty due to the pervasive nature of work, including the knock-on-thedoor or the lurking student with a question. Therefore, when the participant was in the mindset of home and any moment a student or a member of the staff could knock and then the participant would have to be in work mode, even if they didn't answer the door they would know that the knock was work and thus would transition into that mindset. 
Even Harry, an integrative segmentor who does set boundaries, reported still having to think about work a majority of his time due to the integrative environment he lived in.

Ashforth, Kreiner, and Fugate (2000) assert, "The act of creating and maintaining boundaries... complicates the act of crossing from one domain into another" (p. 474). The integrative nature of my participants reflects an adaptation to the integrative environment that exists all around them. Sam, who is an integrative segmentor with stronger boundaries then most of the other participants, still does not feel she can be herself outside her door. Sam discussed how, even when she was going out with friends at night, she worried about how she dressed because she did not want a student to see her and judge her as unprofessional. Sam thus exhibited what all the participants' reported feeling: When you are in the building, you are working. I assert that participants have little choice when creating boundaries but to make them weak and easy to transcend in order to cope with the integrative environment they live in.

Integrative Coping Strategies. Participants reported using different integrative coping strategies (like laying low, leaving campus to feel off work, enforcing boundaries against late night interruptions, setting clear boundaries with staff and students, turning off work cell phone when off duty, scheduling personal time, and keeping the home space private) as the primary way they created work/life balance. The use of these strategies sometimes created boundaries but they also often served as little more than temporary and, often, ad hoc coping mechanism. The most used strategy in this study was leaving campus to escape to third places.

Ashforth (2001) also divides the domains a person occupies into three categories: work, home, and third places such as church, the health club, or a neighborhood bar. He 
built on the work of Oldenburg and Brissett (1982) that saw third places as important areas for informal socialization. Ashforth et al. further posited that these third places could also help people manage boundaries and serve as an addition way to balance work and life (2000). Participants in this study used third places (e.g., the gym, chain restaurants, bookstores, bowling, and the homes of friends and family in the area) to escape from the integrative environment. Escaping to third spaces, in fact, was the most used integrative coping strategy by all of the participants. The exception was Harold. Harold only left campus to run errands and not for escape. The practice of leaving campus in order to prevent burnout was recommended by Wiggers, Forney, and WallaceSchutzman as far back as 1982 . No participant in this study reported hearing or reading about that recommendation in training, however. Therefore, the participants had to discover the integrative coping strategy of escaping campus for themselves through experience.

Professional Boundaries. Plaut (2008) defines the management of boundaries in professional relationships as follows: "Healthy professional relationships require that certain boundaries be maintained, especially if there is a power differential between the parties" (p. 85). Contrary to the relatively boundary-less nature of most of my participants' work and home life, they did report establishing stronger boundaries around the relationships they had with students and staff. Megan described this idea best:

Generally speaking, with most of the students I have kind of the acquaintance sort relationship and there are few that I'm closer with like including like my staff members, but I guess I look at myself more in a mentoring role to them as in a friendship type role.

Although all of my participants reported not being trained in work/life boundary management, they did report receiving training in the boundaries they needed to set with 
students. Participants indicated that they understood the need to be professional around students. They also discussed a need for building relationships with students and staff.

The need to be professional and yet build relationships with students resulted in boundary blurring that is typical of an integrative person. Participants would often cross boundaries they had set with their students and staff in attempts to build relationships. This manifested in building friendships with the students and staff that may have included the professional sharing of personal information. For example, Steve and his wife would regularly invite students and staff into their apartment for a movie or dinner. They did this so the students would have a reminder of home and for relationship building. Mary confided that she would sometimes share personal information with staff members she was close to in order to again build a relationship with them.

Yet these boundary crossings were not boundary violations. Smith and Fitzpatrick (1995) characterize sexual misconduct and harassment as boundary violations but include nonsexual dual relationships in the category of boundary crossing which is less serious and may be necessary therapeutically. Smith and Fitzpatrick were discussing boundaries in relation to the psychological profession. Barnett (2008) added to their work expanding the idea of boundary crossing to mentorships and professional relationships:

Boundaries are the basic ground rules for the professional relationship. They add a structure to mentorships that provides guidance regarding appropriate actions and interactions for mentors and protégé... Boundaries in professional relationships include dimensions such as touch, location, self-disclosure, time, gifts, fees, and personal space. Boundaries may be rigidly enforced, crossed, or violated. (pp. 5-6)

The idea that boundaries can be crossed, which is not always a negative, or violated, which is always negative, is consistent with the work of Smith and Fitzpatrick 
(1995). In addition to the stories of Mary and Steve presented above, Dean also reported that he had closer friendships with those resident advisors he was mentoring. Trevor similar to Steve was concerned about his staff members beginning able to escape and feel at home. He allowed his staff to come and stay in his apartment with the understanding that they were forbidden to talk about work. Only the participants on the integrative segmentor end of the continuum (Harry, Sam, and Sally) maintained stronger boundaries that typically did not include friendships with staff or students.

\section{What Role Does Technology, and, More Specifically, Social Media, Play in}

\section{Boundary Management for These Resident Life Professionals?}

Eleven of the twelve participants reported using social media. All eleven reported having students and staff as friends on their personal Facebook account. Only Rue used a separate account for a work-related profile that was used to "friend" students and staff. Of the ten participants who had students and staff on their personal Facebook accounts, only one of those set any boundaries (i.e. privacy settings) between the students and staff they supervise and their personal family and friends. The most common strategy reported by this majority was to keep their profiles clean of material they deemed inappropriate. Golden and Giesler (2007) found that:

Technology introduces an additional dimension into the boundary management dialectic of integration-segmentation. That is, not only do individuals express, at different times, desires for both integration and segmentation of work and personal-life; they also express conflicting attitudes toward the technology itself and toward work (and its relationship to personal-life). (pp. 542-545)

From Golden and Giesler's perspective, technology brings an additional dimension into the equation for some of the participants that allowed them to increase boundaries by 
using technology to limit face-to-face interactions with students and keep the students and staff from visiting their apartments.

Both personal- and work-specific Facebook accounts were used to communicate about events and work hours to students. Facebook was also sometimes used to find out information about students before judicial meetings or resident life interviews.

Participants did not report using Facebook to look for students misbehaving. The decision to not try and find students negative pictures and postings, in essence, functioned as a boundary that kept the participants who employed the decision from finding additional work.

Facebook was not the only technology used at work, however. A more common technology used was mobile communication. Hill, Hawkins, and Miller (1996) discussed how the use of mobile technology in telecommuting allowed their participants to establish offices at home and to create different areas for work that did not follow traditional norms. All participants I interviewed reported having a cell phone they used for work, with only two who used the work cell phone as a personal phone, as well. Participants set boundaries using their phones by turning them off or leaving them in the apartment when they were off duty and did not want to engage in work. They also reported using cell phones, and, more specifically text messaging, to answer staff and student questions without having to see messaging students and staff members in person.

Steve, who is a full integrator, best exemplified this strategy. He met with his staff at the beginning of the year to establish boundaries. His boundaries established his preference for using text messaging for simple questions and phone calls only for more important matters. Accordingly, technology allowed him to present more boundaries 
than what were natural for him to employ. Participants at the other end of the continuum also reported using cell phones to help manage their workloads, as well. However, participants who were firmly on the integrative segmentor end went even further, limiting their cell phone use after-hours and, instead, relying on email as an "after-hours" communication.

Overall, the participants, who worked in an environment that forced integration of work and home life and were, to varying degrees, integrative with work/life boundaries, used technologies to both establish boundaries (e.g. around phone use) and integrate boundaries (e.g. around social media activity). Participants choosing to limit personal posts on a public social media network such as Facebook, as opposed to imposing boundaries that would keep their postings for people in their personal lives out of view of "friends" in their professional lives, illustrates the preference for the work domain over personal domain that was a general characteristic of the residence life professionals I studied who live where they work.

\section{If Resident Life Professionals are Creating Boundaries Around the Domains of} Work and Life, is it Due to a Desire to Achieve Some Type of Work/Life Balance or is There Another Rationale at Work?

All of my participants were asked about their work/life balance. They gave me estimates of how much time they spend on work and on personal life. The most common answer was $60 \%$ work and $40 \%$ personal time. (Actual reported percentages can be found under the participant profiles in chapter four.) The integrative nature of my participants lives, coupled with the integrative environment that inevitably is found in residence life, resulted in a weak focus on boundaries between work and life. The nature 
and quality of the boundaries created were flexible and permeable. The rationale behind my participants creation of boundaries can probably best be understood by focusing on role boundaries and, more specifically, by looking at the explanations for the existence of role boundaries provided by Ashforth (2001) and Clark (2000).

Role Identity. A role is an identity that a person has within a specific domain. Roles are typically associated with the domain in which they are created but can be carried over or spill over into other domains. In my study, some of the roles participants had where resident director, father, mother, friend, mentor, trainer, judicial officer, counselor, and boy/girlfriend just to name a few. The integration of boundaries in terms of roles helps to decrease the difficulty of role transition (Ashforth et al., 2000). Therefore when my participants walked the few steps from their office to their front door, having a greater integration of role boundaries allowed them to go from resident director to father very quickly and, when the knock on the door was heard, they could jump back into resident director mode quickly. Steve, a full integrator, was a good example of this role transition; he indicated that it required little effort to "change hats" from his role at work to his role with his family.

The boundaries that define roles have traditionally been discussed using the concepts of flexibility and permeability (Ashforth et al., 2000; Ashforth, 2001; Bulger, Matthews, \& Hoffman, 2007; Clark, 2000; Desrochers, Hilton, \& Larwood, 2005; Hall \& Richter, 1989; Kossek, Lautsch, \& Eaton, 2006; Pleck, 1977). A role that has flexibility is considered to have pliable space and time boundaries and can be enacted in various domains at various times (Ashforth et al., 2000; Ashforth, 2001; Hall \& Richter, 1989). An example of this was the story Sam told about finding a student climbing her building 
one night at 2am when she was opening the door for her fiancé. She had to quickly switch from fiancé to resident director.

While flexibility is about where and when a role can be enacted, permeability is considered to be the degree to which an individual can be physically located in a domainspecific role, but psychologically and/or behaviorally involved in another (Ashforth et al., 2000; Ashforth, 2001; Pleck, 1977). The most common example in this study was how participants would use text messaging and/or emails to handle work related questions while at home with their families. Steve illustrated this aspect well when talking about working when he was supposed to be off-duty on the weekend. He said, "That's sort of ongoing... sort of checking in with somebody... insignificant things are like a text message... [and an] easy text message back solves the problem." Participants valued role permeability because it allowed them to address problems quickly as they came up instead of being hit with a pile of issues on Monday when they arrived at work in a more official capacity.

Clark (2000) argued that work and home "constitute different domains or spheres which influence each other... [and] individuals can shape to some degree the nature of work and home domains, and the borders and bridges between them, in order to create a desired balance" (p. 751). She further articulated that borders with a great deal of permeability and flexibility, would have greater blending between the domains (Clark, 2000). If a border is blended it cannot be considered in either domain and creates a borderland. For my participants, the blurring of boundaries around work and home created a borderland around their apartment, but also, more often than not, the entire building they lived in as well as the outside spaces adjacent to that building. The 
participants that allowed students or staff in their apartments extended the borderland into their home, reducing the personal and private space to their bedrooms. Having such a large borderland is the direct result of living in the integrative environment. Based on the data, I theorize that having such a large borderland helped to enforce the identity of work over any other, more personal identity. This is also reflected in the data about how much easier it is to date people who also work in residence life or student affairs. Consequently, I assert that the identity of resident life professional become the primary role identity enacted for these participants.

\section{Clark's Work/Family Theory Propositions. Some of Clark's (2000)} propositions about work/life balance are useful here for explaining why boundaries and work/life balance are harder to maintain in the integrative environment. Proposition $1 \mathrm{~A}$ states, "When domains are similar, weak borders will facilitate work/family balance" (Clark, 2000, p. 746). Since participants lived where they work, the domain of home was in the same building as the domain of work. It appears as if physical co-location created similarities in the home and work domains that resulted in the creation of weak borders or boundaries between spaces. These weaker borders allowed my participants to create a balance in their lives that was satisfying to them, even if it was not a $50 / 50$ balance. Only Windy, the participant with the least amount of experience, reported a lack of satisfaction with her work/life balance. This finding is consistent with findings from other participants who reported a lack of satisfaction with their balance when they started their positions (and, presumably, when they had no experience even with establishing weak boundaries. 
Propositions two and six, described further below, also apply to my sample. Both explain why participants seemed to most strongly identify with their work role over all other roles. Those two propositions are:

Proposition 2: When the border is strong to protect one domain but is weak for the other domain. Individuals will have: a) greater work/family balance when they primarily identify with the strongly bordered domain; and b) lesser work/family balance when they primarily identify with the weakly bordered domain.

Proposition 6: Border-crossers whose domain members show high commitment to them will have higher work/family balance than border-crossers whose domain members have shown low commitment to them. (Clark, 2000, p. 746)

Both of these propositions speak to the need for the resident life professional to have people in their life that understand the job they are doing and thus the role they must most-strongly express. Again, participants' balance was not 50/50 and these propositions apply only if understood as meaning satisfaction with balance and not a 50/50 work/life balance.

All participants felt a stronger identification with work over home. They also created more boundaries to prevent home from overlapping into work then they did for work overlapping into the home domain. In accordance with proposition $2 \mathrm{~A}$, this meant that the identification with work allowed the participants to maintain some type of balance, which was skewed toward work; $60 \%$ work $/ 40 \%$ personal life and was the most frequently reported balance. Also, in accordance with proposition 6, having partners or family members who agreed with work being the primary identity of the participant allowed the participants more flexibility to create a balance that worked in the integrative environment. 
How, if at all, does Boundary Management Contribute to Job Satisfaction for Resident Life Professionals and How Does Training, or Lack of Training, Impact Resident Life Professionals' Work/Life Boundary Management?

Satisfaction. To address the third research question, I asked my participants what were the biggest frustrations about living where they worked. In combination with other questions about work/life balance, a picture of how satisfied my participants were in their positions became clear in the data. Out of 12 participants only Windy expressed a lack of satisfaction with her position. Most participants appeared to be satisfied, although they expressed varying degrees of frustration and stress. The frustration and stress was less of a problem for those who adopted or developed multiple integrative coping strategies, something they did over time as they gained experience in their positions.

Windy was the participant with the least experience in residence life and was struggling a great deal to balance the new demands of her job with her personal life. Windy's frustrations were, however, typical of the first year experience echoed in other participants' stories. Steve, a full integrator, discussed how his first year made him feel as if his "head is going to explode." After that year of stress and frustration, he began to adapt integrative strategies such as scheduling personal time and getting away from campus when possible. Steve, who was in the middle of his second year when I interviewed him, was still struggling with feelings of being overwhelmed, but he indicated he was experiencing increased satisfaction with his position as he created more work/life balance.

Training. Through other participants' stories, I came to understand a process that occurs within the integrative environment that is reflected in my model. Part of this 
process involved learned responses to the constant boundary stressors; learned responses took the form of integrative coping strategies. For example, Steve, who is a full integrator and who is in this second year in the position, had a terrible first year. He was overwhelmed with work and, having few boundaries, felt he was not going to survive. Steve learned from that first year and set more boundaries around work time in his second year. He also started to get off campus more often to relieve stress. He reported being less frustrated with his balance. Sam, an integrative segmentor with over 3 years of experience, also related a how she learned balance not through training but with experience, "So much of my ability to find balance in this job has come through making mistakes and then talking through them with people later." Steve and Sam both reflected a common theme that experience instead of training allowed them to develop integrative coping strategies that allowed them to have greater balance.

The training —or, to be more accurate, the lack of training—a participant had prior to accepting the position, as well as after taking the position, was asked about in a specific interview question that focused asked, "What, if anything, in your training or background, helped you to create those successes (or deal with problems) [in boundary setting or balance]?" I thought to add this question to my interview guide because of the work of Waple (2006).

Waple (2006) examined various studies in residence life and found that, while it is well known what competencies are needed to excel in residence life, newly hired professionals are seldom trained in those areas. His study of 160 new entry-level residence life professionals found that they needed much more training in the supervision of staff, a competency that most certainly related to boundaries. While the Waple study 
suggests that there is a need for more training for residence life professionals, in general, Waple's study also focused on skills typically taught in a masters program in student affairs. The list of skills that were taught did not include work/life balance or boundary management. This null curriculum (i.e. the curriculum that is not taught) reflects a lack of focus within masters level training for student affairs and residence life professionals on work/life balance issues, despite evidence that burnout and a lack of interest in the profession from graduate students are related to lack of work/life balance inherent in the positions they hold (Barham \& Winston, 2006; Belch \& Mueller, 2003; Wiggers, Forney, \& Wallace-Schutzman, 1982).

No participant reported being trained on boundary management strategies or work/life balance. Only two of my participants reported having any training on boundaries at all. Megan remembered the only training she had on balance was nine years earlier and it was a brief session that offered no "tips or tricks to try." Harry reported only learning that he should do what he feels comfortable with when it comes to boundaries and balance. Neither participant reported learning any specific skills or techniques from formal training; instead, as Megan further explained most of the tips and tricks she learned were from conferences.

Nick, who was on the full integration side of the continuum and thus set fewer boundaries around work and home, learned boundary management from mentors at a previous school. He told me, "l've had phenomenal mentors in my past. I've had folks that didn't just say to create balance but [they also] have role modeled it. They have shown me in every way and showed that they authentically supported my ability to balance myself." 
Nick's involvement with mentors was unique. As was discussed in Chapter Four, most other participants reported that their supervisors were not good at balance and mentored them by saying, "Do as I say and not as I do." Consequently, the primary way participants learned integrative coping strategies was from experience, and, occasionally, picking up "tips and tricks" at conferences. Nick's experience confirms what Belch, Wilson, and Dunkel (2009) found in their study of senior-level housing professionals. They found that "throughout the levels of the organizations, mid- and senior-level professionals spoke of significant autonomy and responsibility given to entry-level staff. They were empowered to act in their positions and to design a plan to create the experience they want" (p. 185).

The struggles that many of my participants recounted with establishing boundaries early in their careers suggest that the autonomy given to the entry-level professionals may not, necessarily, be positive, a conclusion also reached by Herr and Strange (1985). They found, in their study of 102 residence hall directors, that in their female participants, in particular, autonomy was a significant predictive factor of both emotional exhaustion and depersonalization. In this study, participants, both male and female, shared stories indicating how difficult their first year had been because they had not yet learned to establish at least reasonable facsimiles to boundaries in what is often a relatively boundary-less world that they inhabit (and, or course, work in).

A high level of autonomy and a lack of training in work/life balance meant that many participants had to learn the skills of work/life balance and boundary setting during their first year. Learning these skills while learning a new job produced a steep learning curve. Rue exhibited frustration when she discussed how she received little training her 
first year and ended up working 60-hour workweeks. She felt that, if she didn't make work the priority, she would fail. It was only after she found that her relationships with friends and family were "falling by the wayside" at the end of her first year, that she was able to start setting boundaries. Rue's eventual realization that she had to make time for her friends led her to set boundaries around work and created an interest for her in work/life balance that made her the integrative segmentor that she is now.

Ultimately, all of my participants learned the bulk of their integrative coping strategies from experience over time. The stress and frustration they felt while learning could explain the high rates of burnout and turnover found in several studies examining residence life (Anderson, Guido-DiBrito, \& Morrell, 2000; Barham \& Winston, 2006; Belch et al., 2009; Collins \& Hirt, 2006; Herr \& Strange, 1985; Renn \& Jessup-Anger, 2008; Wiggers, Forney, \& Wallace-Schutzman, 1982). Perhaps the lack of training and autonomy afforded to resident life professionals surrounding work/life boundaries and integrative coping strategies sets up an initial expectation of stress that is currently only mitigated through time and experience. It is possible that a lower rate of burnout and turnover could be achieved through targeted training in the necessary integrative coping strategies early in this process.

\section{A Model of the Integrative Environment}

Integrators as defined by Ashforth (2000) and Nippert-Eng (1996a) are workers who set weaker boundaries between work and home. Integrators often let work life flow into personal time and personal life flow into work time. For example, integrators would take time during work to talk to family or, perhaps, even to take their child to work. At home, the integrator might work on job-related projects, answer work emails or take 
professional phone calls. All of my participants reported behaviors that would classify them as integrators by the definition employed in the literature. The nature of and the location of the work in residence life, however, also made the environment more integrative, as well.

When a person lives where they work professional life literally surrounds the home domain. The simple act of going through the front door brings work front and center, whether or not a person is supposed to be working. If a residence life professional's child or pet runs into the hallway they, too, have crossed a threshold into the workspace. Also an important part of work in residence life involves supervising people who also live in the same community both staff and students. Therefore aspects of the work environment can actually come and knock on the door at any time of the day and/or walk by the window and look into the professionals home domain should the curtains be open. This breakdown of the personal/professional dichotomy is a fundamental aspect of the integrative environment defined in chapter four.

In this grounded theory investigation of boundary management for resident life professionals, I discovered that one consequence of living in an integrative environment is experiencing a constant flow of boundary stressors that push against any home boundaries and, in the process, shrink or destroy them. The "work" of creating and maintaining boundaries that Nippert-Eng (1996a) described in her seminal work becomes that much harder to do. As classic integrators, the participants in this study didn't always turn to boundaries as a means to cope with the boundary stressors. While boundaries, or a reasonable facsimile, were created by the participants, other strategies that better suited their integrative nature were also used. I found that participants created integrative 
coping strategies (e.g. "laying low," leaving campus to feel off work, enforcing boundaries against late night interruptions, setting clear boundaries with staff and students, turning off work cell phone when off duty, scheduling personal time, and keeping home space private) to reclaim a modicum of private space, to escape from the environment and recharge, or to create flexible and permeable boundaries that pushed back against the boundary stressors (e.g. like the late night knock on the door, catching students violating rules, supervisors' late night emails, on-duty schedules, student and staff events, the off-duty need to help with critical events in the building that the resident advisor oversees (and lives in), student or staff questions when the person is technically off work, and need for relationship building with staff and students).

Since the participants reported little or no training in work/life boundary management or how to create some semblance of balance in their lives, integrative coping strategies were learned through experience. Analysis of the data showed the longer the participant stayed in a live-in/on position the more integrative coping strategies they would have at their disposal and also that they were more likely to be labeled integrative segmentors. In other words, the data for this study, at least, suggest that there is a relationship between the amount of integrative coping strategies and the level to which a participant creates boundaries within the integrative environment even though the integrative strategies do not necessarily create boundaries.

The only outlier not to commonly use integrative strategies was Harold, a full integrator who has worked in residence life for 36 years living in. Harold uses very few integrative strategies. His long-term endurance and thus long-term employment seemed 
to be a matter related to simply enjoying the integrative environment and, thus, not needing many integrative coping strategies.

A visual representation of the process of boundary stressors pushing in on the home boundary and integrative strategies pushing back is found in my Model of the Integrative Environment presented in Figure 1. In this figure, the domain of home is located within the domain of work. Both exist within the integrative environment of residence life. Boundary stressors are constantly pressing in on the home domain boundary and integrative coping strategies are pushing out against the boundary stressors.

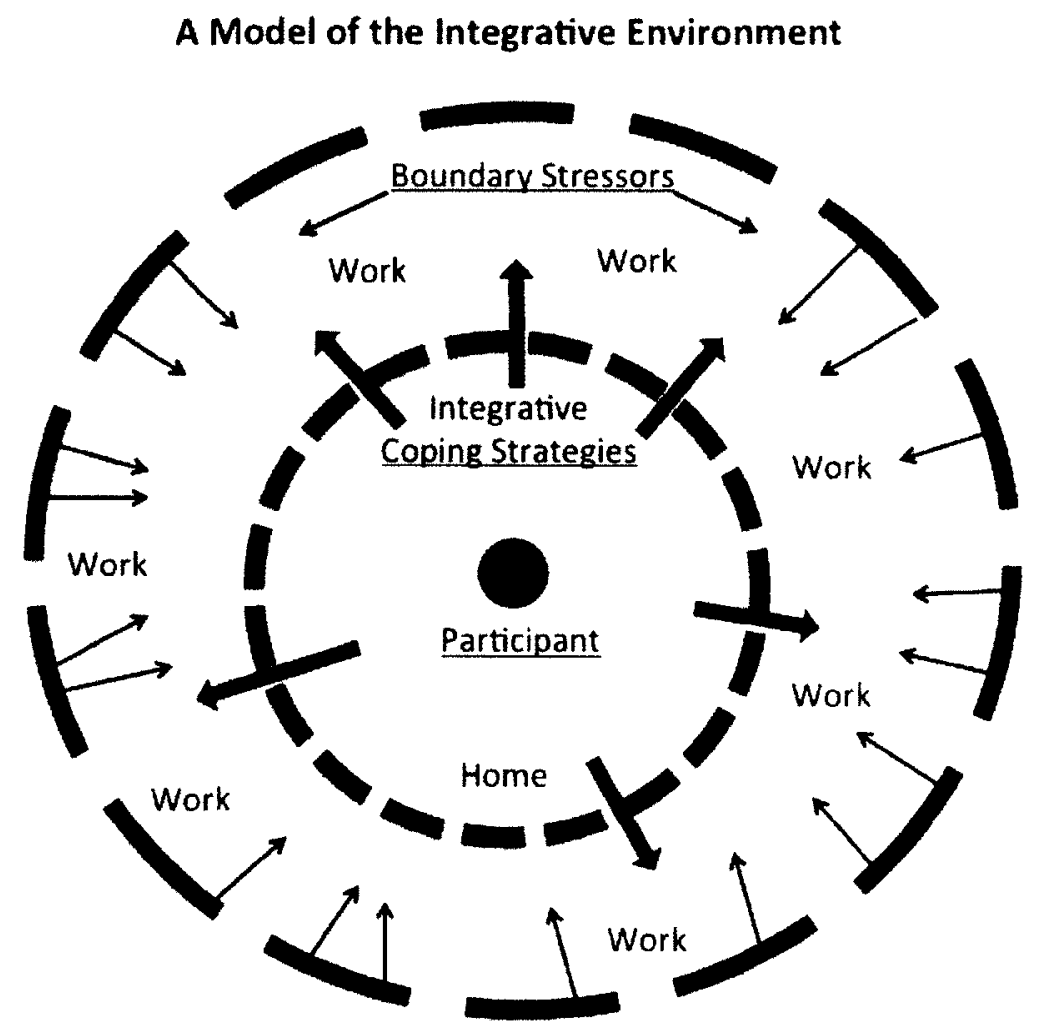

Figure 1. A model of the integrative environment in residence life. 
Both the home boundary and the work boundary have certain areas that are flexible and permeable but other areas are less so. The illustration of the model is static but the actual boundaries represented change over time and during different work seasons.

With the exception of the outlier, Harold, participants learned integrative coping strategies over time and the more they applied them the stronger the boundaries between work and life became. As participants' boundaries became stronger, participants moved toward the integrative segmentor end of the continuum and expressed less frustration and more satisfaction with their position, ultimately staying in their position longer.

Thus, I posit that while it may be impossible to become a work/life segmentor within the integrative environment of residence life, the more segmentation a person can create and, thus, the more of an integrative segmentor a resident hall professional becomes, the longer the professional can stay in a resident hall position with the limited frustration and burnout.

\section{Implications for Leadership and Practice}

This study demonstrated that while work satisfaction may not wholly be based on how many integrative coping strategies a participant used, implementing more strategies meant most participants could stay in their positions without succumbing to frustration generated by a work environment that is ever present and that constantly stresses the boundaries between work and home life. Therefore, resident life professionals need to know which integrative coping strategies they are currently using and what other strategies they could add to their repertoires to help them increase their ability to resist their environment's inevitable push toward integration and minimize boundary stressors 
by resisting and managing the push within the environments in which they simultaneously live and work.

Increasing the length of time in a spent in these entry-level positions, could allow professionals greater options when choosing their next career move rather than impulsively jumping to an available position due to the stress and frustration with their current position. Tull (2006) found attrition within the first five years for new student affairs professionals to be 50 to 60 percent. Tull's findings mirrored the findings of Belch and Mueller (2003) that also discovered, in a survey of 250 residence life supervisors that there were few qualified candidates applying for entry-level resident life live-in positions and many supervisors reported having to open residential facilities with at least one resident director vacancy. Therefore, I posit that trainings, which specifically help new candidates to learn more integrative coping strategies, might address attrition in the field and help solve the hiring problems reported by supervisors.

Any training sessions developed to teach new candidates in residence life about boundaries and work/life balance should also address the boundary stressors inherent in their positions and the costs of integrating work and personal time in terms of stress, frustration, and lack of personal space should be highlighted. A stronger focus on work/life balance from the perspective of living in a highly integrative environment during preparation programs and professional development that occurs after hire would allow a resident life professional to understand the relationship between the boundary stressors they experience and how integrative coping strategies could relieve stress and allow them to create a home environment that gives them time to recharge. 
In light of the previously cited research showing high burnout and turnover rates within the live-in populations of new professionals, residence life leadership professionals need to be concerned about the integrative environment and how to better help their employees be successful in it. Two questions that arise from the data and that must be considered when considering boundary training are: would resident life professionals create stronger personal boundaries if they were trained in integrative coping strategies and educated about the integrative environment, or are the type of people attracted to jobs in residence life mostly integrative people who would not create boundaries even if taught to?

Understanding which came first, the integrative environment or integrative employees, has many implications for the leadership in residence life. In answer to the first question posited above, data from this study supports that integrative coping strategies do support boundary setting. Participants learned integrative strategies as they gained more experience in their position. They also were more likely to be integrative segmentors on the integrative continuum the longer they stayed in residence life. Integrative segmentors set firmer boundaries than full integrators. Therefore, training professionals on integrative coping strategies when they start their position might accelerate the process of boundary setting and limit the first year stress and frustration commonly reported.

With regard to the second question, if the resident life professional live-in lifestyle does in fact attract integrative people, as the data seems to show, leadership professionals need to change the current permissive and self-directed culture and, instead, provide more direction about boundary setting and work/life balance. As discussed 
previously, the autonomy provided to entry-level professionals may not be the best environment for natural integrators to develop boundaries and fight the boundary stressors inherit in the integrative environment in residence life.

There is also another question raised but not answered in this study: Are resident life professionals on the full integrator end of the continuum who, by definition, are inclined to blur boundaries between work and personal life, creating problematic situations when they allow students into their apartments? None of my participants reported that opening up one's living space to students was against policy, and only one participant reported that it even was frowned upon by supervisors. However, allowing students and staff into a professional's home on a regular basis is fraught with concerns about harassment claims, favoritism, bias, and liability. In addition to legal concerns, there is also the argument that a resident life professional should not have to sanitize his or her home to make what is, in essence, the professional's private space acceptable for students to visit. Even if the professionals, themselves, are happy to do invite students into their professional space, should resident life leaders and supervisors establish policies to protect extreme integrators from themselves?

In short, I am questioning whether new standards need to be implemented by the leadership in residence life to change expectations and prevent behaviors on the part of their staff that not only enforce the integrative environment but lead to an atmosphere of personal sacrifice that is passed down from the leadership to the professional staff and on down to the paraprofessional staff whom will some day apply for professional positions. Perhaps the integrative environment is a result of a culture that just keeps doing what was done before because the participant pool for each level is typically drawn from the pool at 
the level below. In effect, students become resident advisors while in undergraduate programs; if they like the field they go on to become resident directors who ultimately hope to become residence life supervisors. Effecting real change within the field would require leadership making top down changes to the existing integrative culture.

Belch, Wilson, and Dunkel's (2009) findings relating to the autonomy resident life supervisors give to these entry level professionals also addresses the above point that in order to change this integrative culture perhaps a less autonomy would create boundary structure in this position and thus further protect the resident life professionals who are entry level from burnout and attrition.

To summarize, residence life supervisors, who may, themselves, be natural and/or well-socialized integrators, may need to move from recommending that their employees not follow their example, to a place where they require, to the extent possible, the professionals they oversee to achieve balance. While this sort of policy-oriented activism represents what is, undoubtedly, a major change for those who work in resident life, the change may be necessary to address the problems of burnout and attrition that the literature has repeatedly documented.

\section{Recommendations for Future Research}

The findings in this study allowed me to create the Integrative Continutu for Resident Life Professionals, as well as A Model of the Integrative Environment. Both the instrument and the model could use further testing within the residence life professional population, among paraprofessionals in residence life, and, possibly, with live-on residence life leaders. The continuum, in particular, requires additional factor analysis work to transform it from something that was developed inductively and qualitatively 
into an instrument with documented psychometric properties that can be used in future quantitative studies to explore empirically at least some of the issues that were highlighted in the previous section and other issues as well. The factor analysis would require a follow-up quantitative study with hundreds of participants to produce anything meaningful. Still I believe as a purely qualitative tool it could allow for a more detailed discussion of the highly integrative population in residence life.

Adding more boundary stressors, and seeking to better refine the ones presented, could further refine the model of the integrative environment. In addition to boundary stressors, of particular interest would be the discovery and presentation of more integrative coping strategies to enhance the skill set of entry-level professionals through training either in masters programs or in new hire trainings. Ultimately, the model I presented is predicated on the idea that the integrative environment is inherent within residence life as it is currently practiced. Research could also focus on the possibility of changes the leadership in residential life departments could implement to limit this environment, and aid in the establishment of stronger boundaries around the living quarters of the live-in/on professionals.

This study also found that most resident life professionals learned boundary strategies from experience and/or mentorship rather than through training. Research could further investigate why training does not occur around boundary management and boundary setting strategies within residence life. A greater understanding of the leadership boundaries resident life supervisors have between their work and personal lives could add a needed dimension to the picture of work/life balance in residence life. Empirical studies could also determine whether this assumption is supported by data. 
Outside of residence life, my model could be adapted for studying other populations who live where they work. Nippert-Eng (1996a) reported that extreme integrators are rare in the populations she studied, but she did not focus her research on people who live where they work. Nannies, live-in servants, military personnel living on base, scientists conducting field research, live-on faculty, and university presidents just to name a few, are all populations that could add to the generalizability and complexity of the model that was developed from this study's data.

The grounded theory game, in fact, normally involves looking at the same phenomenon in different settings over a number of studies. The theory that emerges from a series of studies is more general but also describes differences across different contexts. Consequently additional work with other populations is necessary if we are to have a more general theory of boundary setting in situations where people work where they live and live where they work.

\section{Conclusion}

This dissertation examined twelve residence life professionals from different parts of the country and from different universities. They all presented a common story about an environment that surrounded them with boundary stressors. Participants responded to this stressful environment by developing coping strategies that matched their integrative styles of boundary management. These integrative coping strategies primarily resulted from experience, though sometimes it was learned from supervisors reverse mentorship (don't do what I do), and rarely was it through positive mentorship from a supervisor or peer who practiced good boundary management. Despite the participants having little or no training prior to their hiring and no subsequent training after hiring, they reported 
developing similar integrative strategies, which seems to point to the consistency in the resident life culture, even in different university types and regions.

The integrative environment in residence life seems to also point to an integrative culture within residence life that extends to the supervisors and perhaps to other areas in student affairs. Participants were given a large amount of autonomy in their positions, which led to a first year that was stressful and unbalanced. While the majority of my participants had worked in residence life as a paraprofessional, four of my participants did not have any prior training in residence life. The high rate of burnout presented in the literature shows the effects of this 'learn boundary management on the job' mentality present in the integrative culture of residence life. The data presented in this study points to the need for more structure from supervisors and additional training to fight burnout. While this is not a new recommendation, what is new, is this study's demonstration of the importance of work/life boundaries and work/life balance training as a way to combat frustration and stress within the live-in or live-on environment.

The research presented here on boundary stressors could help the leadership in residence life to understand the areas in the daily life of a residence life professionals that could use additional structure to reduce the stress and increase boundaries which would ultimately enhance work/life balance. While developmentally this integrative position may attract people who see their professional identity as their personal identity, the creation of more boundary structure around the professional role of residence life professional by the leadership in residence life will reduce the boundary stressors and therefore give the professional time to develop personally and ultimately professionally. 
One of the last questions on my interview guide asked about advice the interviewee would give to someone else beginning a career in resident life. This advice reflects what the participants learned from experience and could help struggling first-year professionals. I would like to conclude this chapter with that advice (see Table 8). 
Table 8

Participant Advice to New Resident Life Professionals

\begin{tabular}{|c|c|}
\hline Nick & $\begin{array}{l}\text { You have to find an institution that fits you well and if you don't find an institution that } \\
\text { matches what you are trying to do and where you want to go, you are going to be } \\
\text { unhappy and you are going to burnout quickly. }\end{array}$ \\
\hline Megan & $\begin{array}{l}\text { Well, I would say, one don't be afraid to put a note on your doors that says, you know, } \\
\text { I'm off right now, even if it might mean actually be in the building or around and don't } \\
\text { be afraid to say, no... If you have to even schedule time for yourself to be able to do that } \\
\text { and it could be anything that's on or off campus, but that's really important. }\end{array}$ \\
\hline Harry & $\begin{array}{l}\text { It really is easy to lose yourself in this. When you live where you work, you work } \\
\text { where you live, and you live with who you work with, it really is easy to lose yourself } \\
\text { and it's important to be self-aware enough to know when you are getting burnt out and } \\
\text { to know when you need to get away. }\end{array}$ \\
\hline Mary & $\begin{array}{l}\text { Be very adamant about the personal time that you have because, for me, my weekends } \\
\text { are mine. Unless I really have to work, they're my two days off. I will not do anything } \\
\text { work-related all those weekends. I will stay holed up in my apartment and not come } \\
\text { out, I'm still on campus. And so, I'm very adamant about it. And so, if there is a } \\
\text { weekend event called on, my first question is do I have to be there. If I don't have to be } \\
\text { there, I will not be there. }\end{array}$ \\
\hline Sally & $\begin{array}{l}\text { I would say, before they accept anything, is to ask questions about kind of the location } \\
\text { of where their apaitment might be on campus because there's a difference between live- } \\
\text { in or live-on, I mean, in my opinion. And I think that outside entrance is huge, that to } \\
\text { have that is a big part of not having to lock your residence hall or not having to walk } \\
\text { through an apartment building. You kind of have your own entrance and it's private. }\end{array}$ \\
\hline Sam & $\begin{array}{l}\text { I would say have a support system outside of work. It has always been a part of who I } \\
\text { am, to have many different pockets of people in my life, I have my family and then I } \\
\text { have a couple different groups of friends. Some that I like to just more casually go hang } \\
\text { out with and talk to, some that } 1 \text { like to do more activity based things with, but having } \\
\text { some other outlet besides your colleagues and your work environment is so important. }\end{array}$ \\
\hline Steve & $\begin{array}{l}\text { So finding someone who is advocating on your behalf because unfortunately, no matter } \\
\text { how structured and hard you work at managing your own life, if your supervisor doesn't } \\
\text { protect that boundary or respect it... Like, if you get an e-mail on a Saturday from your } \\
\text { boss, you're going to do it. }\end{array}$ \\
\hline Trevor & $\begin{array}{l}\text { One thing that I learned in my counseling master's was to create some cither rituals and } \\
\text { physical separation, often called "inter-processes," that would really separate you from } \\
\text { work time to your personal time. I think those are really the pretty much critical things } \\
\text { that you can do as a professional, to set up this kind separation... I think it's essential } \\
\text { that you come up with at least two out of a three to do that. Then I think you're in a } \\
\text { better place. }\end{array}$ \\
\hline Windy & $\begin{array}{l}\text { I guess I could say is to not let...it's like work take over your life because it's really easy } \\
\text { to let that happen and like I just see that happening all the time... I think just having } \\
\text { time to do your own thing that doesn't involve students is important }\end{array}$ \\
\hline
\end{tabular}




\section{REFERENCES}

American time use survey summary. (2011). Department of Labor. Retrieved from http://www.bls.gov/news.release/atus.nr0.htm

Anderson, J. E., Guido-DiBrito, F., \& Morrell, J. S. (2000). Factors that influence satisfaction for student affairs administrators. New Directions for Institutional Research, (105), 99. doi:10.1002/ir.10509

Ashforth, B.E. (2001). Role transitions in organizational life: An identity-based perspective. Mahwah, NJ: Lawrence Erlbaum Associates, Inc.

Ashforth, B. E., Kreiner, G. E., \& Fugate, M. (2000). All in a day's work: Boundaries and micro role transitions. The Academy of Management Review, 25(3), 472-491. Retrieved from http://www.jstor.org/stable/259305

Barham, J. D., \& Winston, R. B. (2006). Supervision of new professionals in student affairs: Assessing and addressing needs. College Student Affairs Journal, 26, 6489.

Barnett, J. E. (2008). Mentoring, Boundaries, and Multiple Relationships: Opportunities and Challenges. Mentoring \& Tutoring: Partnership in Learning, 16(1), 3-16. doi: $10.1080 / 13611260701800900$

Bazalgette, J. (2009). Leadership: The impact of the full human being in role. Adaptation and Innovation: Theory, Design and Role-Taking in Group Relations, Conferences and Their Applications (pp. 31-50). London: Karnac Books.

Belch, H. A., \& Mueller, J. A. (2003). Candidate pools or puddles: challenges and trends in the recruitment and hiring of resident directors. Journal of College Student Development, 44, 29-46. doi:10.1353/csd.2003.0001

Belch, H. A., Wilson, M. E., \& Dunkel, N. (2009). Cultures of success: recruiting and retaining new live-in residence life professionals. College Student Affairs Journal, 27(2), 176-193.

Benshoff, J. M. (1993). Students helping students: A collaboration between counselor education and residence life. College Student Affairs Journal, 13(1), 65-70.

Blimling, G. (2003). The resident assistant: applications and strategies for working with college students in residence halls. Dubuque, IA: Kendall/Hunt Pub. Co.

Bourdieu, P. (2005). The logic of practice. Cambridge: Polity Press. 
Bulger, C. A., Matthews, R. A., \& Hoffman, M. E. (2007). Work and personal life boundary management: Boundary strength, work/personal life balance, and the segmentation-integration continuum. Journal of Occupational Health Psychology, 12(4), 365-375. doi:10.1037/1076-8998.12.4.365

Bhabha, H. K. (1988). The commitment to theory. New Formations, 5(1), 5-23.

Bhabha, H. K. (1994). The location of culture. New York: Routledge.

Charmaz, K. (2006). Constructing grounded theory: A practical guide through qualitative analysis. London: Sage Publications Ltd.

Clark, S. (2000). Work/family border theory: A new theory of work/family balance. Human Relations, 53(6), 747-770. doi:10.1177/0018726700536001

Cohen, R. L. (2008). Work relations and the multiple dimensions of the work-life boundary: Hairstyling at home. In C. Warhurst, D. R. Eikhof, \& A. K. Haunschild (Eds.), Work less, live more? (pp. 115-135). Basingstoke, NY: Palgrave Macmillan.

Collins, D., \& Hirt, J. B. (2006). The nature of professional life for residence hall administrators. Journal of College \& University Student Housing, 34(1), 14-24.

Carpenter, S., \& Stimpson, M. T. (2007). Professionalism, scholarly practice, and professional development in student affairs. Journal of Student Affairs Research and Practice, 44(2), 265-284.

Creswell, J. (2009). Research design: qualitative, quantitative, and mixed methods approaches (3rd ed.). Thousand Oaks, CA: Sage Publications, Inc.

Creswell, J. W. (2007). Qualitative inquiry \& research design: Choosing among five approaches (2nd ed.). Thousand Oaks, CA: Sage Publications, Inc.

de Man, R., de Bruijn, J., \& Groeneveid, S. (2008). What makes the home boundary porous? The influence of work characteristics on the permeability of the home domain. In C. Warhurst, D. R. Eikhof, \& A. K. Haunschild (Eds.), Work less, live more? (pp. 92-114). Basingstoke, NY: Palgrave Macmillan.

Desrochers, S., Hilton, J. M., Larwood, L. (2005). Preliminary validation of the workfamily integration-blurring scale. Journal of Family Issues, 26(4), 442-466. doi: $10.1177 / 0192513 \times 04272438$

Draucker, C. B., Martsolf, D. S., Ross, R., \& Rusk, T. B. (2007). Theoretical sampling and category development in grounded theory. Qualitative Health Research, 17(8), 1137-1148. doi:10.1177/1049732307308450 
Duxbury, L., \& Smart, R. (2011). The "myth of separate worlds": An exploration of how mobile technology has redefined work-life balance. Creating balance? International perspectives on the work-life integration of professionals (pp. 269285). Berlin: Springer.

Eikhof, D. R., Warhurst, C., \& Haunschild, A. K. (2007). Introduction: What work? What life? What balance? Critical reflections on the work-life balance debate. Employee Relations, 29(4), 325-333.

Fangel, A. B., \& Aalokke, S. (2008). Getting the job done: The impact of employees' conception of work on work-life balance. In C. Warhurst, D. R. Eikhof, \& A. K. Haunschild (Eds.), Work less, live more? (pp. 136-152). Basingstoke, NY: Palgrave Macmillan.

Frederiksen, C. F. (1993). A brief history of collegiate housing. In R.B. Winston \& S. Anchors (Eds.), Student housing and residential life (1st ed., pp. 167-183). San Francisco: Jossey-Bass.

Gajendran, R. S., \& Harrison, D. A. (2007). The good, the bad, and the unknown about telecommuting: Meta-analysis of psychological mediators and individual consequences. Journal of Applied Psychology, 92(6), 1524.

Glaser, B. G. (1978). Theoretical sensitivity: Advances in the methodology of grounded theory. Mill Valley, CA: Sociology Press.

Glaser, B. G., \& Strauss, A. L. (1967). The discovery of grounded theory. London: Weidenfeld \& Nicolson.

Glavin, P., Schieman, S., \& Reid, S. (2011). Boundary-Spanning Work Demands and Their Consequences for Guilt and Psychological Distress. Journal of Health and Social Behavior, 52(1), 43-57. doi:10.1177/0022146510395023

Golden, A. G., \& Geisler, C. (2007). Work-life boundary management and the personal digital assistant. Human Relations, 60(3), 519-551. doi:10.1177/0018726707076698

Greenhaus, J. H., \& Beutell, N. J. (1985). Sources of conflict between work and family roles. Academy of Management Review, 10(1), 76-88.

doi:10.5465/AMR.1985.4277352

Greenhaus, J. H., \& Powell, G. N. (2006). When work and family are allies: A theory of work-family enrichment. Academy of Management Review, 31(1), 72-92. doi:10.5465/AMR.2006.19379625

Guba, E. G., \& Lincoln, Y. S. (1994). Competing paradigms in qualitative research. Handbook Of Qualitative Research, 2, 163-194. 
Hall, D. T., \& Richter, J. (1989). Balancing work life and home life: what can organizations do to help? The Academy of Management Executive (1987-1989), 213-223.

Henninger, A., \& Papouschek, U. (2008). Occupation matters- blurring work-life boundaries in mobile care and media industry. In C. Warhurst, D. R. Eikhof, \& A. K. Haunschild (Eds.), Work less, live more? (pp. 153-172). Basingstoke, NY: Palgrave Macmillan.

Herr, S. K., \& Strange, C. (1985). The Relationship between burnout and the work environments of residence hall directors. Journal of College and University Student Housing, 15(2), 12-16.

Higgins, C., Duxbury, L., \& Lee, C. (1994). Impact of life-cycle stage and gender on the ability to balance work and family responsibilities. Family Relations, 43(2), 144150 .

Hill, E. J., Hawkins, A. J., \& Miller, B. C. (1996). Work and family in the virtual office: perceived influences of mobile telework. Family Relations, 45(3), 293-301. Retrieved from http://www.jstor.org/stable/585501

Hirschhorn, L., \& Gilmore, T. (1992). The new boundaries of the "boundaryless" company. Harvard Business Review, 70(3), 104-115. Retrieved from http://www.ncbi.nlm.nih.gov/pubmed/10117998

Hochschild, A. R. (1997a). The time bind: when work becomes home and home becomes work (1st ed.). New York: Metropolitan Books.

Hochschild, A. R. (1997b). When work becomes home and home becomes work. California Management Review, 39(4), 79-97.

Hochschild, A. R. (2008). On the edge of the time bind: time and market culture. In C. Warhurst, D. R. Eikhof, \& A. K. Haunschild (Eds.), Work less, live more? (pp. 80-91). Basingstoke, NY: Palgrave Macmillan.

Holton, J. A. (2010). The coding process and its challenges. Grounded Theory Review, $9(1), 21-40$.

Katz, D., \& Kahn, R. L. (1978). The social psychology of organizations. New York: Wiley.

Kegan, R. (1982). The evolving self: Problem and process in human development. Cambridge, MA: Harvard University Press. 
Kegan, R. (1994). In over our heads: The mental demands of modern life. Cambridge, MA: Harvard University Press.

Komives, S. R. (1991). The relationship of same- and cross-gender work pairs to staff performance and supervisor leadership in residence hall units. Sex Roles, 24(5-6), 355-363. doi: $10.1007 / \mathrm{BF} 00288308$

Komives, S. R., Longerbeam, S. D., Owen, J. E., Mainella, F. C., \& Osteen, L. (2006). A Leadership Identity Development Model: Applications from a Grounded Theory. Journal of College Student Development, 47, 401-418.

doi: $10.1353 /$ csd.2006.0048

Kossek, E. E., Lautsch, B. A., \& Eaton, S. C. (2006). Telecommuting, control, and boundary management: Correlates of policy use and practice, job control, and work-family effectiveness. Journal of Vocational Behavior, 68(2), 347-367.

Kretovics, M. A., \& Nobles, J. (2005). Entry-level hiring practices used in college and university housing: competencies recruited versus competencies hired. Journal of College \& University Student Housing, 33(2), 44-50.

Kylin, C., \& Karlsson, J. C. (2008). Re-establishing boundaries in home-based telework. In C. Warhurst, D. R. Eikhof, \& A. K. Haunschild (Eds.), Work less, live more? (pp. 173 190). Basingstoke, NY: Palgrave Macmillan.

Leifer, R., \& Delbecq, A. (1978). Organizational/environmental interchange: A model of boundary spanning activity. Academy of Management Review, 3(1), 40-50.

Lewis, P., Forsythe, G. B., Sweeney, P., Bartone, P. T., \& Bullis, C. (2005). Identity Development During the College Years: Findings from the West Point Longitudinal Study. Journal of College Student Development, 46, 357-373. doi: 10.1353/csd.2005.0037

Lorden Lisa P. (1998). Attrition in the Student Affairs Profession. NASPA Journal, 35(3), 207-16.

Love, P. G. (1995). Interpretive Frameworks: A Qualitative Analysis of Individual SenseMaking in a Department of Residence Life. Journal of College Student Development, 36(3), 236-43.

Love, P. G., \& Guthrie, V. L. (1999). Kegan's Orders of Consciousness. New Directions for Student Services, 1999, 65-76. doi:10.1002/ss.8806

Macdonald, C. L. (1996). Shadow mothers: Nannies, au pairs, and invisible work. In C. L. Macdonald \& C. Sirianni (Eds.), Working in the service society (pp. 244-263). Philadelphia: Temple University Press. 
Macdonald, C. L. (1998). Manufacturing motherhood: the shadow work of nannies and au pairs. Qualitative Sociology, 21(1), 25-53. doi:10.1023/A:1022119309086

MacInnes, B. (2008). Work-life balance: three terms in search of a definition. In C. Warhurst, D. R. Eikhof, \& A. K. Haunschild (Eds.), Work less, live more? (pp. 44-61). Basingstoke, NY: Palgrave Macmillan.

Marks, S. R., \& MacDermid, S. M. (1996). Multiple roles and the self: A theory of role balance. Journal of Marriage and the Family, 417-432.

Matthews, R. A., \& Barnes-Farrell, J. L. (2010). Development and initial evaluation of an enhanced measure of boundary flexibility for the work and family domains. Journal of Occupational Health Psychology, 15(3), 330-346.

Moje, E. B., Ciechanowski, K. M. ., Kramer, K., Ellis, L., Carrillo, R., \& Collazo, T. (2004). Working toward third space in content area literacy: An examination of everyday funds of knowledge and discourse. Reading Research Quarterly, 39(1), $38-70$.

Myrie, J., \& Daly, K. (2009). The use of boundaries by self-employed, home-based workers to manage work and family: a qualitative study in Canada. Journal of Family and Economic Issues, 30(4), 386-398. doi:10.1007/s 10834-009-9166-7

Newsroom: Families \& Households: U.S. Census Bureau Reports Men and Women Wait Longer to Marry. (2010). U.S. Census Bureau. Retrieved from http://www.census.gov/newsroom/releases/archives/families_households/cb10174.html

Nippert-Eng, C. E. (1996a). Home and work negotiating boundaries through everyday life. Chicago: University of Chicago Press.

Nippert-Eng, C. E. (1996b). Calendars and keys: The classification of "home" and "work." Sociological Forum, 1l(3), 563-582. doi:10.1007/BF02408393

Oldenburg, R. (1989). The great good place: Cafes, coffee shops, community centers, beauty parlors, general stores, bars, hangouts, and how they get you through the day. New York: Paragon House.

Oldenburg, R., \& Brissett, D. (1982). The third place. Qualitative Sociology, 5(4), 265284. doi:10.1007/BF00986754

Orgera, J. (2007). The work experiences of student affairs professionals: What values guide practice? The University of Arizona.

Patton, M. Q. (2002). Qualitative research and evaluation methods. Thousand Oaks, CA: Sage Publications, Inc. 
Pilkington, E. (2007). Six in 10 US BlackBerry users check emails in bed, survey finds. The Guardian. Retrieved from http:/www.guardian.co.uk/technology/2007/jul/28/blackberry.

Piotrkowski, C. (1979). Work and the family system: a naturalistic study of working-class and lower-middle-class families. New York: Free Press.

Pipes, R. B., Holstein, J. E., \& Aguirre, M. G. (2005). Examining the personalprofessional distinction: Ethics codes and the difficulty of drawing a boundary. American Psychologist, 60(4), 325-334. doi:10.1037/0003-066X.60.4.325

Plaut, S. M. (2008). Sexual and nonsexual boundaries in professional relationships: Principles and teaching guidelines. Sexual and Relationship Therapy, 23(1), 8594.

Pleck, J. H. (1977). The work-family role system. Social Problems, 24(4), 417-427.

Pocock, B., Skinner, N., \& Williams, P. (2008). Work-life outcomes in Australia: concepts, outcomes, and policy. In C. Warhurst, D. R. Eikhof, \& A. K. Haunschild (Eds.), Work less, live more? (pp. 22-43). Basingstoke, NY: Palgrave Macmillan.

Rankin, P.R. (2011). [Residence Life Professional Boundary Survey]. Unpublished raw data.

Ransome, P. (2008). The boundary problem in work-life balance studies: Theorizing the total responsibility burden. In C. Warhurst, D. R. Eikhof, \& A. K. Haunschild (Eds.), Work less, live more? (pp. 62-79). Basingstoke, NY: Palgrave Macmillan.

Renn, K. A., \& Hodges, J. P. (2007). The First Year on the Job: Experiences of New Professionals in Student Affairs. NASPA Journal, 44(2), 367-391.

Renn, K. A., \& Jessup-Anger, E. R. (2008). Preparing new professionals: Lessons for graduate preparation programs from the national study of new professionals in student affairs. Journal of College Student Development, 49(4), 319-335.

Rosser, V. J. (2004). A national study on midlevel leaders in higher education: The unsung professionals in the academy. Higher Education, 48(3), 317-337.

Schneider, S. C. (1987). Managing boundaries in organizations. Political Psychology, $8(3), 379-393$. Retrieved from http://www.jstor.org/stable/3791041

Schuh, J. H., \& Shipton, W. C. (1985). The residence hall resource team: Collaboration in counseling activities. Journal of Counseling \& Development, 63(6), 380-381. 
Shumate, M., \& Fulk, J. (2004). Boundaries and role conflict when work and family are colocated: A communication network and symbolic interaction approach. Human Relations, 57(1), 55-74. doi:10.1177/0018726704042714

Smith, D., \& Fitzpatrick, M. (1995). Patient-therapist boundary issues: an integrative review of theory and research. Professional psychology, research and practice, $26(5), 499-506$.

St. Onge, S., Ellett, T., \& Nestor, E. (2008). Factors affecting recruitment and retention of entry-level housing and residential life staff: Perceptions of chief housing officers. The Journal of College and University Student Housing, 35(2), 10-23.

Stebbins, R. A. (1982). Serious leisure: A conceptual statement. The Pacific Sociological Review, 25(2), 251-272. Retrieved from http://www.jstor.org/stable/1388726

Steinkuehler, C. A., \& Williams, D. (2006). Where everybody knows your (screen) name: Online games as "third places." Journal of Computer Mediated Communication, $1 /(4), 885-909$.

Stolba, C. (2001). Women work \& family: achieving a balance. Arlington, VA: Independent Women's Forum.

Strauss, A., \& Corbin, J. M. (1990). Basics of qualitative research: Grounded theory procedures and techniques. Thousand Oaks, CA: Sage Publications, Inc.

Table 7. Job-related work at home on primary job by reason for working at home, sex, class of worker, and pay status. (2004). U.S. Bureau of Labor Statistics. Retrieved from http://www.bls.gov/news.release/homey.t07.htm

Taylor, L., McMinn, M. R., Bufford, R. K., \& Chang, K. B. T. (2010). Psychologists' Attitudes and Ethical Concerns Regarding the Use of Social Networking Web Sites. Professional Psychology: Research and Practice, 4l(2), 153-159.

Terkel, S. (1974). Working people talk about what they do all day and how they feel about what they do (1st ed.). New York: Pantheon Books.

Thomas, L. T., \& Ganster, D. C. (1995). Impact of family-supportive work variables on work-family conflict and strain: A control perspective. Journal of Applied Psychology, 80(1), 6-15. doi:10.1037/0021-9010.80.1.6

Thompson, E. P. (1982). Time, work-discipline and industrial capitalism. In A. Giddens \& D. Held (Eds.), Classes, Power and Conflict. Berkeley: University of California Press. 
Tull, A. (2006). Synergistic supervision, job satisfaction, and intention to turnover of new professionals in student affairs. Journal of College Student Development, 47(4), 465-480. doi:10.1353/csd.2006.0053

Upcraft, M. L. (1993). Organizational and administrative approaches. In R.B. Winston, S. Anchors, \& Associates (Eds.), Student housing and residential life: $A$ handbook for professionals committed to student development goals (1st ed.). San Francisco: Jossey-Bass.

Urban, R. (2007). Second life, serious leisure and LIS. Bulletin of the American Society for Information Science and Technology, 33(6), 38-40.

Walls, P., Parahoo, K., \& Fleming, P. (2010). Grounded theory: The role and place of knowledge and literature in grounded theory. Nurse Researcher, 17(4), 8-17.

Waple, J. N. (2006). An assessment of skills and competencies necessary for entry-level student affairs work. Journal of Student Affairs Research and Practice, 43(1), 118.

Warhurst, C., Eikhof, D. R., \& Haunschild, A. K. (2008a). Work less, live more? Basingstoke, NY: Palgrave Macmillan.

Warhurst, C., Eikhof, D. R., \& Haunschild, A. K. (2008b). Out of balance or just out of bounds? Analysing the relationship between work and life. In C. Warhurst, D. R. Eikhof, \& A. K. Haunschild (Eds.), Work less, live more? (pp. 1-21). Basingstoke, NY: Palgrave Macmillan.

Warner, M. J. (1986). Performance appraisals for residence hall professionals: an essential element for effective management. Journal of College and University Student Housing, 16(2), 9-13.

Whitchurch, C. (2008). Beyond administration and management: reconstructing the identities of professional staff in UK higher education. Journal of Higher Education Policy and Management, 30(4), 375-386.

Wiggers, T. T., Forney, D. S., \& Wallace-Schutzman, F. (1982). Burnout is not necessary: Prevention and recovery. NASPA Journal, 20(2), 13-21.

Winston, R. B., Anchors, S., \& Associates. (1993). Student housing and residential life: A handbook for professionals committed to student development goals (1 st ed.). San Francisco: Jossey-Bass.

Winston, R. B., \& Ender, S. C. (1988). Use of student paraprofessionals in divisions of college student affairs. Journal of Counseling and Development, 66(10), 466-473. 
Work At Home Summary. (2004). U.S. Bureau of Labor Statistics. Retrieved March 12 , 2011, from http://data.bls.gov/cgi-bin/print.pl/news.release/homey.nr0.htm 
APPENDIX A

Initial Semi-Structured Interview Guide 
Introduction of study and confirmation of consent.

Social Chat.

General Background information:

For this research project, I want to study people who live where they work. I feel that residence life professionals are an excellent population to look at since you live in the residential facilities you are also managing.

\section{Interview Questions:}

1. What pseudonym would you like to go by in this study?

2. Please share a little history of how you came to work in this position.

3. I would like to understand an average day. Could you go through your typical day with me indicating what you do that is work related and what is personal?

4. So, what is it like to live where you work?

a. What is the best thing about living where you work?

b. What is your biggest frustration living where you work?

5. Let's talk about the relationship between your work and personal life or vice versa.

a. How would you characterize that relationship?

b. Can you discuss a specific time or times when you feel you have had success keeping work from overlapping your personal life or vice versa? Can you give me some specific examples? What things do you think made these occasions successful?

c. What, if anything, in your training or background, helped you to create those successes? 
d. Could you talk about a specific time or times when you have had problems with work overlapping your personal life or vice versa? What happened after that? How did you resolve the problem? Has it occurred again? In what context?

e. What, if anything, could your training or background, have done to prepare you to deal with those issues?

6. Do you use any social networking tools (like Facebook or twitter)? (If Yes) How are you creating boundaries around social networks in relation to your work? Are you expected to use social media for work? Do you want to be connected to your residents through social media? Do you use social media to monitor or learn about residents?

7. Would you consider work/life balance to be important in your role as a resident life professional? Note: Balance is relative and may not be $50 / 50$. (If not) What are you striving for instead between work and life?

Ok to wrap up I would like to ask you a few more questions.

8. What advice would you give others in residence life who live where they work?

9. Is there anything else you'd like to say? 
APPENDIX B

Altered Semi-Structured Interview Guide 
Introduction of study and confirmation of consent.

Social Chat.

General Background information:

For this research project, I want to study people who live where they work. I feel that residence life professionals are an excellent population to look at since you live in the residential facilities you are also managing.

\section{Interview Questions:}

1. What pseudonym would you like to go by in this study?

2. Please share a little history of how you came to work in this position.

3. Can you describe the physical layout of your facility?

4. What is an average day like? Could you go through your typical day indicating what you do that is work related and what is personal?

5. What is an atypical day like?

6. When you have a whole day off what do you do?

7. Do you do personal things during the work time or vice versa?

8. So, what is it like to live where you work?

a. What is the best thing about living where you work?

b. What is your biggest frustration living where you work?

c. Is there anything you do to transition from work to personal or vice versa?

d. Do you have a personal relationship and how do you integrate it?

9. Let's talk about the relationship between your work and personal life or vice versa.

a. How would you characterize that relationship? 
b. Can you discuss a specific time or times when you feel you have had success keeping work from overlapping your personal life or vice versa? Can you give me some specific examples? What things do you think made these occasions successful?

c. What, if anything, in your training or background, helped you to create those successes?

d. Could you talk about a specific time or times when you have had problems with work overlapping your personal life or vice versa? What happened after that? How did you resolve the problem? Has it occurred again? In what context?

e. What, if anything, could your training or background, have done to prepare you to deal with those issues?

10. Tell me about the relationships you have with RA's and your Students? Do you socialize with them?

11. Do you use any social networking tools (like Facebook or twitter)? (If Yes) How are you creating boundaries around social networks in relation to your work? Are you expected to use social media for work? Do you want to be connected to your residents through social media? Do you use social media to monitor or learn about residents?

12. Would you consider work/life balance to be important in your role as a resident life professional? Note: Balance is relative and may not be 50/50. (If not) What are you striving for instead between work and life?

13. Looking over the past semester what would your percentage split be? 
14. You wear many hats, judicial, counseling, programming how does that affect your work/life balance?

15. How is the work life balance of your supervisors how do they communicate to you about balance?

16. How would you describe your personal boundary management?

Ok to wrap up I would like to ask you a few more questions.

17. What advice would you give others in residence life that live where they work?

18. Is there anything else you'd like to say?

19. May I call you back for a follow-up interview?

20. If I need to get further participants, may I contact you to get other names especially people that might have had a different experience or maybe a person of color? 
APPENDIX C

Participant Extended Profiles 
As part of the consent agreement signed by each of my participants, they understood that this study would make every effort to keep their identities confidential. Consequently, I am using pseudonyms and only locating the professional with a region of the country rather than in a specific city or state to help preserve that confidentiality.

Mary. The first participant I interviewed was Mary. I conducted this interview over the computer at the end of January. Mary is a Residence Hall Director at a small four-year primarily residential and public non-profit university located in the northeast. She is in her late 20's and has been a residence life professional for three and a half years. Mary described her ethnicity as Southern Asian. She graduated with a master's degree and became a residence hall director to experience "every aspect of student life". Her office is located on the first floor of the building and her apartment is on the second floor, which she reported was atypical for her university. She has family and a boyfriend who both live within driving distance from her location, albeit a long drive, which she tries to make any weekend she is free. Mary reports her work/life balance at $70 \%$ work $30 \%$ life. She regularly supervises student organizations, works on campus committees, supervises student events, and in her spare time teaches a self-defense class on campus. At the time of the interview, she reported that she was looking for a non-live-in position.

Sam. The next participant I interviewed by telephone was Sam, a Caucasian female in her late 20 's. Sam is a resident director at a large, primarily non-residential four-year private religious university in the Great Lakes region. She came to this position after working as a resident advisor. She decided to go to graduate school after being mentored by a supervisor during her senior year, and while in graduate school, got an assistantship in resident life as resident director. When she left school, she continued 
working in the same position at another university, and has been a resident director for a total of four years. Her office is on the first floor, and her apartment is on the second floor surrounded by students. The residential facility she is responsible for contains 400 students. Sam reported that at this point she feels like she is at the "end of her rope" with residence life and live-in positions. Her main motivation for staying in her position is related to her love of living in a large city that she couldn't otherwise afford to stay in. She estimates that her work/life balance is around $60 \%$ work and $40 \%$ personal time. She described her work/life balance as a work in progress that has gotten better over time.

Sally. Also within the first week in February I interviewed Sally over the telephone. She is a Caucasian woman in her early 30 's. Sally works as an assistant director at a small four-year primarily residential private religious university in the MidAtlantic region. She has a master's degree in education, and when she graduated, the job market for K-12 administration was poor, so she decided to take a job in residence life. She has previously worked in residence life while in school as an assistantship. While working in a full time residence life position, she went back to school to get another masters in higher education. After graduating she has continued working in residence life and has been at the director level for just over eight years.

She currently supervises eight staff members and 250 freshman students. Sally's office is located outside her building in a student affairs general office space. Her apartment is on the first floor of her building in a private wing and has a private outside entrance. She is currently in a relationship with a person who is also in student affairs but they do not live together. Sally describes herself as very private and she does not let anyone know about her personal life. She is also concerned about the "Catholic 
dimension" of her school because all employees must be aware of the mission of the school and behave accordingly. Therefore, she keeps many things private from the staff and students. She also has a dog she described as "her baby." Sally reports that her work/life balance is around $60 \%$ work and $40 \%$ private life but in the fall semester that changes to $75 \%-35 \%$. Sally did not indicate that she was looking for work nor unhappy in her position.

Harry. The next participant was interviewed, also by phone, during the second week of February. Harry, my first male participant, works as a Hall Director for large primarily non-residential four-year public university. The university is located in the Upper-Midwest. He has been in the position for two and a half years and is a Caucasian male in his mid-twenties. Harry was a resident advisor during his undergraduate school experience and upon graduation, decided to get a master's in higher education. During that time he worked as a hall director for two years. Upon graduation, he started working in his current position running two residential facilities - one suite styled building with 300 students and one apartment styled building with 80 students. His apartment and his office are both located in the front of the larger building. His apartment does not have a private entrance. Harry does not cook so he depends on the meal plan that is part of his salary package. He has a fiancé that lives in another state and plans to move her into his apartment once they are married. He says his work/life balance is around $60 \%$ work and $40 \%$ personal life. He is happy in his current position and did not report that he was looking for other work.

Megan. Within a couple of weeks of interviewing Harry, I interviewed Megan over the telephone. She is a Caucasian woman in her early 30 's. Her current position is 
an Area Director for a small four-year primarily residential private religious university in the Southeastern region. She was a resident advisor in college and decided to work as a graduate hall director during her masters program in chaplaincy. When she graduated, she became a chaplain resident for a year but didn't like it, so she came back to residence life and got her current position, which she has been in for three and a half years. Her apartment is two bedrooms and located on the first floor of her building. Her office is in another location a short walk from her building. She lives with her husband, her 14month-old son, and a family dog. She does allow staff and students in her apartment and her son will play in the lobby of the building sometimes. She reports that her work/life balance is around $75 \%$ work and $25 \%$ personal life. She and her husband are happy in the current position but anticipate having to move off campus as their family grows.

Steve. The next two interviews (Steve and Nick) happened at the end of February by telephone. Steve is a Caucasian male in his early 30's who works at a large four-year primarily nonresidential public university in the Northwest region. He is currently a resident director and has been in his position for one and a half years. Steve worked in government before going back to school for a masters in higher education. He took an assistantship as a hall coordinator his final year in the program. He currently lives with his wife and two children in a second floor apartment. No students surround his unit but it is above the first floor offices, which serve as the main office space for all of student affairs on his campus. His four-year-old daughter often plays in the building and Steve believes "more people know her than we know who they are." Steve's wife often invites staff members to dinner at the couple's apartment. He reports that living in a small town sometimes feel claustrophobic compared to his previous life, but he is very happy in his 
current position. He says that his work/life balance is between $60 \%$ work and $40 \%$ personal to $70 \%$ work during certain times of the year.

Nick. Similar to Steve, Nick is also a married Caucasian male who has been working as a resident director for a year and a half. Nick is in his middle 20 's however and works at a medium four-year, primarily residential, private religious university in the Great Lakes region. Nick started as a resident advisor during his time in school. He held an assistantship during his master's program and his current position as resident director is his first position out of school. Nick oversees several apartment style buildings on campus. His apartment is on the second floor of one of his buildings. His office is across the street about 100 meters from his front door. Nick and his wife often host movie nights and programs for the students and staff in their apartment. He is also a friend to several other resident directors on campus. His wife is getting her masters and works in student affairs at another school. Both enjoy living in a big city without having to pay rent. Nick puts is work/life balance at about $70 \%$ work $30 \%$ personal life.

Dean. All my final interviews occurred during the last two weeks of March. The first of those is my only live-on participant Dean. Dean is an Assistant Director of Residential Life at a large four-year primarily nonresidential private university in the Southeastern region. He has been in this position for about two years. He is a Caucasian male in his late 30's. Dean worked as a resident advisor and a hall director while in his undergraduate program. During his masters degree he worked in other areas of student affairs and was not live-in. After graduating he worked in several positions before coming back to living-on for his current position. He does not supervise resident directors, and instead is responsible for hiring and training the resident advisors on 
campus. He also has judicial and coordinator responsibilities and reports that he is oncall 365 days a year. His apartment is on the first floor of a large building holding 500 students. He has a private entrance as well as an entrance on hall. Dean is not currently in a relationship and reports that he has some issues explaining to dates why he still lives on campus. Most of his friends are off campus and his only interaction with students is as a mentor. He reports that even though he is on call every day, his work/life balance is typically $60 \%$ work $40 \%$ personal life, which is something he consciously works to maintain. He believes that living on campus keeps him connected to the younger world and is happy in his current position.

Rue. My next participant was Rue, a multiracial woman in her late 20 's. Rue is an Area Director for a medium four-year primarily residential private religious university in the Upper-Midwest. She has been in her position for about four years and is looking for another position at the same level to broaden her student affairs experience. Prior to this position she had never worked in or studied student affairs. Rue lives on the sixth floor of a building housing 500 students. Her floor is specialized with a certain type of student community dedicated to female religious students. Rue reported her office is on the first floor directly across from the entrance. Rue has a female partner who does not live with her and faces challenges balancing a same-sex relationship at a religious university. One reason she is leaving is that the school only allows married partners to live together and the state she lives in does not allow same-sex marriage. Rue reports her work/life balance in several ways. She says her actual work/life balance is $60 \%$ work to $40 \%$ personal life, but her mental balance is $70 \%$ to $30 \%$ because she thinks about work a 
lot when she is at home. Finally she reported that if she were single her work/life balance would be $80 \%$ to $20 \%$.

Windy. After Rue, I interviewed Windy. She is a Caucasian female in her early 20's. Her position is Greek Area Hall Director for a public primarily residential, large four-year university in the Upper-Midwest region. She is responsible for several Greek life buildings which each hold 60-70 students. She lives in a small apartment in one of the buildings with her boyfriend. Windy had never worked in student affairs before and this is her first position. She has been working in this position for just over one semester. Windy is having a harder time balancing work and life. She has meetings in her apartment and reports being frustration while trying to have private time amidst constant interruptions. She says her work/life balance is $65 \%$ work $35 \%$ personal life.

Harold. My next interview was with the person who had been in a residence life position the longest. Harold is a Caucasian man in his early 60 's. He is currently a Hall Director at a medium sized four-year primarily residential public university in the Northeast region. He has been in his position for 36 years. Harold lives in a building that houses 112 students and also supervises three other buildings housing mostly graduate students. His office is in the front of the building he lives in. For the past 36 years Harold has lived in a first floor apartment, which for 13 years he shared with his wife until she divorced him, unhappy with the live-in lifestyle,. Harold feels connected to the students and the campus life. He works in his spare time for a department on campus and sometimes teaches. He makes sure that he says hello to every student in his building at least once a day. He likes to check in and make sure they feel connected. He does not typically friend students or staff until they have left school. When he was married he 
would travel and get off campus weekly. Since his divorce, he stays closer to campus feeling that all he needs is within reach. Harold could not put a percentage on his work/life balance, saying "I'm Peter Pan. I came here when I was 23, and a couple of weeks ago, I turned 61 , which is a little frightening, but everyday, since l've been here, I've never been bored, not once, not for five minutes."

Trevor. My last interview was Trevor a Southeast Asian male in his early 30's. He has been the Resident Director at a large four-year primarily nonresidential public university in the Northwest for four years. He got into student affairs as a Resident Advisor during his undergraduate experience, but his senior year was promoted to assistant director, and then associate director. Upon graduating he was hired on full time and decided to pursue a master's degree in counseling. When he graduated he decided to stay in student affairs and found his current position through a placement exchange service. Trevor's apartment is on the third floor, but due to the design of the building he has both an interior entrance and a private exterior entrance. His office is located in the basement of his building. Trevor uses his apartment as a sanctuary for his Resident Advisors and so does not allow students into his apartment. He is currently single and is preparing to enter a doctoral program and to leave student affairs. His free time is spent hiking and communicating with his family and friends back in his native country. He reports that his work/life balance is currently around $65 \%$ work and $35 \%$ personal life. 